\title{
ipen
}

AUTARQUIA ASSOCIADA À UNIVERSIDADE DE SÃO PAULO

CARACTERIZAÇÃO MICROESTRUTURAL DOS COMPOSTOS INTERMETÁLICOS E SEU EFEITO NO COMPORTAMENTO MECÂNICO NAS LIGAS DE AI-9\%Si COM ADIÇÕES DE Fe E Mn

Jefferson Malavazi

Dissertação apresentada como parte dos requisitos para obtenção do Grau de Mestre em Ciências na Área de Tecnologia Nuclear - Materiais

Orientador:

Prof. Dr. Antonio Augusto Couto 


\title{
INSTITUTO DE PESQUISAS ENERGÉTICAS E NUCLEARES
}

Autarquia associada à Universidade de São Paulo

\section{CARACTERIZAÇÃO MICROESTRUTURAL DOS COMPOSTOS INTERMETÁLICOS E SEU EFEITO NO COMPORTAMENTO MECÂNICO NAS LIGAS DE AI-9\%Si COM ADIÇÕES DE Fe E Mn}

\author{
Jefferson Malavazi
}

Dissertação apresentada como parte dos requisitos para obtenção do Grau de Mestre em Ciências na Área de Tecnologia Nuclear - Materiais

Orientador:

Prof. Dr. Antonio Augusto Couto

Versão Corrigida

Versão Original disponível no IPEN 


\section{Dedicatória}

À minha esposa Lilian e aos meus filhos Arthur e André pelo apoio e incentivo. 


\section{AGRADECIMENTOS}

Ao Prof. Dr. António Augusto Couto pelo incentivo e apoio mostrando os horizontes em função da evolução acadêmica.

Ao técnico Márcio Francisco que tanto me auxiliou na elaboração das ligas e obtenção dos corpos de provas cujas tarefas exigiram muito empenho e destreza. Ao André Arakaki, do Laboratórios de Prestação de Serviços da Escola SENAI Nadir Dias de Figueiredo, por agilizar a execução das análises químicas e ensaios de tração. À Ana Carolina de Couto Parreira e estagiárias Gabrielle Ribeiro Duarte e Marina Martins Neres pelo auxílio prestado na execução dos ensaios de tração.

Agradeço também aos alunos Juliana Flor e José Veríssimo Silva dos Santos pela preparação das amostras metalográficas e obtenção das imagens no MEV e finalmente a Marcos Antônio Togni, Coordenador Técnico da Escola SENAI "Nadir Dias de Figueiredo" pela disponibilização dos equipamentos e recursos para elaboração de mais este trabalho. 


\section{RESUMO}

O objetivo deste trabalho foi determinar a influência do ferro e do manganês em uma liga de alumínio com $9 \%$ de silício (\% em peso). Para isto, foram elaboradas duas famílias de liga Al-9\%Si: uma com os teores de 0,1\%, 0,4\%, 0,8\% e 1,2\% de Fe e uma segunda liga de $\mathrm{Al}-9 \% \mathrm{Si}-0,8 \% \mathrm{Fe}$ com teores de $0,1 \%, 0,4 \%$ e $0,7 \%$ de Mn. Para a realização deste estudo, foram produzidos corpos de prova de tração fundidos em coquilha, segundo a norma ASTM B108. Os corpos de prova obtidos foram tracionados para avaliação das propriedades mecânicas, em seguida, foram submetidos a uma análise microestrutural por microscopia óptica (MO) e eletrônica de varredura (MEV). As superfícies de fratura dos corpos de prova tracionados foram também observadas por MEV com a finalidade de comparar o efeito das adições de Fe e Mn. O efeito da adição crescente de Fe na liga Al-9\%Si foi observado no ensaio de tração que mostrou queda tanto nos limites de resistência e de escoamento como no alongamento, decorrentes da formação da fase $\beta$-AlsFeSi que apresentou morfologia em plaquetas, interrompendo a continuidade da matriz de alumínio. Para teores abaixo de $0,4 \%$ de $\mathrm{Fe}$, ocorreu um ligeiro aumento da resistência mecânica que pode ser atribuído à formação da fase $\alpha-\mathrm{Al}_{8} \mathrm{Fe}_{2} \mathrm{Si}$, que apresentou morfologia tipo escrita chinesa, que não interrompe a continuidade da matriz. Com adição de teores crescentes de $\mathrm{Mn}$ na liga Al-9\%Si-0,8\%Fe ocorreu uma elevação do limite de resistência e do alongamento, mas uma queda do limite de escoamento, quando comparados com a mesma liga sem adição de Mn. Conclui-se que esse comportamento pode ser atribuído a mudança de morfologia do intermetálico de plaquetas para escrita chinesa que intercala a matriz dúctil com a fase frágil, devido a adição do Mn.

Palavras-chave: Ligas de alumínio, intermetálicos, ferro, manganês. 


\section{ABSTRACT}

This study aims to determine the influence of iron and manganese in an aluminum alloy with $9 \%$ silicon (\% by weight). Were prepared two families of alloy Al-9\%Si: one with the content of $0.1 \%, 0.4 \%, 0.8 \%$ and $1.2 \% \mathrm{Fe}$ and a second alloy of $\mathrm{Al}-9 \% \mathrm{Si}$ $0,8 \% \mathrm{Fe}$ content of $0.1 \%, 0.4 \%$ and $0.7 \% \mathrm{Mn}$. For this study, tensile specimens were produced in permanent mold casting according to ASTM B108. The specimens obtained were pulled for quantitative evaluation of the mechanical properties and were subjected to a qualitative metallographic evaluation. Qualitative analysis of the bodies of tensile fracture test was conducted in order to compare the effect of additions of $\mathrm{Fe}$ and $\mathrm{Mn}$. The effect of incremental addition of $\mathrm{Fe}$ in the alloy Al-9\% Si was observed in the tensile test that showed a decrease in both the tensile and elongation flow as resulting from the formation of $\beta$-Al5FeSi phase platelet morphology showed that interrupting the continuity of aluminum matrix. To levels below $0.4 \% \mathrm{Fe}$, there was a slight increase in strength can be attributed to the formation of $\alpha-\mathrm{Al}_{8} \mathrm{Fe}_{2} \mathrm{Si}$ phase morphology presented in chinese script that does not interrupt the continuity of the matrix. With addition of increasing concentrations of $\mathrm{Mn}$ in the alloy $\mathrm{Al}-9 \% \mathrm{Si}-0,8 \% \mathrm{Fe}$ was an increase in the tensile strength and elongation but fall of yield stress when compared to the same alloy without Mn addition. We conclude that this behavior can be attributed to a change in morphology of the intermetallic platelets to chinese writing interspersing the ductile matrix with brittle phase due to the addition of Mn.

Keywords: Aluminium alloys, intermetallic, iron, manganese 


\section{ÍNDICE DE FIGURAS}

Figura 1 - Diagrama de equilíbrio Al-Si [11] adaptado..................................... 5

Figura 2 - Microestrutura de uma liga Al-9\% Si mostrando as dendritas da fase $\alpha$ envolvida pelo constituinte eutético $\left(\beta_{\text {eutético }}+\alpha_{\text {eutético }) \ldots \ldots \ldots \ldots \ldots \ldots \ldots \ldots \ldots \ldots \ldots \ldots \ldots \ldots \ldots \ldots \ldots \ldots \ldots \ldots \ldots \ldots \ldots \ldots \ldots \ldots \ldots} 6\right.$

Figura 3 - Dendritas de alumínio-a formadas em uma microporosidade em uma liga

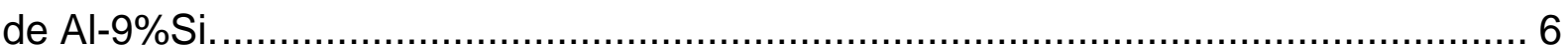

Figura 4 - Diagrama de equilíbrio Al-Fe [5] adaptado....................................... 7

Figura 5 - Micrografia de uma liga Al-Fe 1,5\% fundida em areia. Nos espaçamentos interdendríticos verifica-se a presença do composto intermetálico $\mathrm{Al}_{3} \mathrm{Fe}$ [13]. 200x. . 7

Figura 6 - Microestrutura de uma liga de Al-7\%Si -0,2\% de Fe modificada com $\mathrm{Sr}$ evidenciando a fase intermetálica $\beta-A l_{5} S i F e$. Aumento de 1000x.

Figura 7 - Plaqueta de fase $\beta-\mathrm{Al}_{5} \mathrm{SiFe}$ observada em MEV em uma amostra com $1,0 \%$ de $\mathrm{Fe}$ e $7,0 \%$ de $\mathrm{Si}[13]$.

Figura 8 - Projeção da superfície liquidus do diagrama Al-Si-Fe onde estão representadas as sequências de fases formadas durante a solidificação das ligas Al$5 \%$ Si e Al-11\%Si com teor de ferro de 0,4\%. Adaptado [14].

Figura 9 - Projeção da superfície liquidus do diagrama ternário Al-Si-Fe que mostra o Fe crítico para as ligas de alumínio com teores de silício de 5 à 11,5\%. Adaptado [14].

Figura 10 - Projeção da superfície liquidus do diagrama ternário Al-Si-Fe onde estão representadas as sequências de formação de fases durante a solidificação da liga Al-9\%Si com teor de ferro de 1,4\%. Adaptado [14].

Figura 11 - A agitação na superfície do metal líquido provoca o envelopamento de óxidos próximo à superfície (ocorre o dobramento da película de óxido sobre ela mesma).

Figura 12- Filme duplo de óxido arrastado para o interior do metal formando micro porosidades. [26].

Figura 13 - Partículas de intermetálico que cresceram, independentes, sobre cada um dos lados uma película de óxido dobrada formando uma fissura que pode atuar como concentrador de tensões favorecendo na propagação de trincas [21].

Figura 14 - Micro porosidade formada pela interconexão das plaquetas da fase $\beta$ $\mathrm{Al}_{5} \mathrm{FeSi}$ que nuclearam e cresceram sobre películas de óxidos [13].

Figura 15 - Microtomografia de raio $X$ das plaquetas de $\beta$-Als FeSi obtida durante a solidificação da liga Al-8\%Si-4\%Cu-0,8\%Fe [27].

Figura 16 - Micro porosidade formada nas vizinhanças das plaquetas de $\beta-\mathrm{Al}_{5} \mathrm{FeSi}$ [30]. 16

Figura 17- Micro porosidade formada devido as plaquetas da fase $\beta$-AlsFeSi que 
restringiram o fluxo do líquido eutético na região [13] 16

Figura 18 - Efeito da \%Fe sobre a área porcentual de porosidades em uma liga Al$12 \%$ Si sem e com modificação. Adaptada [30].

Figura 19 - Propagação de trinca ao longo da plaqueta de $\beta$-AlsFeSi submetida ao ensaio de tração [5].

Figura 20 - Superfície de amostra fraturada de uma liga Al-7\%Si-1,0\%Fe mostrando a presença da fase $\beta-A 15 F e S i[13]$. 18

Figura 21 - Fase $\alpha-\mathrm{Al}_{8} \mathrm{Fe}_{2} \mathrm{Si}$ com morfologia em escrita chinesa [36]. 19

Figura 22 - Efeito da temperatura de superaquecimento e teor de ferro sobre a morfologia do intermetálico nas ligas (a) Al-6\%Si e (b) Al-11\%Si. Adaptado [20].... 20 Figura 23 - liga de Al-7 \% Si com 0,7\%Fe e 0,35\%Mn fundida em coquilha. A fase $\alpha-$ $\mathrm{Al}_{15}(\mathrm{Fe}, \mathrm{Mn})_{3} \mathrm{Si}_{2}$ se encontra inserida na dendrita de alumínio [13]. 21

Figura 24 - Projeção da superfície liquidus do diagrama ternário Al-Si-Fe. Adaptado [14].

Figura 25 - Projeção da superfície liquidus do diagrama ternário Al-Si-Fe para teores de $0,1 \%$ de Mn. Adaptado [14].

Figura 26 - Projeção da superfície liquidus do diagrama ternário Al-Si-Fe para teores de 0,2 \% de Mn. Adaptado da referência [14]. 22

Figura 27 - Projeção da superfície liquidus do diagrama ternário Al-Si-Fe para teores de $0,3 \%$ de Mn. Adaptado [14]. 23

Figura 28 - Projeção da superfície liquidus do diagrama ternário Al-Si-Fe para teores de $0,4 \%$ de Mn. Adaptado [14]. 23

Figura 29 - Projeção da superfície liquidus do diagrama ternário Al-Si-Fe para liga com $0,30 \% \mathrm{Mn}$, onde estão representadas as sequências de fases formadas durante a solidificação de uma liga Al-7\% Si com teores de ferro de 0,20\% (A), 0,60\% (D), e 1,4\% (G). Adaptado [14]. 24

Figura 30 - Fase $\alpha-\mathrm{Al}_{15}(\mathrm{Fe}, \mathrm{Mn})_{3} \mathrm{Si}_{2}$ com morfologia poligonal em uma liga de $\mathrm{Al}-13 \%$ Si com 2,5\% de Fe e 1,25\% de Mn [7]. 26

Figura 31 - Correlação entre a temperatura e o fator de segregação para a liga A380 mostrando a temperatura mínima para que não acorra a sedimentação é de $618^{\circ} \mathrm{C}$ segundo Gobrecht e $628^{\circ} \mathrm{C}$ segundo Jorstad para um Fs = 1,4 [41].

Figura 32 - Cristais de silício - fase beta- com morfologia em plaquetas [43]. 28

Figura 33 - Microestrutura de uma liga de Al-Si modificada com Sr em baixa resolução (a) e em alta resolução com ataque profundo (b) [43]. 28

Figura 34 - Microestrutura de uma liga Al-7\%Si-1,0\%Fe mostra as partículas de $\beta$ $\mathrm{Al}_{5} \mathrm{FeSi}$ formadas nas reações eutéticas principal e secundária [13] facilmente identificadas em função da modificação das partículas de silício que se apresentam 
morfologia fibrosa entre as dendritas [10]. 29

Figura 35 - Coquilha confeccionada em aço H13, conforme norma ASTM B108 [44].

Figura 36 - Corpos de prova obtidos com o uso da coquilha segundo a norma ASTM B108 [44] indicando onde foram retiradas as amostras para observação metalográfica e MEV.

Figura 37 - Gráfico de resistência à tração em função do teor de ferro, \% em peso. 34

Figura 38 - Gráfico do alongamento em função do teor de ferro, \% em peso. 35

Figura 39 - Liga Al-9\%Si com 0,1\% de Fe mostrando as dendritas de alumínio e as partículas de silício eutético nas regiões interdendríticas.

Figura 40 - Micrografia da liga Al-9\%Si com 0,1\% Fe mostrando as partículas de silício de formação eutética entre os braços das dendritas de alumínio e em destaque partículas do intermetálico $\alpha-\mathrm{Al}_{8} \mathrm{Fe}_{2} \mathrm{Si}$.

Figura 41 - Micrografia da liga Al-9\%Si-0,1\% Fe obtida pelo MEV mostrando as partículas do intermetálico $\alpha-\mathrm{Al}_{8} \mathrm{Fe}_{2} \mathrm{Si}$ de coloração mais clara (2). A fase (1) se refere à partícula de silício.

Figura 42 - Micrografia da liga Al-9\% $\mathrm{Si}-0,4 \%$ Fe obtida pelo MEV mostrando as partículas da fase $\alpha-\mathrm{Al}_{8} \mathrm{Fe}_{2} \mathrm{Si}$ destacado em vermelho e $\beta-\mathrm{Al}_{5} \mathrm{FeSi}$ destacado em azul.

Figura 43 - Presença de partículas de $\alpha-\mathrm{Al}_{8} \mathrm{Fe}_{2} \mathrm{Si}$ situada entre as dendritas de alumínio e de partículas da fase $\beta-\mathrm{Al}_{5} \mathrm{FeSi}$ formando agulhas refinadas.

Figura 44 - Micrografia da liga Al-9\%Si- 0,4\% Fe obtidas pelo MEV mostrando as partículas do intermetálico $\alpha-\mathrm{Al}_{8} \mathrm{Fe}_{2} \mathrm{Si}$ de coloração mais clara (2). A fase (1) se refere à partícula de silício

Figura 45 - Projeção da superfície liquidus do diagrama ternário Al-Si-Fe onde estão representadas as sequências de fases formadas na solidificação das ligas $\mathrm{Al}-9 \% \mathrm{Si}$ com $0,1 \%$ e $0,4 \%$ de ferro respectivamente. Adaptado [14].

Figura 46 - Microestrutura da liga Al-9\%Si-0,8\%Fe próxima a superfície da amostra.

Figura 47 - Microestrutura da liga Al-9\%Si-0,8\%Fe no centro da amostra. 42

Figura 48 - Micrografia da liga Al-9\%Si-0,8\% Fe obtidas pelo MEV mostra as partículas de $\beta$-AlsFeSi formadas junto ao eutético principal, em dimensões maiores e aquelas formadas junto ao eutético secundário, com menor dimensão. Esta figura mostra ainda uma partícula de $\beta-\mathrm{Al}_{5} \mathrm{FeSi}$ que nucleou formando uma curvatura..... 43

Figura 49 - Ampliação do detalhe da figura anterior obtida pelo MEV mostrando as partículas do intermetálico $\beta$-AlsSiFe de coloração mais clara (1) e partículas de silício de coloração mais escura (2).

Figura 50 - Microporosidade limitada pelas partículas da fase $\beta$-Als FeSi restringindo 
o fluxo de material interdendrítico. Liga Al-9\%Si-0,8\%Fe

Figura 51 - Fase $\beta$-Al 5 FeSi formada junto com o eutético secundário sobre os braços da dendrita no interior de uma microporosidade. 45

Figura 52 - Trinca nucleada no interior da partícula de $\beta-\mathrm{Al}_{5} \mathrm{FeSi}$. 46

Figura 53 - MEV de uma fratura mostrando os planos de clivagem decorrentes da decoesão das partículas de $\beta$-Als FeSi [13].

Figura 54 - Micrografia da liga Al-9\%Si-1,2\% Fe mostrando a distribuição das partículas da fase $\beta-A l_{5} F e S i$ formadas junto com as dendríticas de $\alpha$.

Figura 55 - Micrografia da liga Al-9\%Si-1,2\% Fe mostrando respectivamente as partículas de silício de formação eutética entre os braços das dendritas de alumínio e a fase $\beta-\mathrm{Al}_{5} \mathrm{FeSi}$ de grandes dimensões formadas junto com o eutético principal. 48

Figura 56 - Projeção da superfície liquidus do diagrama ternário Al-Si-Fe onde estão representadas as sequencias de fases formadas na solidificação das ligas $\mathrm{Al}-9 \% \mathrm{Si}$ com $0,8 \%$ e $1,2 \%$ de ferro respectivamente. Adaptado [14].

Figura 57 - Micrografia obtida por Mev na região central da amostra mostrando as partículas de intermetálicos formadas junto ao eutético principal (partículas maiores) e aquelas formadas junto ao eutético secundário (partículas menores). 50

Figura 58 - Ampliação do destaque da figura 57 para microanálise nas partículas enumeradas de 1 e 2 .

Figura 59 - Aspecto da fratura da liga Al-9\%Si-0,1\%Fe. O aspecto frágil é decorrente da presença das partículas de Si com morfologia acicular. Verifica-se algumas regiões com aspecto alveolar como indicados na figura.

Figura 60 - Fratura da liga Al-9\%Si-0,4\%Fe mostrando a presença de regiões alveolares alongadas como indicados na figura. 52

Figura 61 - Fratura referente ao corpo de prova tracionado da liga Al-9\%Si-0,8\% Fe. Aspecto frágil provocada pela presença das partículas de $\beta-\mathrm{Al}_{5} \mathrm{FeSi}$. Verifica-se a presença de regiões alveolares alongadas apontadas na figura.

Figura 62 - Fratura da liga Al-9\%Si-1,2\%Fe com fratura predominantemente frágil provocada pela intensa formação das plaquetas de $\beta-\mathrm{Al}_{5} \mathrm{FeSi}$.

Figura 63 - Gráfico de Limite de resistência e escoamento em função do teor de Mn, $\%$ em peso 55

Figura 64 - Gráfico de alongamento em função do teor de Mn, \% em peso. 56

Figura 65 - Projeção da superfície liquidus do diagrama ternário Al-Si-Fe com 0,1\% de $\mathrm{Mn}$ onde estão representadas as sequencias de fases formadas na solidificação das ligas Al-9\%Si com 0,8\% e 0,1\%Mn. Adaptado [14].

Figura 66 - Micrografia obtida pelo MEV da microestrutura da liga Al-9\%Si-0,8\%Fe$0,1 \% \mathrm{Mn}$ para determinar as composições químicas por microanálise nas regiões apontadas de 1 a 4 . 
Figura 67 - O ponto1 se refere a fase $\alpha-\mathrm{Al}_{15}(\mathrm{Fe}, \mathrm{Mn})_{3} \mathrm{Si}_{2}$, ponto 2 ao intermetálico com a presença de cobre e o ponto 3 a partícula de silício.

Figura 68 - Projeção da superfície liquidus do diagrama ternário Al-Si-Fe para 0,2\% de $\mathrm{Mn}$ onde estão representadas as sequencias de fases formadas na solidificação das ligas Al-9\%Si com 0,8\% Fe e 0,2\%Mn. Adaptado [14].

Figura 69 - Fase $\alpha-\mathrm{Al}_{15}(\mathrm{Fe}, \mathrm{Mn})_{3} \mathrm{Si}_{2}$ formada no interior da fase $\alpha$-alumínio que se formou decorrente de uma reação eutética acoplada.

Figura 70 - Partículas de $\alpha-\mathrm{Al}_{15}(\mathrm{Fe}, \mathrm{Mn})_{3} \mathrm{Si}_{2}(1), \beta-\mathrm{Al}_{5} \mathrm{FeSi}(2)$ e silício(3).....

Figura 71 - Projeção da superfície liquidus do diagrama ternário Al-Si-Fe para 0,4\% de $\mathrm{Mn}$ onde estão representadas as sequencias de fases formadas na solidificação das ligas Al-9\%Si-0,8\% Fe e 0,4\%Mn. Adaptado [14]. 62

Figura 72 - A micrografia mostra as partículas da fase $\beta-A{ }_{15}(\mathrm{Fe}, \mathrm{Mn})_{3} \mathrm{Si}_{2}$. 63

Figura 73 - Fase $\alpha-\mathrm{Al}_{15}(\mathrm{Fe}, \mathrm{Mn})_{3} \mathrm{Si}_{2}$ com morfologia poligonal formada junto com a dendrita de alumínio.

Figura 74 - Ampliação da região destacada na figura 73 mostra as fases: 1- $\alpha-$ $\mathrm{Al}_{15}(\mathrm{Fe}, \mathrm{Mn})_{3} \mathrm{Si}_{2}$ com morfologia poligonal; 2- $\alpha-\mathrm{Al}_{15}(\mathrm{Fe}, \mathrm{Mn})_{3} \mathrm{Si}_{2}$ com morfologia em escrita chinesa e 3 - partículas de silício com morfologia fibrosa (modificada).

Figura 75 - Fase $\alpha-\mathrm{Al}_{15}(\mathrm{Fe}, \mathrm{Mn})_{3} \mathrm{Si}_{2}$ com morfologia poliédrica na interfase de um braço dendrítico no interior de uma microporosidade. 65

Figura 76 - Intermetálicos alinhados na superfície de um corpo de prova tracionado.

Figura 77 - Micrografia obtida no Mev mostra a nucleação da partícula de silício (3) sobre a partícula de $\alpha-\mathrm{Al}_{15}(\mathrm{Fe}, \mathrm{Mn})_{3} \mathrm{Si}_{2}$.

Figura 78 - Fase $\alpha-\mathrm{Al}_{15}(\mathrm{Fe}, \mathrm{Mn})_{3} \mathrm{Si}_{2}$ (1) grosseira, partículas de $\beta-\mathrm{Al} 5 \mathrm{FeSi}(2)$ e silício(3).

Figura 79 - Ataque profundo com NaOH 20\% em amostra de Al-9\%Si-0,8\%Fe com $0,7 \%$ de $\mathrm{Mn}$ revelando a fase $\alpha-\mathrm{Al}_{15}(\mathrm{Fe}, \mathrm{Mn})_{3} \mathrm{Si}_{2}$ com morfologia em escrita chinesa.

Figura 80 - Concentração de intermetálicos $\alpha$-Al ${ }_{15}(\mathrm{Fe}, \mathrm{Mn})_{3} \mathrm{Si}_{2}$ 70

Figura 81- Detalhe do intermetálico com morfologia poligonal. 70 


\section{ÍNDICE DE TABELAS}

Tabela 1- Produção de Produtos Transformados de Alumínio

Tabela 2- Sequência de solidificação das ligas Al-Si 5\% e Al-Si 11\% com teor de ferro de 0,4\%, como representadas na Figura 8.

Tabela 3-Sequência de solidificação da liga Al-9\%Si com teor de ferro de 1,4\%, como representada na Figura 10.

Tabela 4 - Sequência de solidificação das ligas Al-7\%Si com teores de Fe de 0,20\%, 0,60\% e 1,40\% para um teor de Mn de 0,30\%, como representadas na Figura 29. 24

Tabela 5 - Composição química das ligas obtidas da série Al-9\%Si. 33

Tabela 6- propriedades mecânicas obtidas do ensaio de tração nas ligas da série Al$9 \%$ Si em função do ferro. 34

Tabela 7 - Composição química das partículas apontadas na figura 41.

Tabela 8 - Microanálise do ponto 1 referente a partícula $\alpha-\mathrm{Al}_{8} \mathrm{Fe}{ }_{2} \mathrm{Si}$ e 2 partícula de silício.

Tabela 9 - Sequência de solidificação das ligas Al-9\%Si e com teores de ferro de $0,1 \%$, e $0,4 \%$ como representadas na figura 45 .

Tabela 10 - Microanálise das partículas da fase $\beta-A l_{5} F e S i$ e silício.

Tabela 11 - Sequência de solidificação das ligas AI-9\%Si com teores de ferro em $0,8 \%$, e $1,2 \%$ como representadas na figura 56 .

Tabela 12 - Microanálise das partículas da fase $\beta-A l_{5} F e S i$ e silício referente à figura 58.

Tabela 13 - Composição química das amostras obtidas. 54

Tabela 14 - Resultados obtidos dos testes de tração em cada um dos experimentos. 55

Tabela 15 - Sequência de solidificação das ligas Al-9\%Si com teor de ferro em 0,8\% e $0,1 \% \mathrm{Mn}$ como representado na figura 65 .

Tabela 16 - Microanálise das fases enumeradas na figura 66.

Tabela 17 - Microanálise dos pontos 1, 2 e 3 referente às fases $\alpha-\mathrm{Al}_{15}(\mathrm{Fe}, \mathrm{Mn})_{3} \mathrm{Si}_{2}$, intermetálico com cobre e partícula de silício respectivamente.

Tabela 18 - Sequência de solidificação das ligas Al-9\%Si com teor de ferro em 0,8\% e $0,2 \% \mathrm{Mn}$ como representado na figura 68 . 60

Tabela 19 - Composição química referente às partículas da figura 70. 62

Tabela 20 - Sequência de solidificação das ligas Al-9\%Si-0,8\% e 0,4\%Mn como representado na figura 71 .

Tabela 21 - Composição química aproximada da fase $1\left(\alpha-\mathrm{Al}_{15}(\mathrm{Fe}, \mathrm{Mn})_{3} \mathrm{Si} 2\right.$ )poligonal e fase 2 escrita chinesa apontada na figura 74. 
Tabela 22 - Microanálise dos constituintes enumerados na figura 77 ................... 67

Tabela 23 - Microanálise das fases enumeradas na figura 78. ............................ 68 
1. INTRODUÇÃO

2. OBJETIVOS

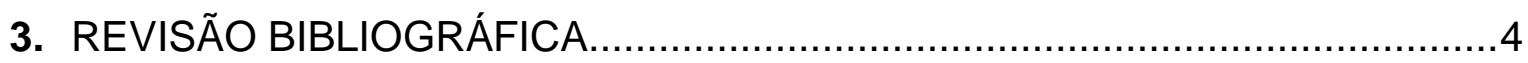

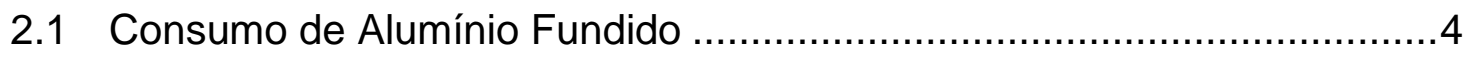

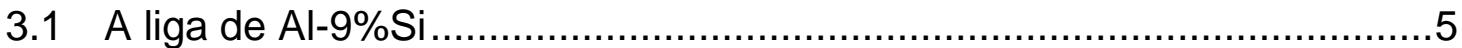

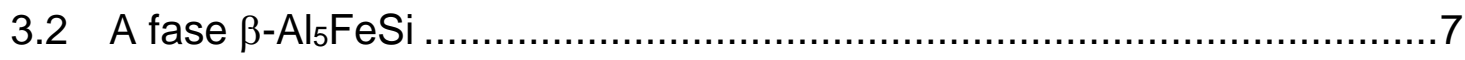

3.2.1 Nucleação da fase $\beta-A l_{5} F e S i$.............................................12

3.2.2 Porosidades ........................................................................ 15

3.2.3 Propriedades Mecânicas..................................................17

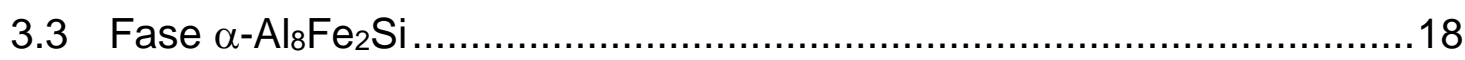

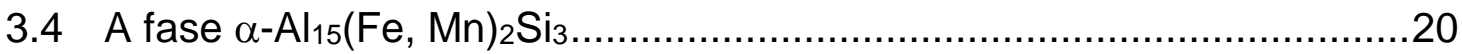

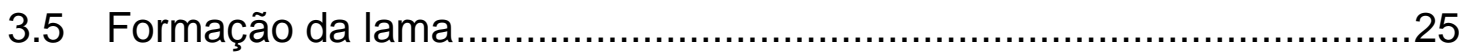

3.6 Modificação das ligas Al-Si......................................................27

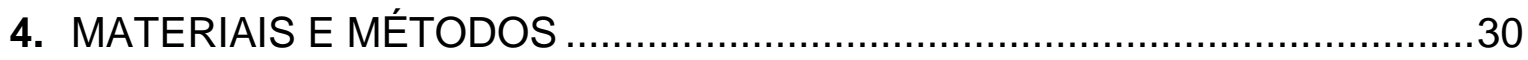

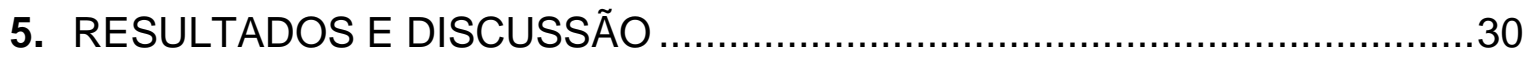

5.1 Ligas de Al-9\%Si com adições de ferro ..........................................33

5.1.1 Ligas de Al-9\%Si-0,1\% Fe ...............................................35

5.1 .2 Ligas de Al-9\%Si-0,4\% Fe ...........................................37

5.1.3 Ligas de Al-9\%Si-0,8\% Fe ............................................. 41

5.1 .4 Ligas de Al-9\%Si-1,2\% Fe ...............................................47

5.1.5 Fractografia nas ligas Al-9\%Si com Fe..............................51

5.1 Ligas de Al-9\%Si -0,8\%Fe com adições de $\mathrm{Mn}$.................................54

5.1.1 Ligas de Al-9\%Si-0,8\%Fe-0,1\%Mn .....................................56

5.1.2 Ligas de Al-9\%Si-0,8\%Fe-0,2\%Mn ....................................59

5.1.3 Ligas de Al-9\%Si-0,8\%Fe-0,4\%Mn ......................................62

5.1.4 Ligas de Al-9\%Si-0,8\%Fe-0,7\%Mn ....................................66

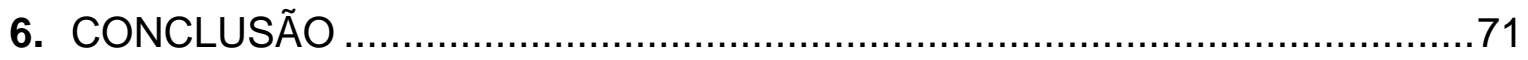

7. SUGESTÕES PARA TRABALHOS FUTUROS ...................................... 73 


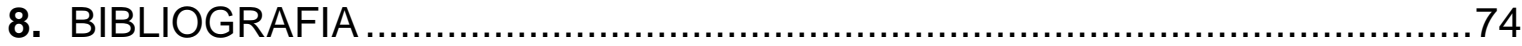




\section{INTRODUÇÃO}

As ligas de alumínio silício são as mais utilizadas entre todas as ligas de alumínio fundidas em função de sua ampla aplicação na produção de produtos comerciais. O silício é um elemento de liga que confere excelente fundibilidade à liga, ou seja, pelo fato de possuir excelente fluidez, permite a perfeita reprodução da geometria do molde com o mínimo de defeitos [1]. A importância destas ligas também está baseada na baixa contração em comparação com o metal base bem como na boa soldabilidade e resistência à corrosão [2]. O uso destas ligas tem aplicação crescente na indústria automobilística, pois permite a redução do peso do veículo e, consequentemente, menor consumo de combustível [3]. Outros elementos químicos, tais como o $\mathrm{Cu}, \mathrm{Mg}, \mathrm{Mn}, \mathrm{Zn}, \mathrm{Sr}$, Ti e B são incorporados às ligas de alumínio-silício com a finalidade de melhorar a tenacidade à fratura e a resistência à corrosão, ampliando o limite de utilização destas ligas [4].

Contudo, alguns elementos são incorporados à liga involuntariamente, como é o caso do ferro e que pode ser decorrente do processo de obtenção do alumínio primário ou devido às contaminações durante os processos de reciclagem e também durante o manuseio do metal líquido com ferramentas fabricadas com materiais ferrosos [5].

Em ligas primárias de elevado grau de pureza, o ferro contido é relativamente baixo, geralmente entre 0,02 e $0,15 \%$ em peso. Isso se deve ao fato de que na bauxita existe alguma contaminação de ferro, que não pode ser completamente eliminado nos processos de obtenção do alumínio [5].

Outra fonte de contaminação de ferro ocorre na elaboração das ligas primárias de alumínio-silício, uma vez que o silício comercialmente puro pode apresentar até $0,6 \%$ de Fe. No manuseio do alumínio líquido nas fundições também pode acontecer alguma contaminação por ferro via ferramentas de aço que mantêm contato com o alumínio líquido ou mesmo contaminação com retornos que contêm insertos de aço. Estes fatores contribuem para um crescente aumento do teor de ferro nas ligas de alumínio-silício. Não se conhece ainda nenhum processo economicamente viável para a remoção do ferro nas ligas de alumínio durante o processo de elaboração. A única maneira de reduzir o teor deste elemento é por diluição com adição de alumínio comercialmente puro. 
Quando ligas recicladas são utilizadas na produção de peças em moldes de areia ou em coquilha, os teores de ferro são mais elevados, da ordem de 0,4 e 0,6\% em peso. Nestas ligas existe a necessidade comercial de contrabalançar os benefícios de redução de custo da matéria prima com uma perda aceitável da capabilidade de processo e das propriedades mecânicas finais [5].

No processo de fundição sob pressão, a presença do ferro em teores da ordem de 0,8 a $1,2 \%$ se faz necessária para diminuir a afinidade do alumínio com o ferro presente na superfície do molde. Em consequência disto, fica reduzida a possibilidade de ocorrer o efeito de aderência da peça sobre a superfície do molde, impedindo a formação uma fase intermetálica, diminuindo o ataque do alumínio líquido à matriz e aumentando a vida útil do ferramental $[6,7]$.

Como o ferro tem baixo limite de solubilidade no alumínio sólido a $655^{\circ} \mathrm{C}(0,03 \%$ em peso), o excedente a este valor formará compostos intermetálicos com o alumínio e o silício. Destes compostos, o mais comum nas ligas de alumínio-silício é a fase $\beta$ $\mathrm{Al} 5 \mathrm{FeSi}$, cuja morfologia em plaquetas interrompe a continuidade da matriz, tornandose locais preferenciais para nucleação e crescimento de trincas [2, 5]. Além disso, durante o processo de solidificação das peças, restringem o fluxo do líquido interdendrítico, dificultando a alimentação destas regiões e contribuindo para a formação de microporosidades, principalmente em componentes fundidos por gravidade [6, 8].

Mesmo no caso de fundição sob pressão, a morfologia da fase $\beta-\mathrm{Al}_{5} \mathrm{FeSi}$ em plaquetas não é desejável, sendo comum sua alteração para uma morfologia menos susceptível à fragilização. Esta alteração é possível com adição de Mn que transforma a fase $\beta$-Als $\mathrm{FeSi}$ de plaquetas para $\alpha-\mathrm{Al}_{15}(\mathrm{Fe}, \mathrm{Mn})_{3} \mathrm{Si}_{2}$ com morfologia do tipo escrita chinesa $[2,5,8]$. 


\section{OBJETIVOS}

\section{Objetivo Geral}

- Comprovar os efeitos das adições em teores variados de Fe e Mn sobre a microestrutura e as propriedades mecânicas de uma liga Al-9\%Si.

\section{Objetivos Específicos}

- Analisar, via micrografia ótica e eletrônica, o efeito de adições crescentes de Fe na liga Al-9\%Si quanto ao tipo de intermetálico formado no que se refere à morfologia (chinesa e plaquetas);

- Comparar as dimensões dos intermetálicos quando das adições crescentes de $\mathrm{Fe}$ e consequentemente redução dos limites de resistência e escoamento;

- Comprovar o papel da fase $\beta-\mathrm{Al}_{5} \mathrm{FeSi}$ quanto a formação das microporosidades nas regiões interdendríticas durante o processo de solidificação;

- Comprovar, por meio do ensaio de tração, que a fase $\beta-A{ }_{5} F e S i$ atua como elemento fragilizante propiciando a nucleação e crescimento das trincas e consequentemente fratura de caráter frágil;

- Mostrar que a adição de Mn na liga de Al-9\%Si-0,8\%Fe permite a obtenção da fase intermetálico $\alpha-\mathrm{Al}_{15}(\mathrm{Fe}, \mathrm{Mn})_{3} \mathrm{Si}_{2}$ com morfologia em escrita chinesa reduzindo a quantidade da fase $\beta$-Als $\mathrm{FeSi}$ com morfologia em plaquetas permitindo aumentar a resistência mecânica da liga;

- Comprovar que adições crescente de $\mathrm{Mn}$ na liga de Al-9\%Si-0,8\%Fe favorecem na obtenção da fase $\alpha-\mathrm{Al}_{15}(\mathrm{Fe}, \mathrm{Mn})_{3} \mathrm{Si}_{2}$ com morfologia poligonal; 


\section{REVISÃO BIBLIOGRÁFICA}

\subsection{Consumo do alumínio fundido}

No Brasil, o consumo das ligas de alumínio fundidas cresce continuamente (tabela 1) por conta da necessidade de redução do consumo de combustível dos veículos automotores. A aplicação do alumínio na indústria automotiva se justifica por ser um material de baixa densidade, reduzindo o consumo de combustível e de emissões de poluentes e pelo fato de ser reciclável, o que o torna um importante metal para o desenvolvimento sustentável da indústria automotiva. Devido à boa combinação de propriedades mecânicas, de resistência à corrosão e de fundição, o alumínio melhora o desempenho dos diversos componentes automotivos. O setor automotivo e de transportes é o segundo maior consumidor de alumínio no Brasil, sendo superado apenas pelo setor de embalagens.

Tabela 1- Produção de Produtos Transformados de Alumínio

\begin{tabular}{|c|c|c|c|c|c|}
\hline $\begin{array}{l}\text { Tipos de } \\
\text { Produtos }\end{array}$ & 2009 & 2010 & 2011 & 2012 & $2013^{*}$ \\
\hline Chapas ${ }^{(1)}$ & 427,4 & 490,7 & 507,7 & 533,5 & 571,8 \\
\hline Folhas & 82,2 & 94,8 & 92,5 & 88,6 & 92,7 \\
\hline Extrudados & 224,6 & 310,1 & 326,1 & 340,7 & 356 \\
\hline Fios e cabos (2) & 125,6 & 118,5 & 149,2 & 147,7 & 129,8 \\
\hline Fundidos & 183,7 & 231,3 & 246,6 & 208 & 220,2 \\
\hline Pó & 25,5 & 41,7 & 42,6 & 39,8 & 37,3 \\
\hline Usos destrutivos & 31,6 & 39,1 & 41,9 & 41,4 & 43,8 \\
\hline Outros & 17,3 & 22,4 & 22,2 & 28,3 & 28,8 \\
\hline TOTAL & $1.117,90$ & $1.348,60$ & $1.428,00$ & $1.428,00$ & $1.480,40$ \\
\hline
\end{tabular}

Nota: (1) Considera chapas planas, chapas em bobinas, discos e lâminas.

(2) Inclui vergalhão exportado.

* Projeção 2013

Fonte: Anuário Estatístico - ABAL acessado em 18/08/2013 16:57

O uso do alumínio nos veículos automotores é crescente e, segundo a pesquisa da Ducker Worldwide [9], no ano de 2012 os automóveis dos EUA continham $156 \mathrm{~kg}$ de alumínio e a previsão para 2025 é que venham a conter $250 \mathrm{Kg}$. O objetivo é aumentar a eficiência no consumo de combustível em mais de $100 \%$ : de $11 \mathrm{~km} / \mathrm{L}$, 
base 2008, para $23 \mathrm{~km} / \mathrm{L}$ em 2025. Diante deste cenário, as montadoras buscam formas de reduzir o peso dos veículos. O objetivo é eliminar cerca de $180 \mathrm{~kg}$ em cada unidade fabricada. O setor de fundição é o responsável, atualmente, por $73 \%$ dos componentes fabricados em alumínio.

\subsection{A Liga Al-9\%Si}

As ligas de Al-Si são as mais utilizadas dentre aquelas usadas em fundição, em função da sua facilidade para fusão aliada a elevada fluidez, alta resistência à corrosão, boa soldabilidade, menor contração de solidificação e principalmente baixo peso específico. Todas estas características a torna adequada para as mais diversas aplicações, notadamente na indústria automobilística e de transportes.

A liga Al-Si pertence a um sistema eutético binário (figura 1) cujo eutético se dá em torno de $12,6 \%$ de Si na temperatura de $577^{\circ} \mathrm{C}$. Abaixo de $12,6 \%$ a liga é denominada de hipoeutética e acima deste valor é denominada de hipereutética [4]. A liga Al-9\%Si é uma liga hipoeutética que se caracteriza, na solidificação, pela formação inicialmente das dendritas de fase $\alpha$. Esta fase é constituída de uma solução sólida de alumínio com no máximo 1,65\% em peso de $\mathrm{Si}$, a $577^{\circ} \mathrm{C}$. Em seguida, em torno dessas dendritas da fase $\alpha$, ocorre a solidificação do eutético, constituída do alumínio com $1,65 \%$ Si como a fase contínua e partículas de silício (fase $\beta$ ) dispersas na matriz [10].

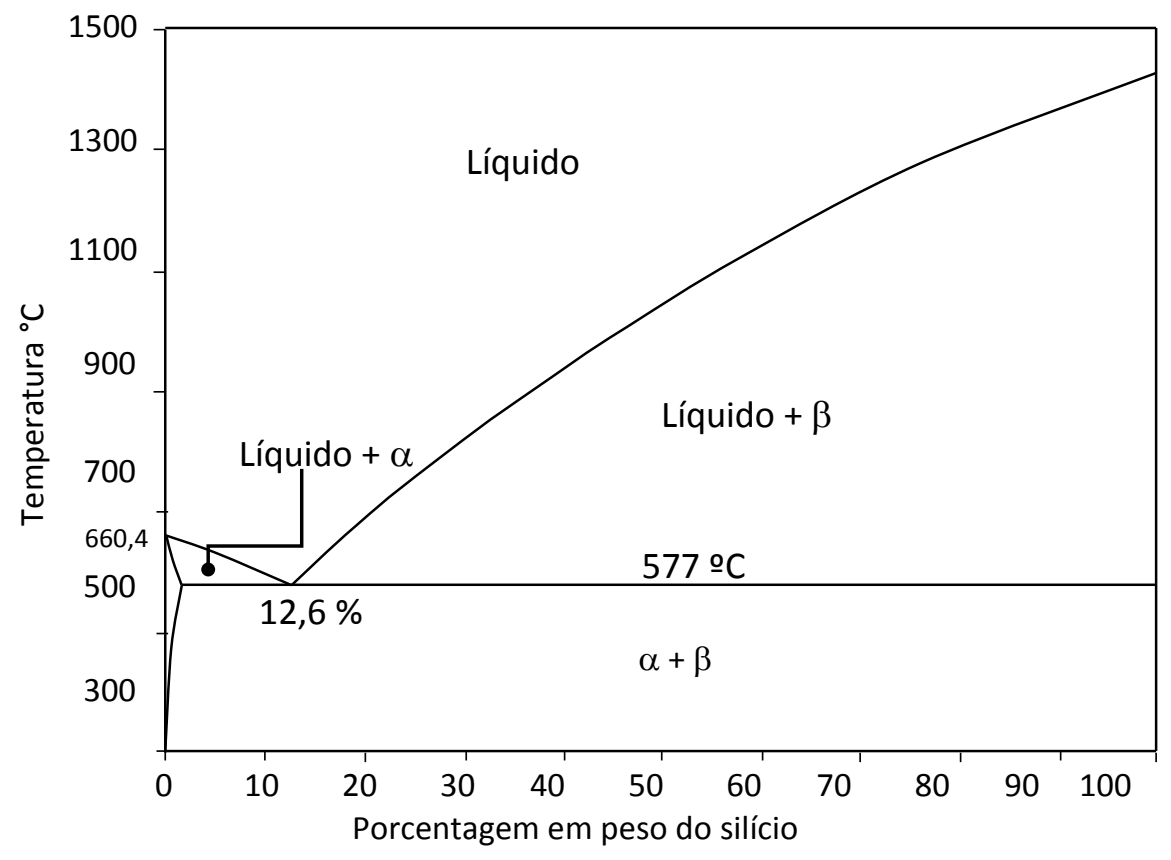

Figura 1 - Diagrama de equilíbrio Al-Si [11] adaptado. 
A microestrutura (figura 2) das ligas de Al-Si hipoeutéticas é formada de

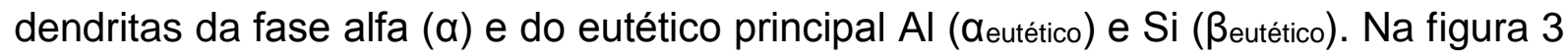
é mostrada a morfologia típica de dendritas de alumínio $\alpha$. Outras fases decorrentes da presença de teores residuais de outros elementos podem ocorrer como reações eutéticas secundárias ou terciárias [10].

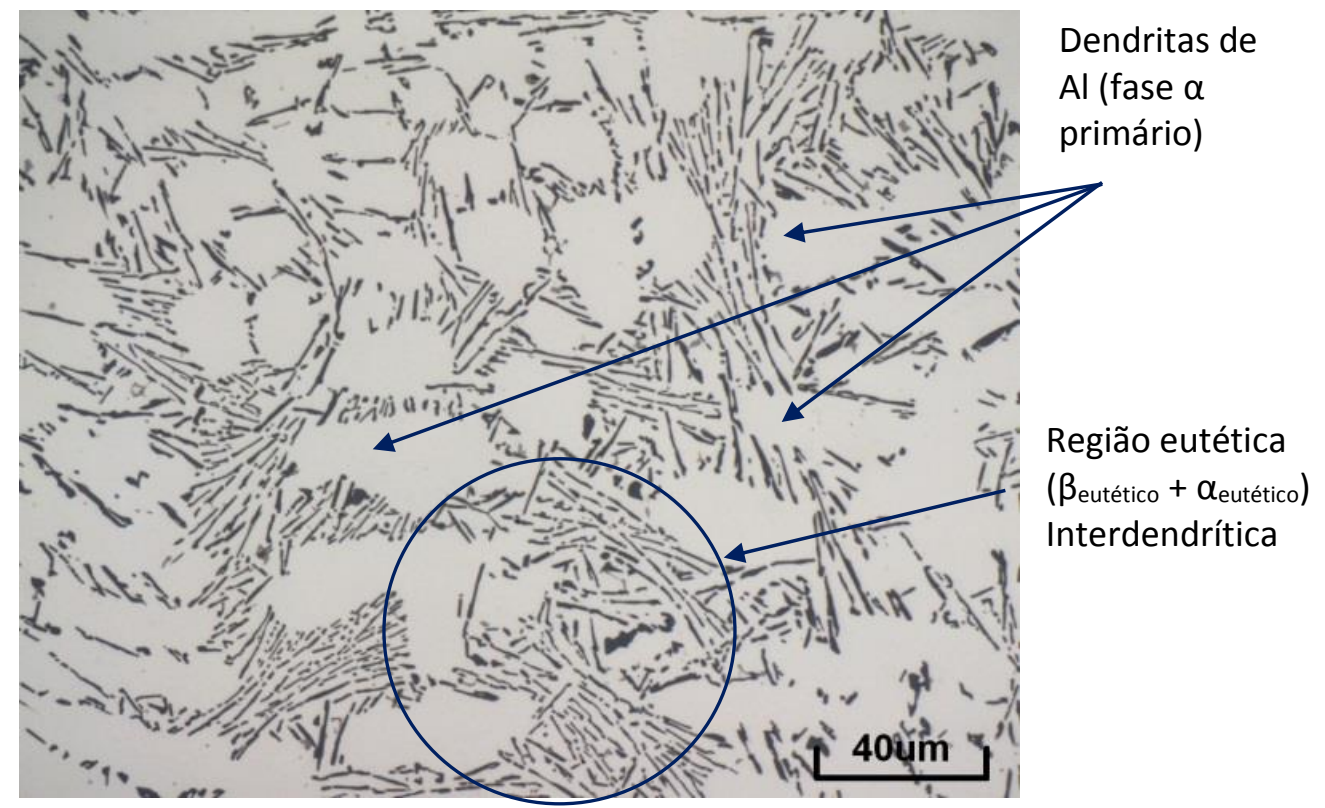

Figura 2 - Microestrutura de uma liga Al-9\% Si mostrando as dendritas da fase $\alpha$ envolvida pelo constituinte eutético ( $\left.\beta_{\text {eutético }}+\alpha_{\text {eutético}}\right)$.

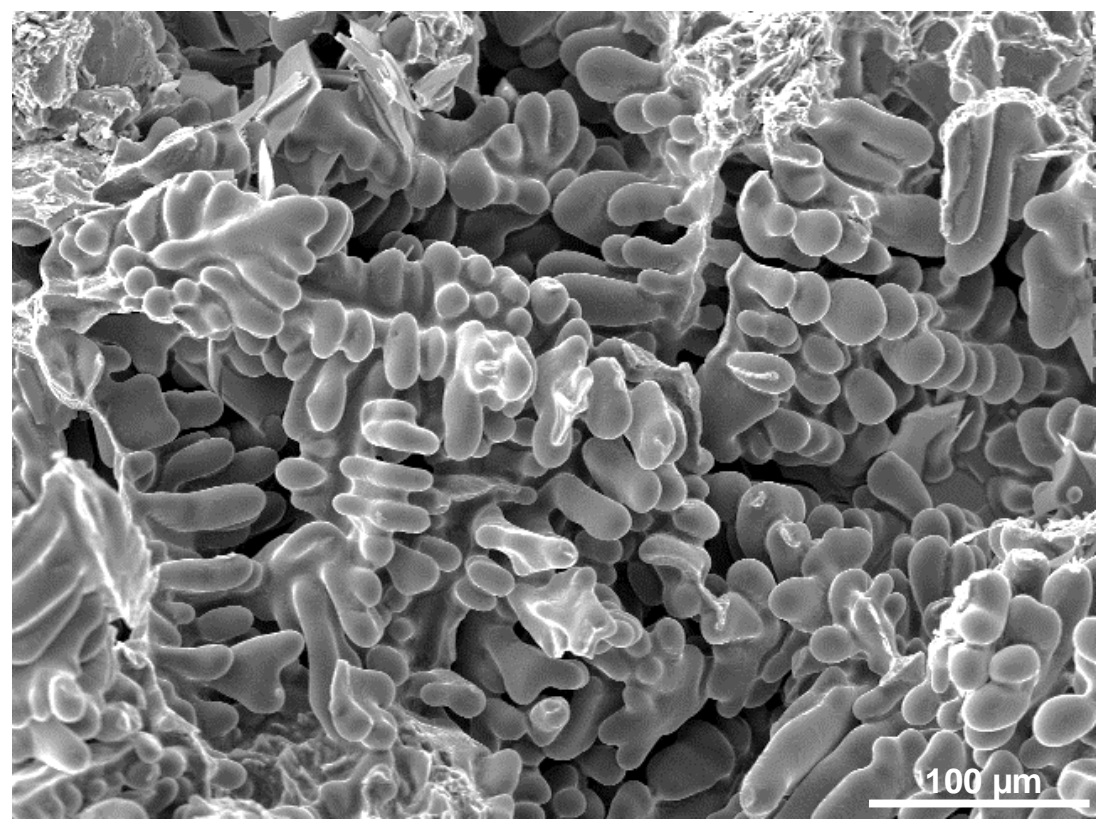

Figura 3 - Dendritas de alumínio- $\alpha$ formadas em uma microporosidade em uma liga de $\mathrm{Al}-9 \% \mathrm{Si}$.

O eutético é constituído de partículas de silício, que apresentam elevada dureza 
e fragilidade, envolvidas pela matriz de alumínio que, por sua vez, apresenta baixa dureza e alta dutilidade. É esta a razão pela qual a maioria das propriedades mecânicas dos fundidos são determinadas pela microestrutura eutética [12].

\subsection{A fase $\beta-\mathrm{Al}_{5} \mathrm{FeSi}$}

O limite de solubilidade do ferro no alumínio líquido é muito baixo, em torno de $0,03 \%$ em peso na temperatura de $650^{\circ} \mathrm{C}$ (figura 4). O eutético Al-Fe se forma nesta faixa de temperatura com $1,8 \%$ de ferro, obtendo-se precipitados de $\mathrm{AlFe}_{3}$ (figura 5) entre os espaçamentos interdendríticos [5].

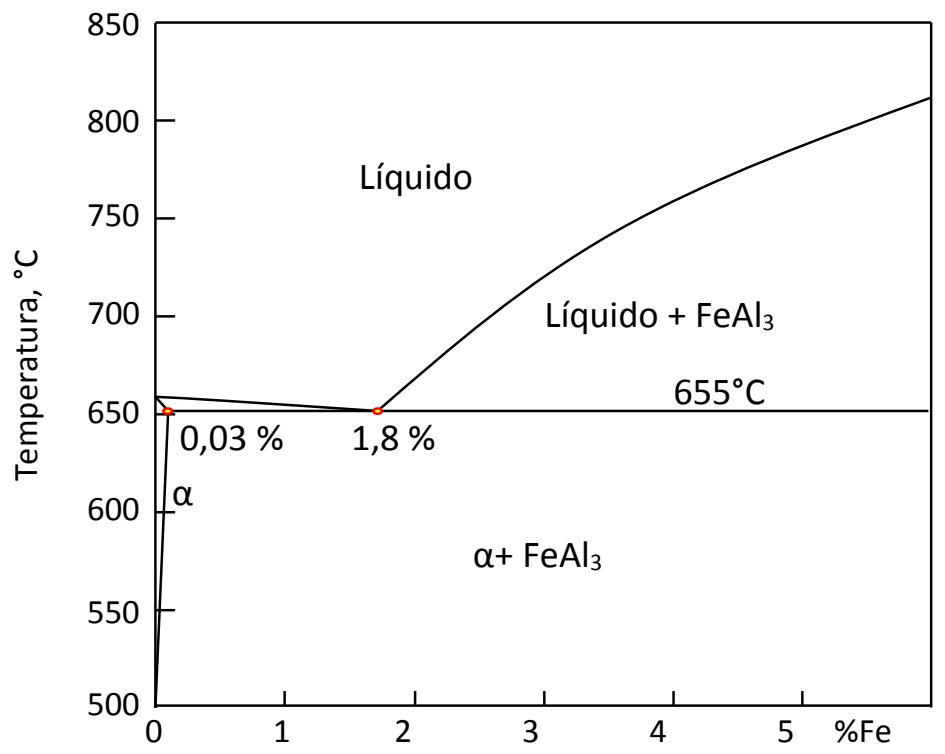

Figura 4 - Diagrama de equilíbrio Al-Fe [5] adaptado.

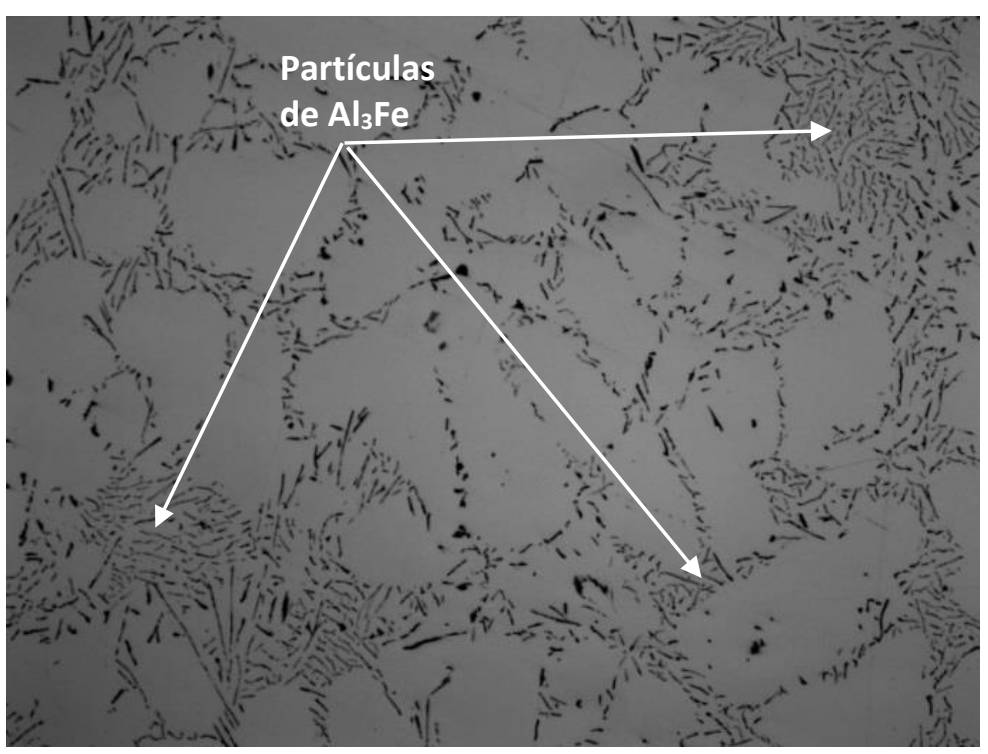

Figura 5 - Micrografia de uma liga Al-Fe 1,5\% fundida em areia. Nos espaçamentos interdendríticos verifica-se a presença do composto intermetálico $\mathrm{Al}_{3} \mathrm{Fe}$ [13]. 200x. 
Nas ligas de Al-Si, a formação do intermetálico $\beta$-AlsSiFe ocorre devido à redução do limite de solubilidade do ferro no alumínio durante a solidificação e que é segregado para contornos de células eutéticas, onde pode formar partículas em conjunto com o eutético principal ou mesmo com eutético secundário dependendo dos teores de $\mathrm{Fe}$ e Si $[5,10]$. Por ser a partícula $\beta$-AlsSiFe altamente facetada, caracterizado por uma interface sólido/líquido lisa, este eutético é denominado de eutético irregular (facetado/não facetado) em que esta fase se solidifica formando plaquetas que, observada no microscópio ótico, apresenta-se na forma de agulhas, como na figura 6 e tridimensionalmente com morfologia em plaquetas como mostra a figura 7 [10].

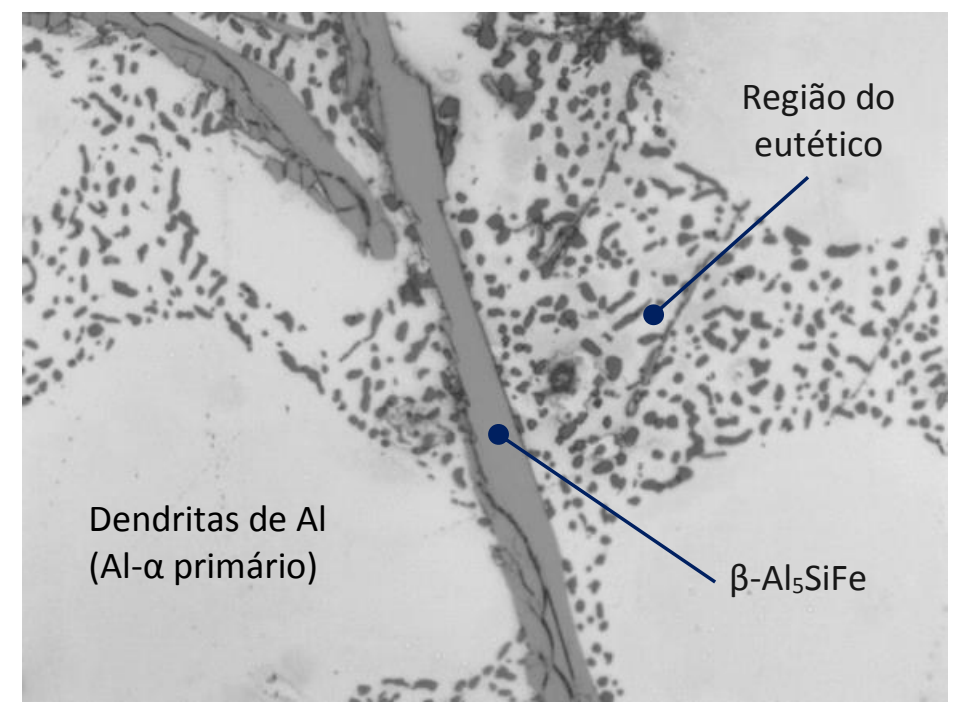

Figura 6 - Microestrutura de uma liga de Al-7\%Si -0,2\% de Fe modificada com Sr evidenciando a fase intermetálica $\beta-\mathrm{Al}_{5} \mathrm{SiFe}$. Aumento de 1000x.

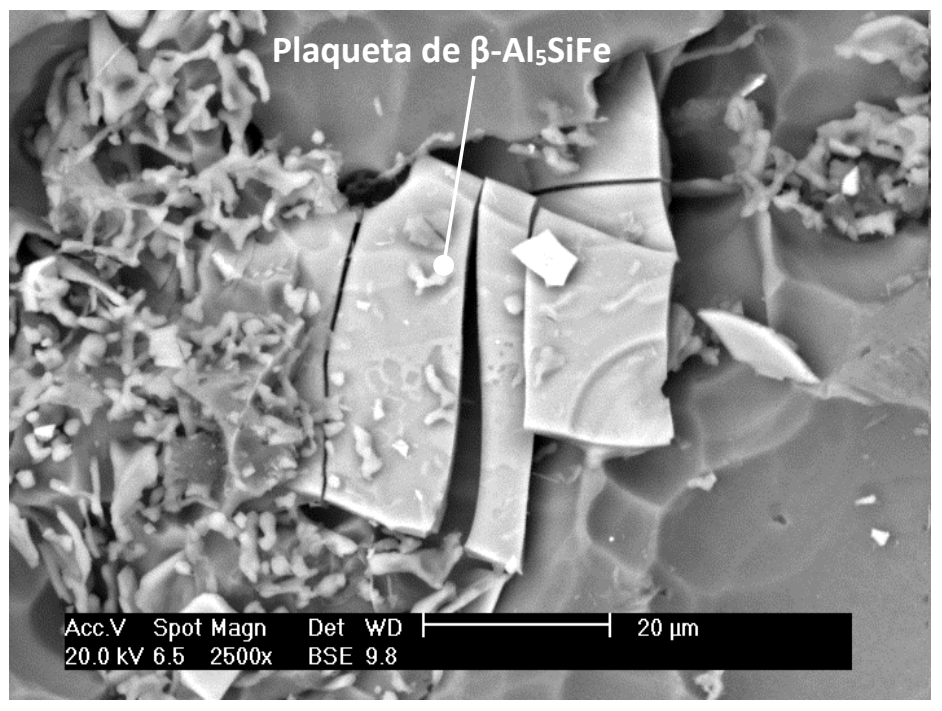

Figura 7 - Plaqueta de fase $\beta-A I_{5}$ SiFe observada em MEV em uma amostra com 1,0\% de Fe e $7,0 \%$ de Si [13] 
A ocorrência da fase $\beta$-AlsFeSi pode ser prevista com o auxílio da projeção da superfície liquidus do diagrama de equilíbrio ternário Al-Si-Fe, como ilustra a figura 8. Nesta figura é apresentada a sequência de solidificação das ligas Al-Si com teores crescentes de silício (5\% e 11\%) [14] para o teor de ferro em $0,4 \%$. As sequências de solidificação estão descritas na Tabela 1. Para determinar esta sequência de solidificação basta tomar a partir da origem do gráfico uma reta que passa pela coordenada dadas pelos teores de silício $(11,0 \%)$ e ferro $(0,4 \%)$ no ponto " $A$ " da liga até encontrar uma das linhas dos campos de transformação, o ponto "B". Se a intersecção das linhas teor de ferro e teor de silício se der no campo de formação das dendritas de alumínio, esta é a fase que se forma primeiro. Quando a reta encontra a linha de mudança de fase do $\mathrm{Si}$, tem-se a solidificação do eutético principal $(\alpha+\mathrm{Si})$. Nesta mesma linha, prolongando-a até o ponto "C", verifica-se a formação dos eutéticos secundários com a presença da fase intermetálica $\left(\alpha+\mathrm{Si}+\beta-\mathrm{Al}{ }_{5} \mathrm{FeSi}\right)$.

Para a liga com menor teor de silício (5,0\%) e com o mesmo teor de Fe ocorre uma a antecipação da formação do intermetálico, ou seja, após atravessar o campo de formação das dendritas de alumínio, a reta encontra a linha de formação da fase $\beta$-Als $F e S i$ (eutético secundário $\alpha+\beta-\mathrm{Al}_{5} \mathrm{FeSi}$ ). Com isto se deduz que haverá maior quantidade desta fase na matriz. Novamente, a solidificação prossegue por esta linha de transformação até o ponto "C", onde a solidificação da liga termina com a formação também dos eutéticos secundários $\left(\alpha+S i+\beta-A l_{5} F e S i\right)$. A tabela 2 descreve a sequência resumida destas ligas. $O$ ponto " $C$ " do diagrama simplificado representa 0 limite de transição e é denominado de "ponto crítico" de teor de ferro [5], onde ocorre o final da solidificação destas ligas. 


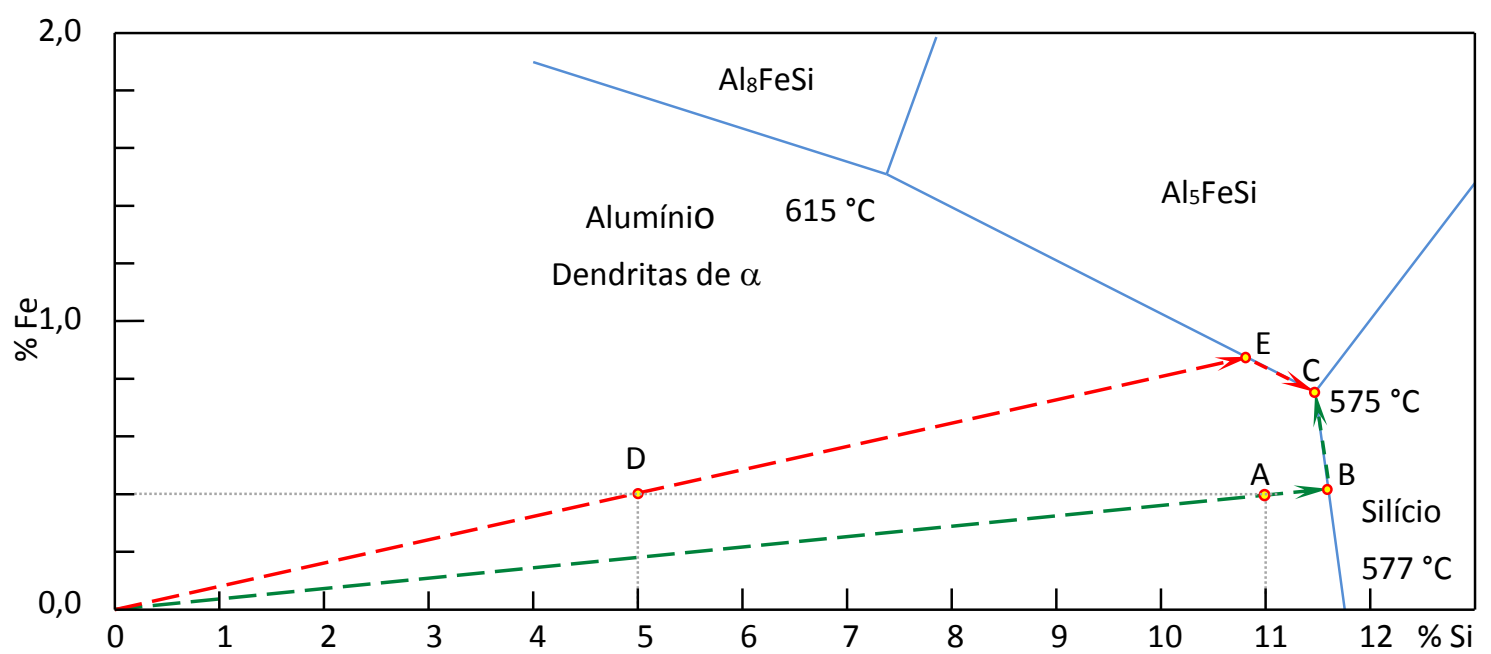

Figura 8 - Projeção da superfície liquidus do diagrama Al-Si-Fe onde estão representadas as sequências de fases formadas durante a solidificação das ligas Al-5\%Si e Al-11\%Si com teor de ferro de 0,4\%. Adaptado [14].

Tabela 2- Sequência de solidificação das ligas Al-Si 5\% e Al-Si 11\% com teor de ferro de $0,4 \%$, como representadas na Figura 8.

\begin{tabular}{|l|c|l|}
\hline \multicolumn{1}{|c|}{ Liga } & Região & \multicolumn{1}{|c|}{ Fases formadas na solidificação } \\
\hline \multirow{2}{*}{ Al-11\%Si-0,40\%Fe } & A - B & L $\rightarrow$ Dendritas de Fase $\alpha$ \\
\cline { 2 - 3 } & B - C & L $\rightarrow$ Eutético principal $(\alpha+\mathrm{Si})$ \\
\cline { 2 - 3 } & C & L $\rightarrow$ Eutético secundário $(\alpha+\mathrm{Si})+\left(\beta-\mathrm{Al}_{5} \mathrm{FeSi}\right)$ \\
\hline \multirow{2}{*}{ Al-5\%Si-0,40\%Fe } & D - E & L $\rightarrow$ Dendritas de Fase $\alpha$ \\
\cline { 2 - 3 } & E - C & L $\rightarrow$ Eutético $\alpha+\beta-\mathrm{Al}_{5} F e S i$ \\
\hline & C & L $\rightarrow$ Eutético secundário $(\alpha+\mathrm{Si})+\left(\beta-\mathrm{Al}_{5} \mathrm{FeSi}\right)$ \\
\hline
\end{tabular}

Entende-se por Fe crítico [5] ( $\mathrm{Fe}_{\text {critico }}$ o teor de ferro a partir do qual, para uma determinada liga de $\mathrm{Al}-\mathrm{Si}$, ocorre a reação $\mathrm{L} \rightarrow$ Eutético $(\alpha+\beta-\mathrm{Al} 5 \mathrm{FeSi})$. Assim sendo, para as ligas de Al-Si com 5\%, 7\% e 9\% de silício, por exemplo, o Fecritico seria de aproximadamente $0,36 \%, 0,44 \%$ e $0,60 \%$, respectivamente como mostra a figura 9 . 


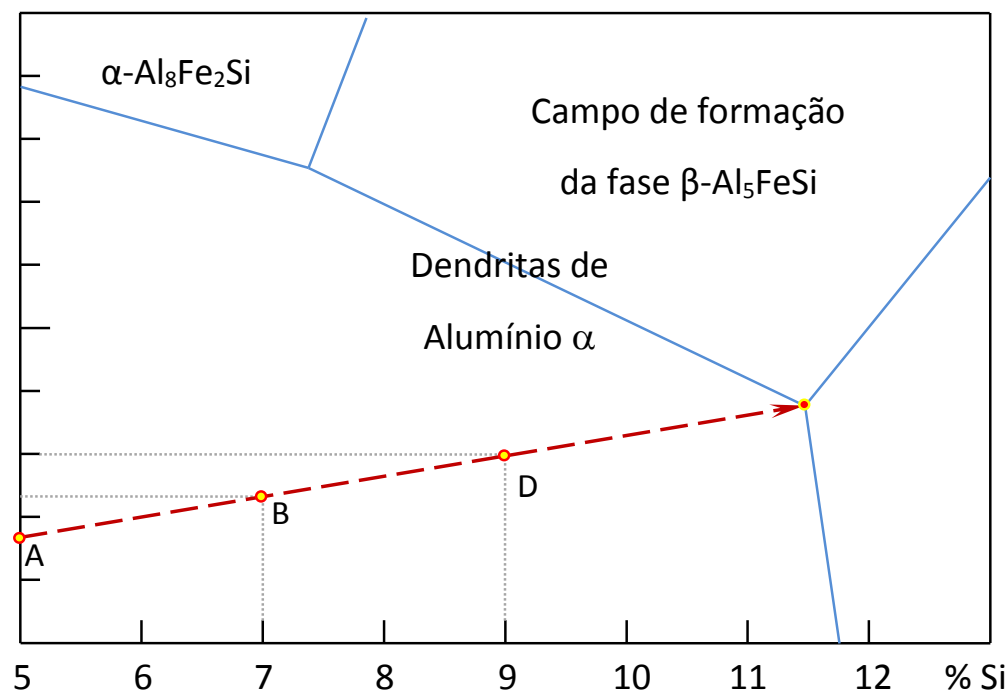

$575^{\circ} \mathrm{C}$

Silício

$577^{\circ} \mathrm{C}$

Figura 9 - Projeção da superfície liquidus do diagrama ternário Al-Si-Fe que mostra o

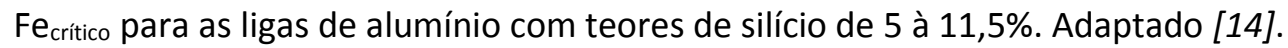

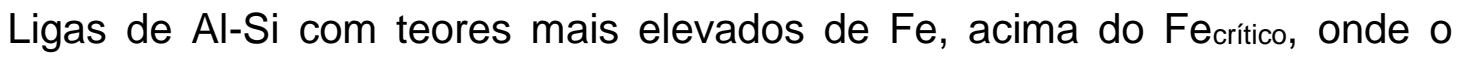
encontro dos teores de Si e Fe se dá acima da linha de formação da fase $\beta-\mathrm{Al} 5 \mathrm{FeSi}$, como por exemplo, Al-9\%Si-1,4\% de Fe, na figura 10, a solidificação iniciará com a formação da fase $\beta-\mathrm{Al}_{5} \mathrm{FeSi}$, conforme sequência descrita na tabela 3 .

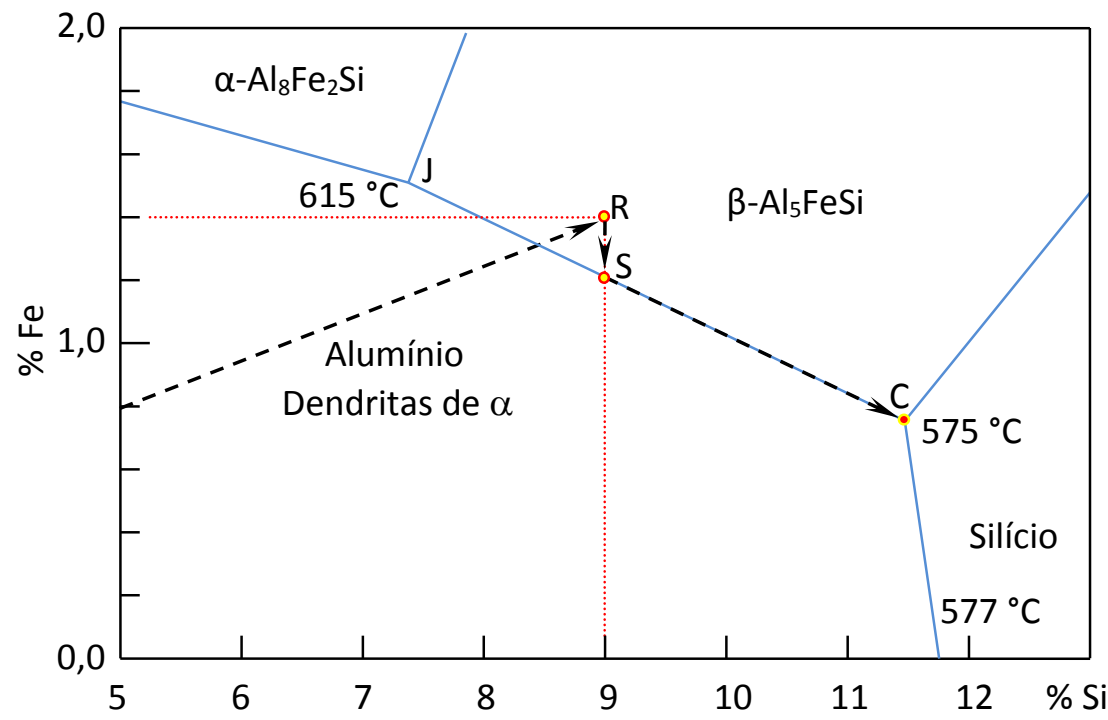

Figura 10 - Projeção da superfície liquidus do diagrama ternário Al-Si-Fe onde estão representadas as sequências de formação de fases durante a solidificação da liga Al9\%Si com teor de ferro de 1,4\%. Adaptado [14]. 
Tabela 3-Sequência de solidificação da liga Al-9\%Si com teor de ferro de 1,4\%, como representada na Figura 10.

\begin{tabular}{|l|c|l|}
\hline \multicolumn{1}{|c|}{ Liga } & Região & \multicolumn{1}{|c|}{ Fases formadas na solidificação } \\
\hline \multirow{3}{*}{ Al-9\%Si-1,40\%Fe } & R - S & L $\rightarrow \beta$-AlsFeSi \\
\hline & S - C & L $\rightarrow$ Eutético $(\alpha+\beta-A l 5 F e S i)$ \\
\cline { 2 - 3 } & C & L $\rightarrow$ Eutético secundário $(\alpha+\mathrm{Si})+\left(\beta-A l_{5} F e S i\right)$ \\
\hline
\end{tabular}

Conforme a sequência de solidificação apresentada na tabela 3, as partículas formadas de $\beta-\mathrm{Al}_{5} \mathrm{FeSi}$ serão maiores e mais grosseiras, que contribui para ductilidade mais baixa $[2,15]$.

\subsubsection{Nucleação da fase $\beta$-AlsFeSi}

Existem evidências de que a formação da fase intermetálica $\beta$-Als $\mathrm{FeSi}$, assim como qualquer evento de solidificação, se dá por nucleação e crescimento, necessitando de um substrato para sua nucleação e de gradiente de concentração para seu crescimento [16].

Alguns trabalhos propõem dois mecanismos para a nucleação da fase $\beta$ AlsFeSi: (i) nucleação em partículas nucleantes de fosfeto de alumínio (AIP) [17, 18, 19] e (ii) a nucleação em pequenos filmes de óxido arrastadas [16, 20, 21, 22, 23]. A primeira proposta se refere a nucleação da fase $\beta$-Als $\mathrm{FeSi}$ que pode ser atribuída a existência de fosforo residual no alumínio, formando AIP que parece atuar como um substrato para o intermetálico, além da células eutéticas Al-Si. A segunda proposta, conforme as referências $[24,25,26]$, propõe que a fase $\beta$-AlsFeSi é formada sobre uma película de óxido presente no metal líquido. Estes trabalhos mostram que a película de óxido imersa no metal líquido apresenta dois lados: uma superfície externa de baixa aderência e a interna de maior aderência que apresenta menor desajuste do reticulado cristalino em relação ao intermetálico com ferro atuando como um excelente substrato para a nucleação.

Os mesmos autores propõem ainda que a película de óxido se dobraria sobre o lado de menor aderência, conforme mostra a figura 11, o que permitiria a formação de um vazio (figura 12) onde, eventualmente, poderiam se formar as 
microporosidades ou mesmo microfissuras, como mostra a figura 13. Essas microporosidades seriam limitadas pelas paredes da película de óxido dobradas sobre si mesmas, enquanto que as partículas da fase $\beta-\mathrm{Al}_{5} \mathrm{FeSi}$ poderiam nuclear e crescer no lado externo do bi-filme de óxido (lado aderente)
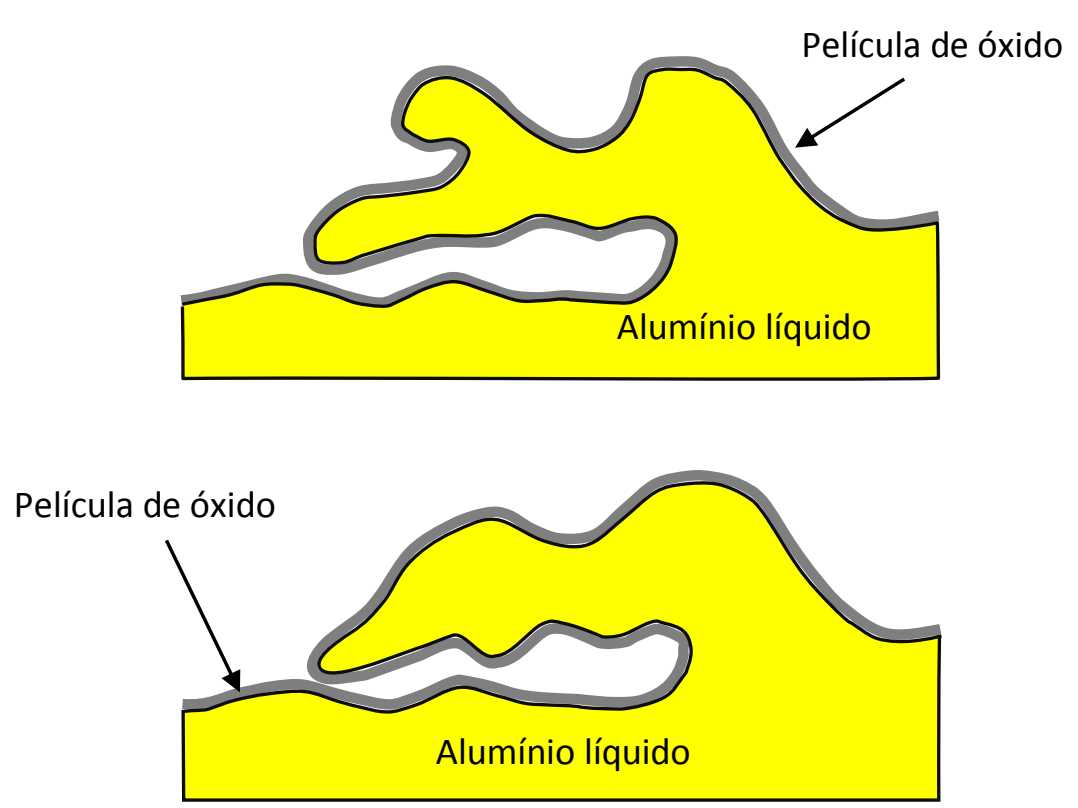

Figura 11 - A agitação na superfície do metal líquido provoca o envelopamento de óxidos próximo à superfície (ocorre o dobramento da película de óxido sobre ela mesma).

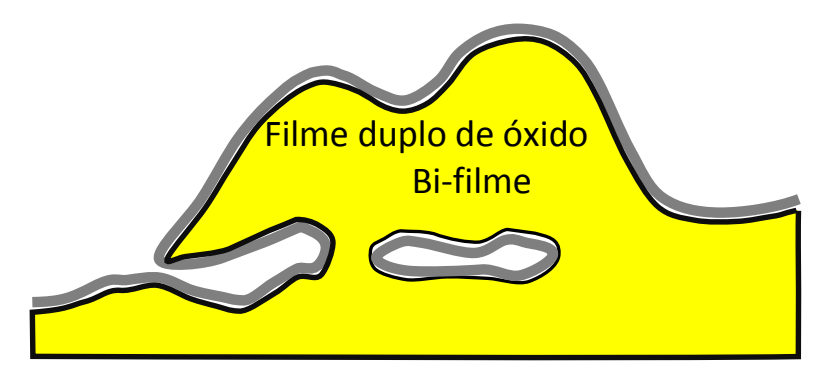

Figura 12- Filme duplo de óxido arrastado para o interior do metal formando micro porosidades. [26]. 


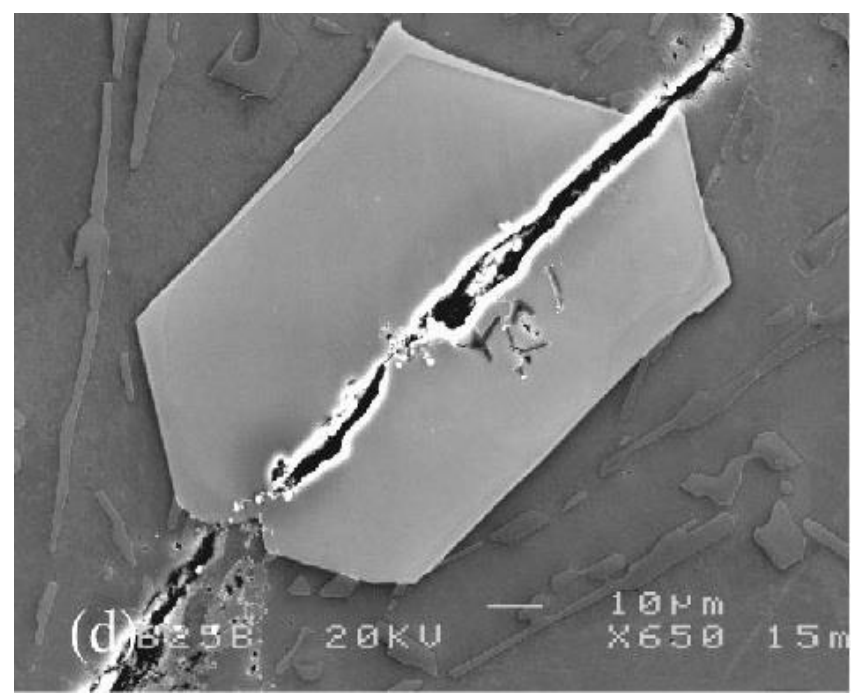

Figura 13 - Partículas de intermetálico que cresceram, independentes, sobre cada um dos lados uma película de óxido dobrada formando uma fissura que pode atuar como concentrador de tensões favorecendo na propagação de trincas [21].

Como a película de óxido é extremamente fina e transparente, a impressão é que de fato as microporosidades seriam limitadas pela presença da fase $\beta-\mathrm{Al}_{5} \mathrm{FeSi}$ como mostra a figura 14 .

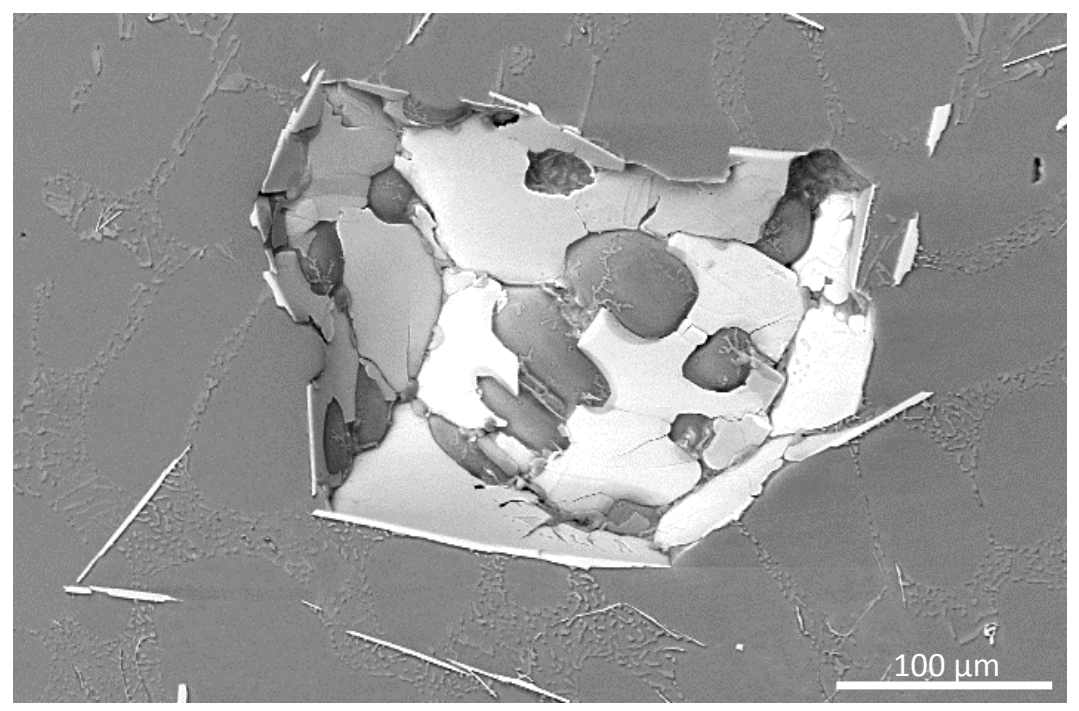

Figura 14 - Micro porosidade formada pela interconexão das plaquetas da fase $\beta-\mathrm{Al}{ }_{5} \mathrm{FeSi}$ que nuclearam e cresceram sobre películas de óxidos [13].

Em trabalhos recentes, Terzi $[17,27]$ mostrou, por meio de imagens obtidas pela microtomografia de raios- $\mathrm{X}$ de uma liga $\mathrm{Al}-8 \% \mathrm{Si}-4 \% \mathrm{Cu}-0,8 \% \mathrm{Fe}$ em solidificação, que a fase $\beta$-Als $\mathrm{FeSi}$ apresenta configuração complexa, formando ramificações cujo crescimento é lateral, tal como mostra a figura 15. 


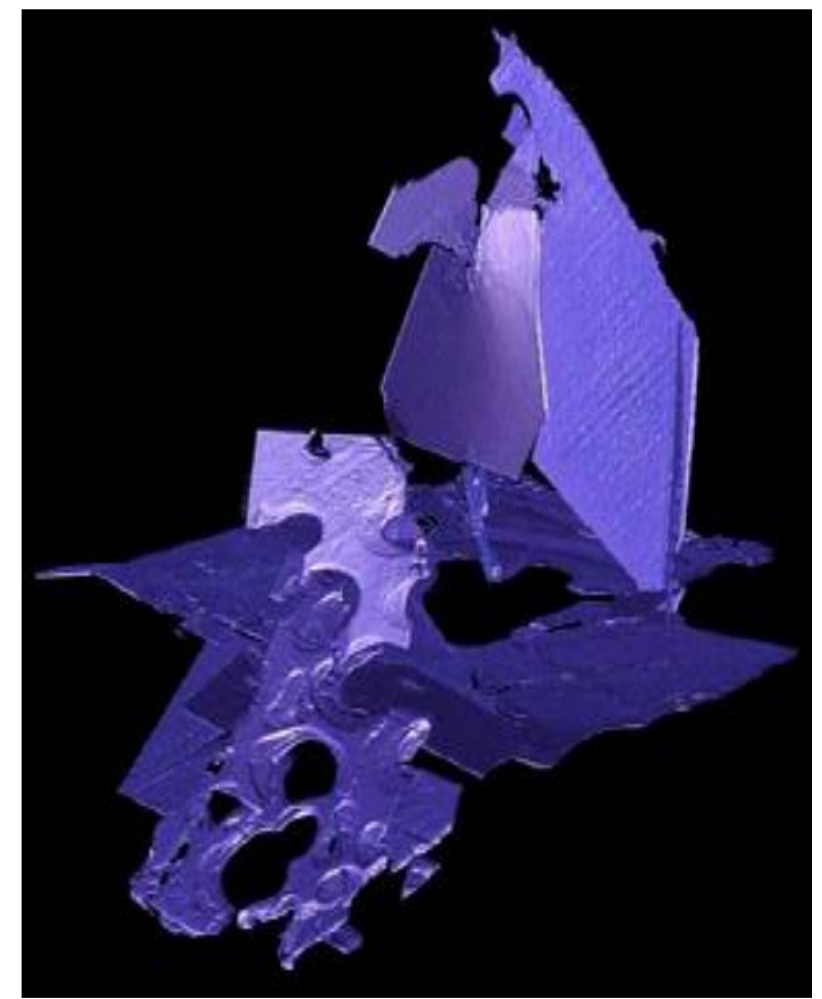

Figura 15 - Microtomografia de raio $\mathrm{X}$ das plaquetas de $\beta$ - $\mathrm{Al}{ }_{5} \mathrm{FeSi}$ obtida durante a solidificação da liga Al-8\%Si-4\%Cu-0,8\%Fe [27].

\subsubsection{Porosidades}

A formação de porosidades, além daquelas decorrentes da contração de solidificação e presenças de gases [28], também pode ocorrer devido a presença do intermetálico $\beta-\mathrm{Al}_{5} \mathrm{FeSi}$ e há concordância de que esta fase é um facilitador na formação de vazios por falta de alimentação nas regiões interdendríticas [2, 5, 7, 29, 30, 31, 32, 33, 34]. Aparentemente, o mecanismo de atuação da fase intermetálica é o de bloquear o fluxo do líquido eutético entre as dendritas durante a solidificação. Este efeito é mais acentuado a partir do teor crítico de $\mathrm{Fe}$ onde a reação $L \rightarrow$ Eutético $\alpha+\beta$-Als FeSi começa a acontecer, formando partículas de fase intermetálica de maiores dimensões ou quando o teor de Fe é elevado o suficiente para ultrapassar a linha de transformação entre os campos $\alpha$ dendrita e $\beta$-Als $\mathrm{FeSi}$ (figura 9, ponto R). Neste caso, a fase intermetálica é primária (forma-se antes das dendritas de fase alfa) e a solidificação segue a sequência da tabela 3 mencionada anteriormente.

As porosidades relacionadas à fase $\beta$-AlsFeSi parecem ser mais acentuadas em ligas Al-Si que também apresentam cobre em sua composição, mas os mecanismos da atuação do cobre neste efeito não estão ainda bem esclarecidos [3]. 
A fase $\beta$-AlsFeSi poderia efetuar um bloqueio nas regiões interdendríticas, impedindo o fluxo do líquido eutético por entre estas regiões, como mostram as figuras 16 e 17 .

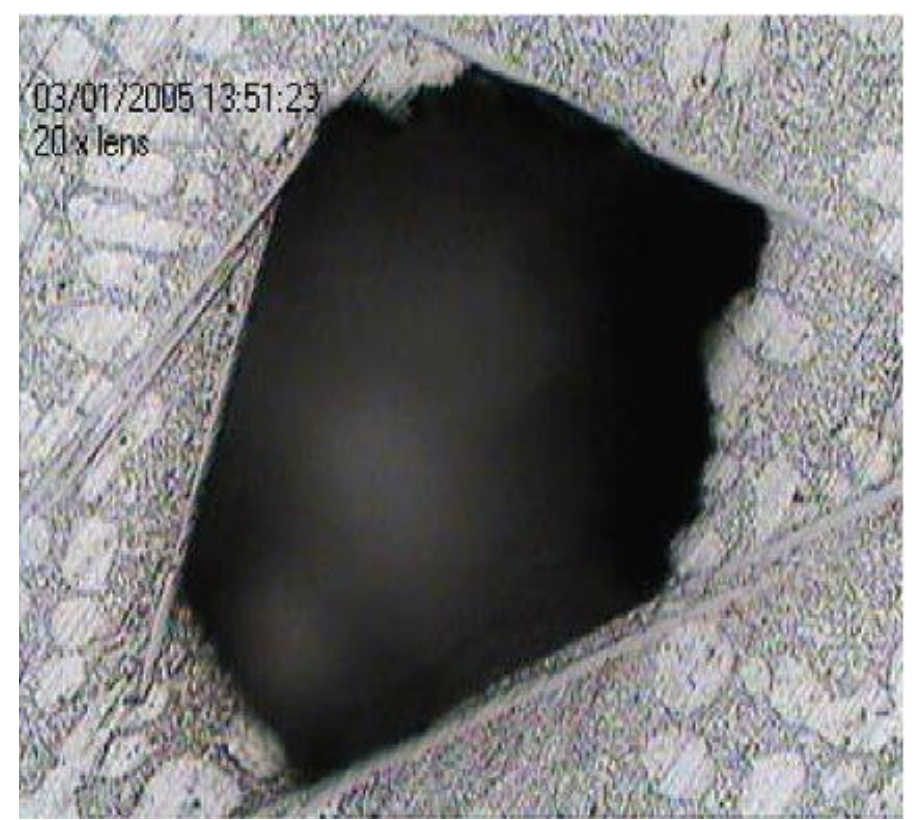

Figura 16 - Micro porosidade formada nas vizinhanças das plaquetas de $\beta-\mathrm{Al}_{5} \mathrm{FeSi}$ [30].

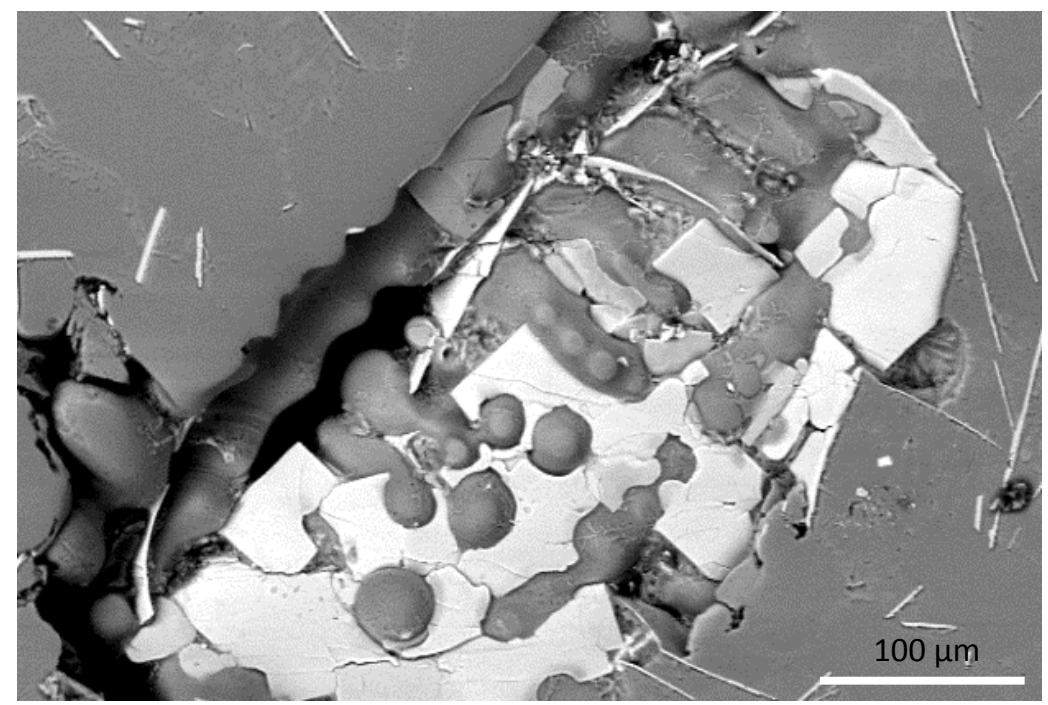

Figura 17- Micro porosidade formada devido as plaquetas da fase $\beta$-Al ${ }_{5} F e S i$ que restringiram o fluxo do líquido eutético na região [13].

Moustafa [30] mostrou que o aumento do teor de Fe em uma liga de Al-Si favorece o aumento da porosidade, como mostra a figura 18, que apresenta a comparação entre uma liga $\mathrm{Al}-12 \% \mathrm{Si}$ modificada com $\mathrm{Sr}$ e a mesma liga sem modificação. 


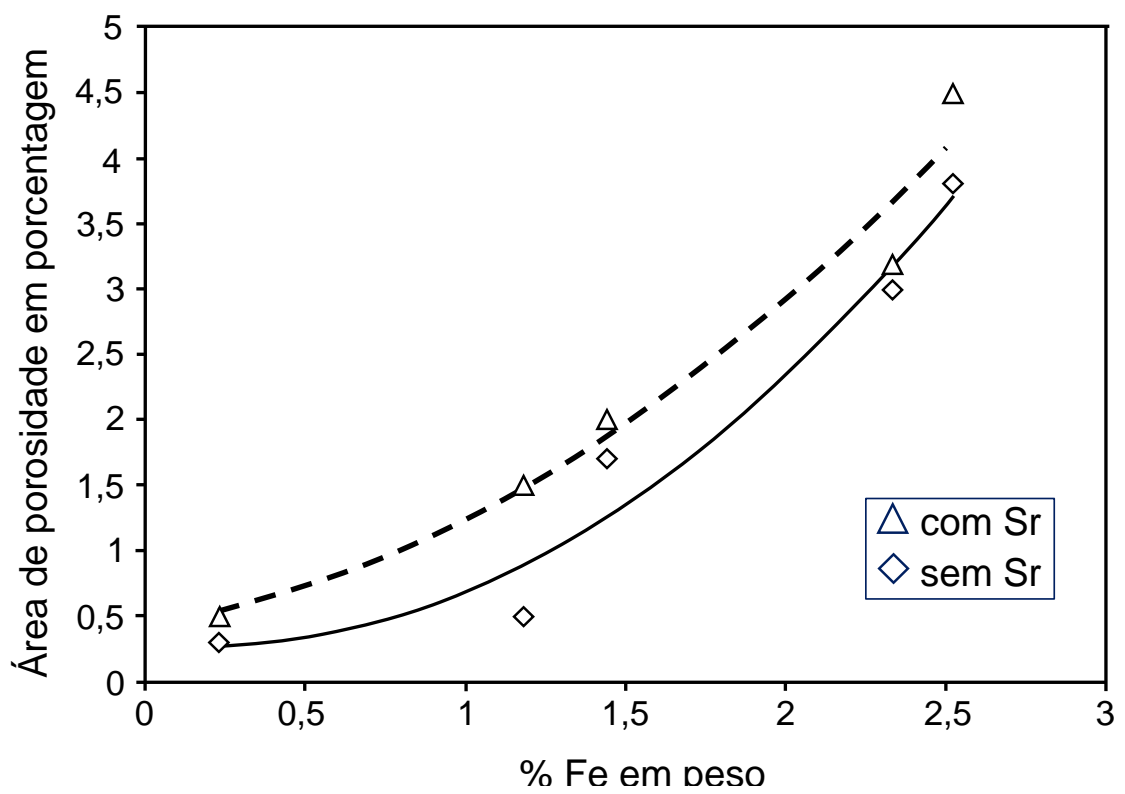

Figura 18 - Efeito da \%Fe sobre a área porcentual de porosidades em uma liga Al-12\%Si sem e com modificação. Adaptada [30].

A hipótese de que a fase $\beta$-Als $\mathrm{FeSi}$ se forma sobre o AlP também explicaria a formação das microporosidades [19]. Como o AlP é um excelente nucleante para formação das células eutéticas de Al-Si sem a presença de ferro, o número de células eutéticas é elevado e de pequenas dimensões e as microporosidades ocorreriam dispersas entre elas. Na presença do ferro e compartilhando do mesmo substrato, a formação da fase $\beta$-Als $\mathrm{FeSi}$ é intensificada em detrimento do número de células eutéticas que diminui, provocando o aumento na dimensão e no número de microporosidades [19].

\subsubsection{Propriedades mecânicas}

A presença da fase $\beta$-Als $\mathrm{FeSi}$ causa impacto considerável sobre as propriedades mecânicas. Como esta fase intermetálica apresenta morfologia em plaquetas, característica frágil e pouca interação com a matriz de alumínio, as propriedades mecânicas da liga são comprometidas [5, 8, 15, 33]. A resistência à tração e a ductilidade diminuem na presença deste intermetálico [30].

Durante esforços mecânicos, a matriz de alumínio (fasea) tende a se deformar, induzindo tensões sobre as partículas de fase $\beta$-Als $\mathrm{FeSi}$ que sofrem microfissuras, se descolam da matriz de alumínio ou mesmo por conta de fissuras pré-existentes em função da nucleação do intermetálico sobre o bi-filme de óxidos, dando início ao 
processo de fratura do material e proporcionando um percurso mais fácil para a propagação das macrofissuras. A figura 19 mostra a propagação de uma fratura em uma amostra com alto teor de Fe submetida ao ensaio de tração. A fratura se propaga ao longo de uma partícula frágil de $\beta$-AlsFeSi.

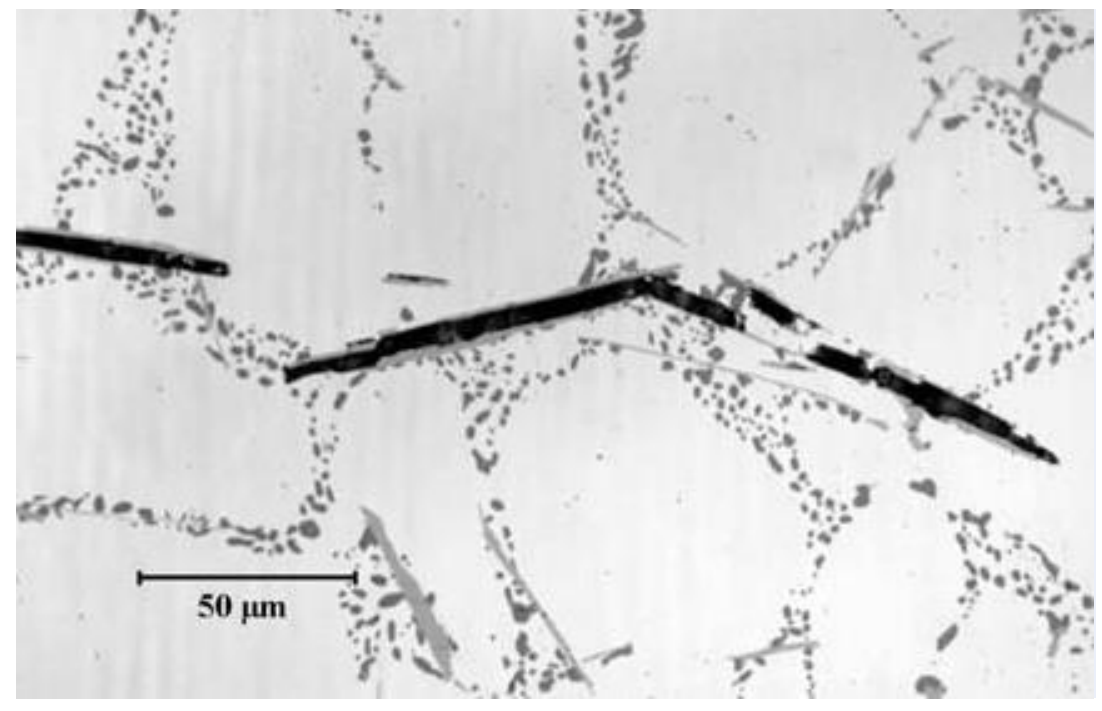

Figura 19 - Propagação de trinca ao longo da plaqueta de $\beta$-Al ${ }_{5} \mathrm{FeSi}$ submetida ao ensaio de tração [5].

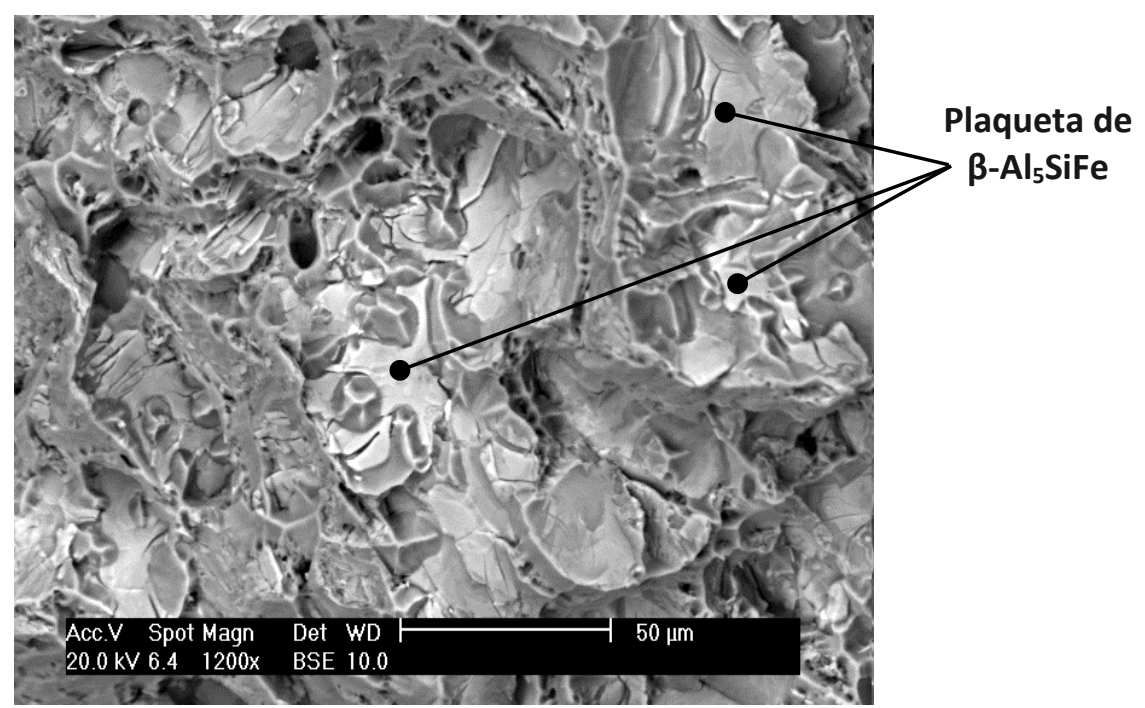

Figura 20 - Superfície de amostra fraturada de uma liga Al-7\%Si-1,0\%Fe mostrando a presença da fase $\beta$-Al5FeSi [13].

\subsection{Fase $\alpha-\mathrm{Al}_{8} \mathrm{Fe}_{2} \mathrm{Si}$}

A fase $\alpha-\mathrm{Al}_{8} \mathrm{Fe}_{2} \mathrm{Si}$ é um intermetálico que se apresenta com morfologia em escrita chinesa (figura 21), sendo menos prejudicial do que a fase $\beta-\mathrm{Al}$ apresenta morfologia em placas. Sua formação também está âssccciada à presença 
de óxidos, mas parece ser mais efetiva quando o metal é superaquecido [20, 21, 22, 23] quando ocorre a formação da alumina alfa $\left(\mathrm{Al}_{2} \mathrm{O}_{3}-\alpha\right)$.

Como o alumínio tem grande afinidade com o oxigênio, a formação do óxido é inevitável, principalmente com a elevação da temperatura quando fundido. No estado líquido sobre a superfície do banho, uma fina camada de óxido de aspecto espelhado se forma em frações de segundos, que é denominada de alumina amorfa. Após alguns minutos, a alumina amorfa se transforma em alumina gama $\left(\mathrm{Al}_{2} \mathrm{O}_{3}-\gamma\right)$, que com a elevação da temperatura do metal, passa por nova transformação se tornado mais compacta e passando a ser denominada de alumina alfa $\left(\mathrm{Al}_{2} \mathrm{O}_{3}-\alpha\right)$ [35]. Assim como a $\mathrm{Al}_{2} \mathrm{O}_{3}-\gamma$ aparentemente, parece ser um bom substrato para a nucleação da fase $\beta$ $\mathrm{Al} 5 \mathrm{FeSi}$, a $\mathrm{Al}_{2} \mathrm{O}_{3-\alpha}$ também parece apresentar um bom desajuste de reticulado em relação à partícula $\alpha-\mathrm{Al}_{8} \mathrm{Fe}_{2} \mathrm{Si}$, mas péssimo para a nucleação de $\beta$-Als $\mathrm{FeSi}$ [21]. Quando o alumínio é superaquecido acima de $750^{\circ} \mathrm{C}$, por exemplo, ocorre a transformação da alumina- $\gamma$ para alumina- $\alpha$, irreversível, inibindo a formação das partículas de $\beta$-AlsFeSi e favorecendo a nucleação da partícula de $\alpha-\mathrm{Al}_{8} \mathrm{Fe}{ }_{2} \mathrm{Si}$ [21].

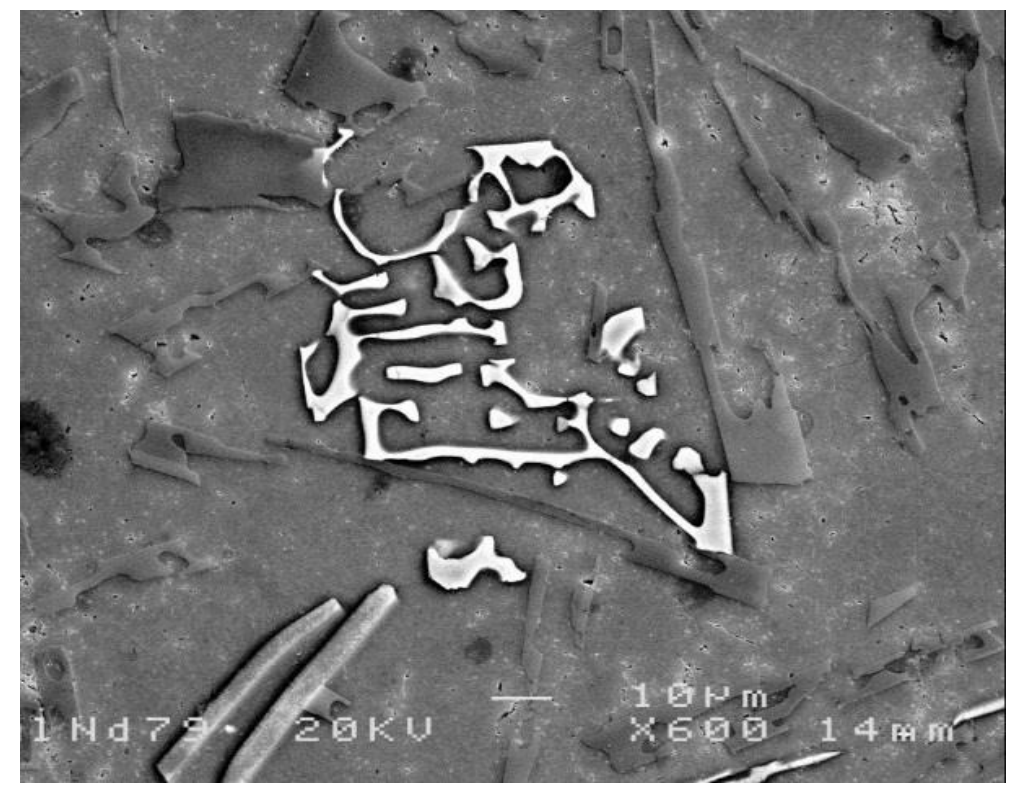

Figura 21 - Fase $\alpha-\mathrm{Al}_{8} \mathrm{Fe}_{2} \mathrm{Si}$ com morfologia em escrita chinesa [36].

Awamo e Shimizu [20], executaram experimentos em que superaqueceram ligas de alumínio com 6 e $11 \%$ de silício à temperaturas que variaram de $700^{\circ} \mathrm{C}$ até $950^{\circ} \mathrm{C}$ e variando o teor de $\mathrm{Fe}$ de 0,1 a $0,9 \%$. Neste estudo, constataram que a formação da fase $\alpha-\mathrm{Al}_{8} \mathrm{Fe}_{2} \mathrm{Si}$ é tanto mais intensa quanto maior o superaquecimento 
do metal conforme mostra a figura 22. Mesmo após a redução da temperatura, os núcleos efetivos para a cristalização de $\alpha-\mathrm{Al}_{8} \mathrm{Fe}{ }_{2} \mathrm{Si}\left(\alpha-\mathrm{Al}_{2} \mathrm{O}_{3}\right)$ já estavam estabilizados, impedindo a formação da fase $\beta-\mathrm{Al}_{5} \mathrm{FeSi}$.
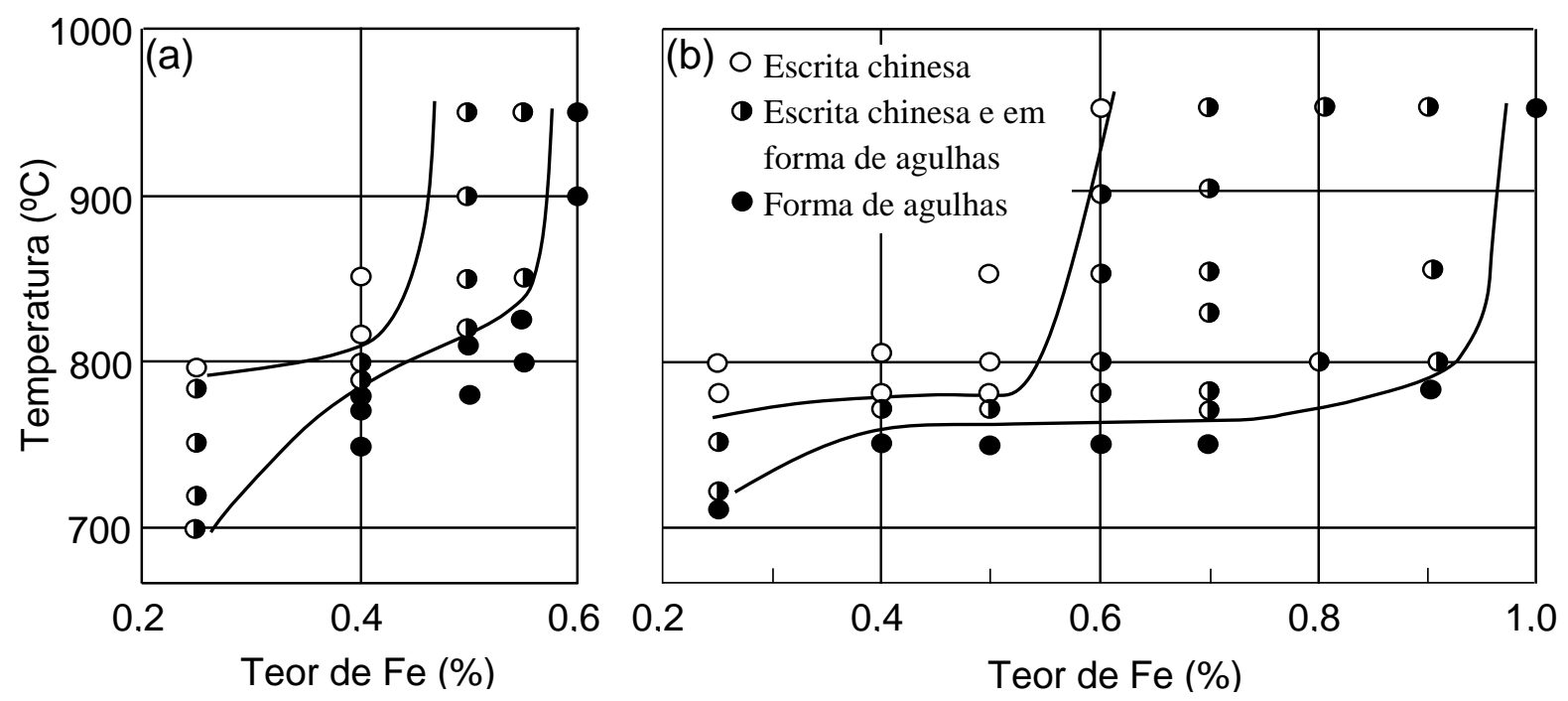

Figura 22 - Efeito da temperatura de superaquecimento e teor de ferro sobre a morfologia do intermetálico nas ligas (a) Al-6\%Si e (b) Al-11\%Si. Adaptado [20].

\subsection{A fase $\alpha-\mathrm{Al}_{15}(\mathrm{Fe}, \mathrm{Mn})_{3} \mathrm{Si}_{2}$}

Existem vários elementos que atuam como neutralizantes do efeito fragilizante do ferro, tais como cobalto, berílio, molibdênio e manganês [37], sendo que este último é o mais utilizado para alterar a morfologia da fase $\beta-\mathrm{Al}_{5} \mathrm{FeSi}$ de plaquetas para uma morfologia do tipo "escrita chinesa" com composição química $\alpha-\mathrm{Al}{ }_{15}(\mathrm{Fe}, \mathrm{Mn})_{3} \mathrm{Si}_{2}$. A morfologia tipo "escrita chinesa" (figura 23) é menos danosa em relação à da partícula $\beta$-Als $\mathrm{FeSi}$ [31]. Esta fase, de maior complexidade, também pode ser prevista com o uso de um diagrama simplificado (figura 24) onde, além da projeção da superfície liquidus do diagrama ternário Al-Si-Fe, leva-se em consideração a presença do Mn. Verifica-se a formação de um novo campo com a introdução do $\mathrm{Mn}$, como se pode observar na comparação entre as figuras 24 (projeção da superfície liquidus do diagrama ternário Al-Si-Fe) e 25 (projeção da superfície liquidus do diagrama ternário Al-Si-Fe com 0,1\% de Mn). 


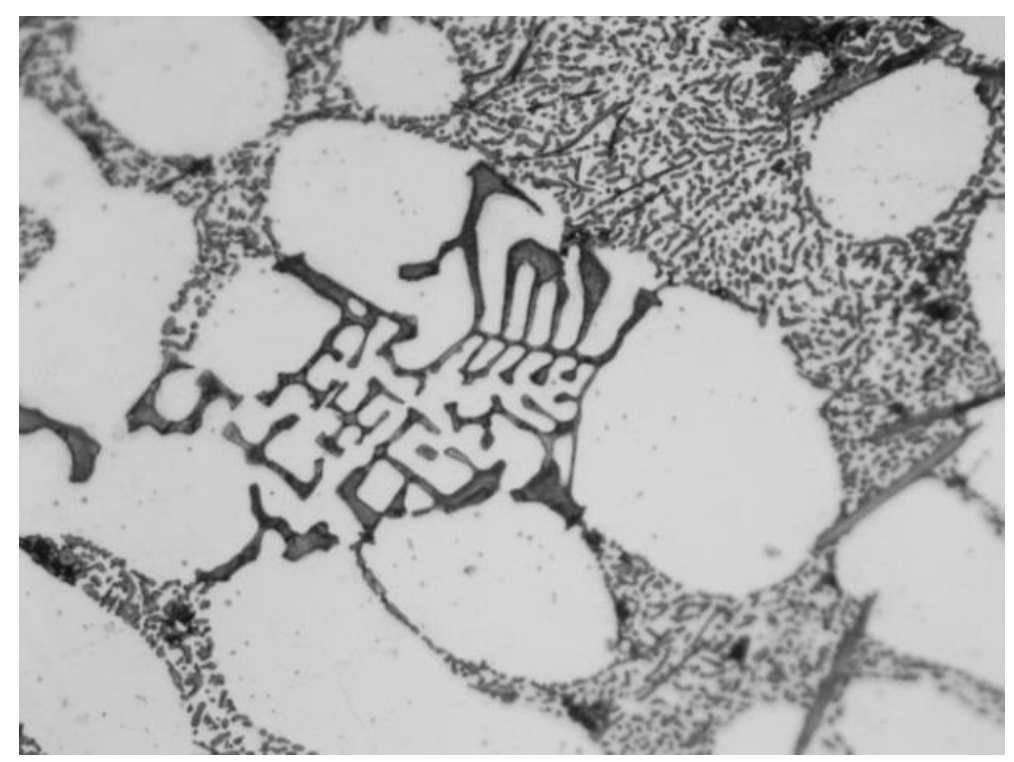

Figura 23 - liga de Al-7 \% Si com 0,7\%Fe e 0,35\%Mn fundida em coquilha. A fase $\alpha$ $\mathrm{Al}_{15}(\mathrm{Fe}, \mathrm{Mn})_{3} \mathrm{Si}_{2}$ se encontra inserida na dendrita de alumínio [13].

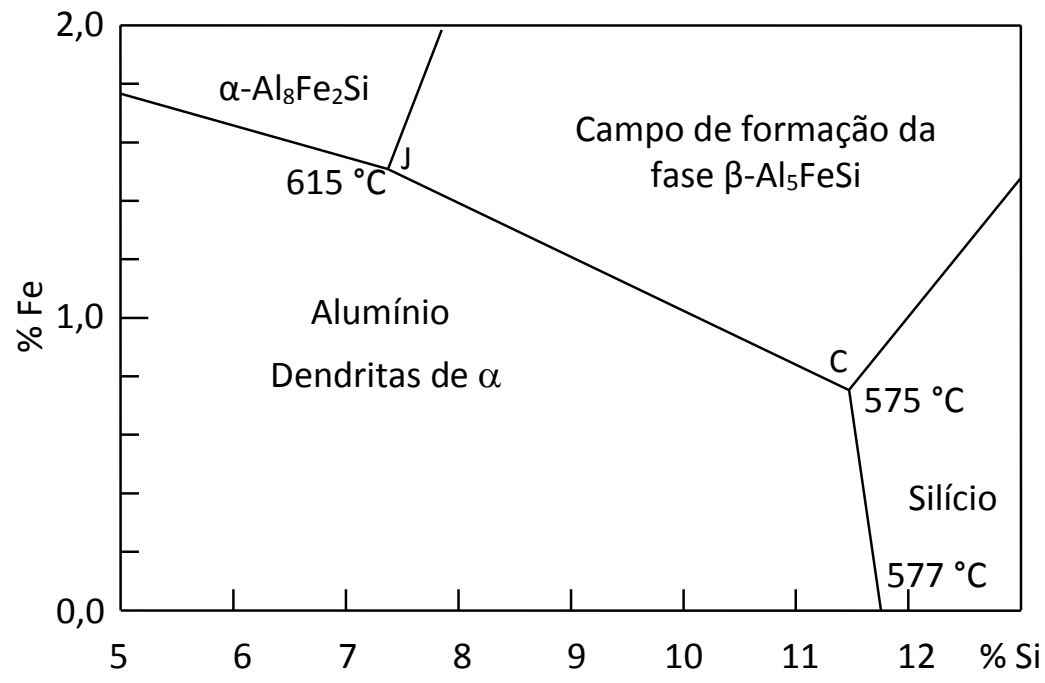

Figura 24 - Projeção da superfície liquidus do diagrama ternário Al-Si-Fe. Adaptado [14]. 


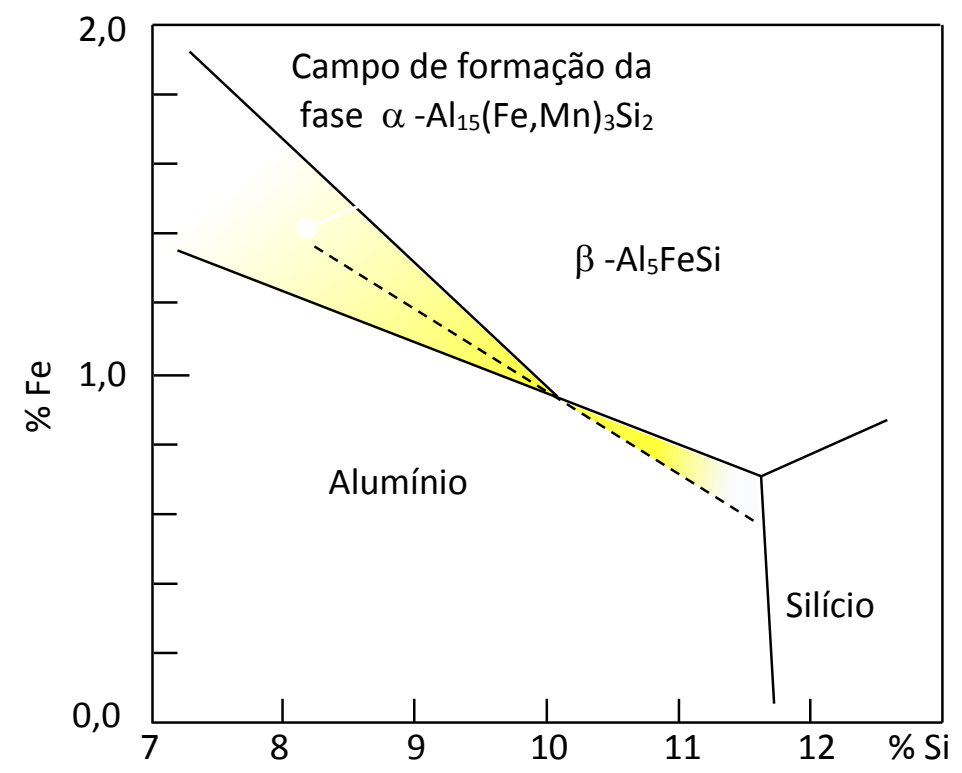

Figura 25 - Projeção da superfície liquidus do diagrama ternário Al-Si-Fe para teores de $0,1 \%$ de Mn. Adaptado [14].

Com a introdução do manganês, os campos se alteram em função da formação da fase $\alpha-\mathrm{Al}_{15}(\mathrm{Fe}, \mathrm{Mn})_{3} \mathrm{Si}_{2}$. Além disto, à medida que o teor de manganês aumenta, o campo referente à fase intermetálica $\alpha-\mathrm{Al}_{15}(\mathrm{Fe}, \mathrm{Mn})_{3} \mathrm{Si}_{2}$ aumenta, como pode ser observado nos diagramas simplificados (sequência de figuras de 26 a 28) para teores crescentes de $\mathrm{Mn}$ a partir de $0,2 \%$ até $0,4 \%$.

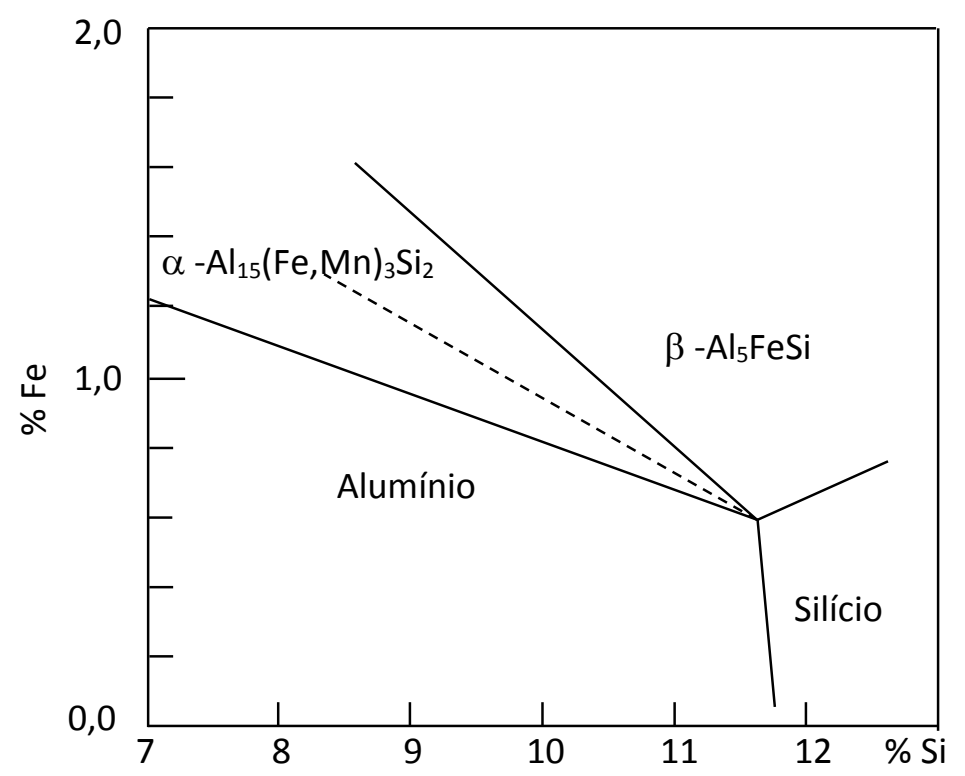

Figura 26 - Projeção da superfície liquidus do diagrama ternário Al-Si-Fe para teores de 0,2 \% de Mn. Adaptado da referência [14]. 


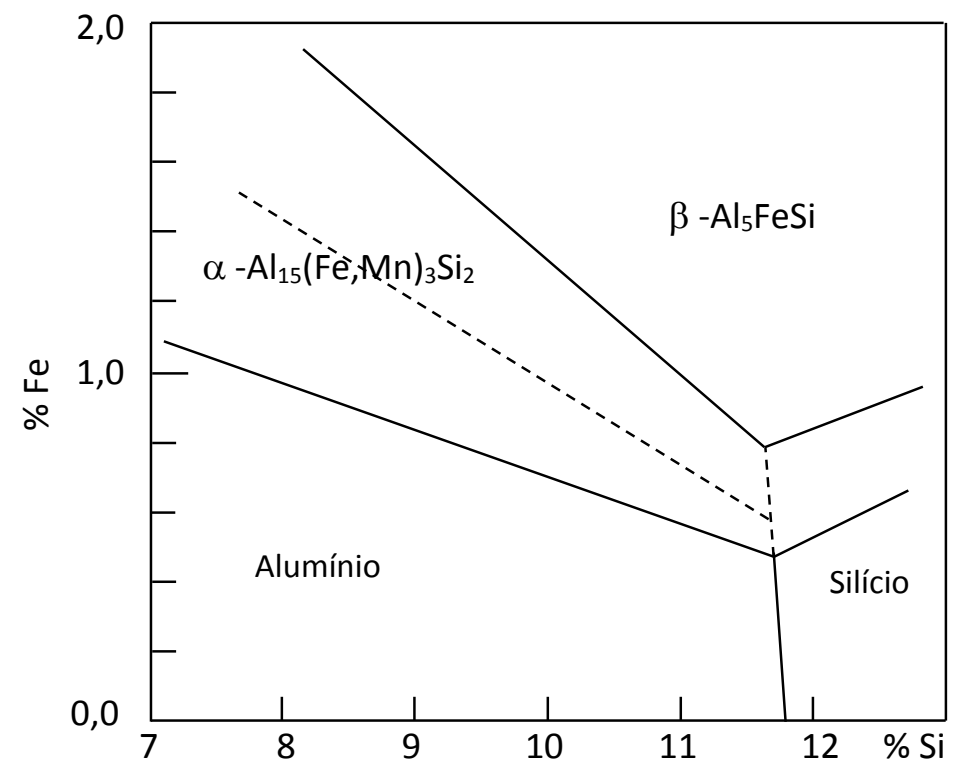

Figura 27 - Projeção da superfície liquidus do diagrama ternário Al-Si-Fe para teores de $0,3 \%$ de Mn. Adaptado [14].

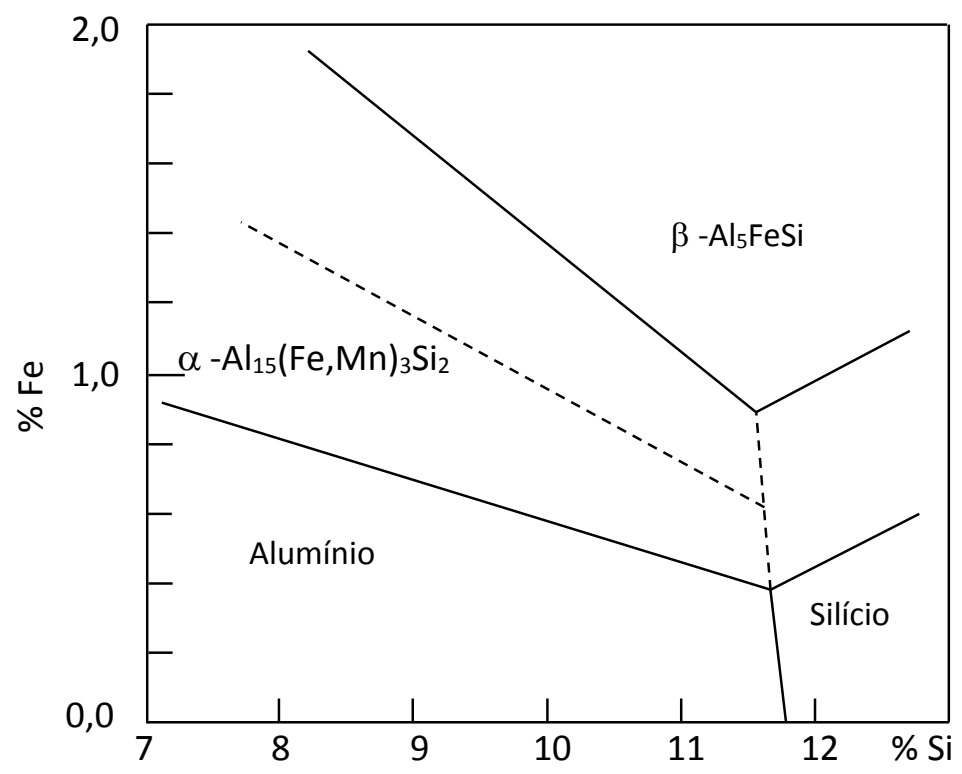

Figura 28 - Projeção da superfície liquidus do diagrama ternário Al-Si-Fe para teores de $0,4 \%$ de Mn. Adaptado [14].

Para exemplificar as sequências de solidificação de ligas Al-Si-Fe com a presença de $\mathrm{Mn}$, a figura 29 mostra os caminhos para a formação das fases, considerando-se a presença de $0,30 \% \mathrm{Mn}$ e teores crescentes de $\mathrm{Fe}(0,20 \%, 0,60 \%$ e 1,40\%). As sequências de solidificação estão descritas na tabela 4 . 


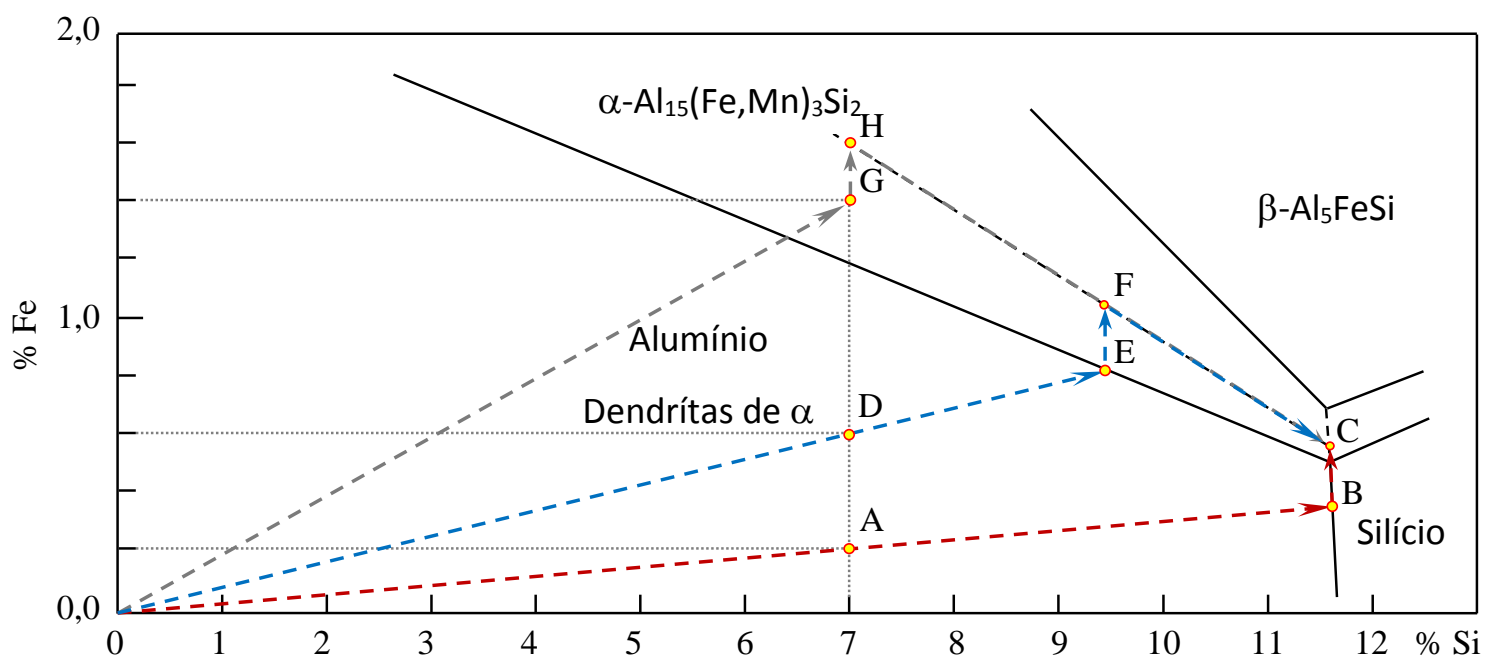

Figura 29 - Projeção da superfície liquidus do diagrama ternário Al-Si-Fe para liga com

$0,30 \% \mathrm{Mn}$, onde estão representadas as sequências de fases formadas durante a solidificação de uma liga Al-7\% Si com teores de ferro de 0,20\% (A), 0,60\% (D), e 1,4\%

(G). Adaptado [14].

Tabela 4 - Sequência de solidificação das ligas Al-7\%Si com teores de Fe de 0,20\%, 0,60\% e 1,40\% para um teor de Mn de 0,30\%, como representadas na Figura 29.

\begin{tabular}{|c|c|c|}
\hline Liga & Região & Fases formadas na solidificação \\
\hline \multirow{3}{*}{ Al-7\%Si-0,20\%Fe } & $A-B$ & $\mathrm{~L} \rightarrow$ Dendritas de $\alpha$ \\
\hline & $C-D$ & $L \rightarrow$ Eutético principal $(\alpha+\mathrm{Si})$ \\
\hline & C & $\mathrm{L} \rightarrow$ Eutético secundário $(\alpha+\mathrm{Si}+\beta-\mathrm{Al}$ FeSi) \\
\hline \multirow{4}{*}{ Al-7\%Si-0,60\%Fe } & $D-E$ & $\mathrm{~L} \rightarrow$ Dendritas de $\alpha$ \\
\hline & $E-F$ & $\mathrm{~L} \rightarrow$ Eutético $\left(\alpha+\alpha-\mathrm{Al}_{15}(\mathrm{Fe}, \mathrm{Mn})_{3} \mathrm{Si}_{2}\right)$ \\
\hline & $F-C$ & $L \rightarrow$ Eutético $\left(\alpha+\beta-\mathrm{Al}_{5} \mathrm{FeSi}\right)$ \\
\hline & C & $\mathrm{L} \rightarrow$ Eutético secundário $\left(\alpha+\mathrm{Si}+\beta-\mathrm{Al}_{5} \mathrm{FeSi}\right)$ \\
\hline \multirow{3}{*}{ Al-7\%Si-1,40\%Fe } & $\mathrm{G}-\mathrm{H}$ & $\mathrm{L} \rightarrow$ Eutético $\left(\alpha+\alpha-\mathrm{Al}_{15}(\mathrm{Fe}, \mathrm{Mn})_{3} \mathrm{Si}_{2}\right)$ \\
\hline & $\mathrm{H}-\mathrm{C}$ & $\mathrm{L} \rightarrow$ Eutético $\left(\alpha+\beta-\mathrm{Al}_{5} \mathrm{FeSi}\right)$ \\
\hline & C & $\mathrm{L} \rightarrow$ Eutético secundário $\left(\alpha+\mathrm{Si}+\beta-\mathrm{Al}_{5} \mathrm{FeSi}\right)$ \\
\hline
\end{tabular}

A substituição de $\beta$-AlsFeSi por compostos intermetálicos contendo manganês também aumenta a resistência à corrosão, pelo menos nas ligas livres de cobre, porque a diferença de potencial entre os compostos de ferro e da matriz é muito 
reduzida [38]. Junto com o aumento da ductilidade proporcionada pela adição de manganês, também ocorre um aumento limitado de resistência à tração e da resistência à fadiga, que ocorre, em parte, devido à redução das porosidades decorrentes da substituição da fase $\beta-\mathrm{Al}_{5} \mathrm{FeSi}$ por $\alpha-\mathrm{Al}_{15}(\mathrm{Fe}, \mathrm{Mn})_{3} \mathrm{Si}_{2}$. A literatura recomenda utilizar uma relação de 2:1 de $\mathrm{Fe}$ em relação ao $\mathrm{Mn}$ entretanto, não garante completa alteração de morfologia da fase $\beta$-Als $\mathrm{FeSi}$ para a fase $\alpha$ $\mathrm{Al}_{15}(\mathrm{Fe}, \mathrm{Mn})_{3} \mathrm{Si}_{2}$ [39] uma vez que no diagrama ternário Al-Si-Fe com $\mathrm{Mn}$ a formação das plaquetas de $\beta$ é prevista para quaisquer teores de Fe e Mn. Testes com teores maiores de $\mathrm{Mn}$ foram realizados e foi constatado um aumento da resistência mecânica, do alongamento e um decréscimo no limite de escoamento [8]. A fase $\alpha$ $\mathrm{Al}_{15}(\mathrm{Fe}, \mathrm{Mn})_{3} \mathrm{Si}_{2}$ é proveniente de uma reação eutética regular complexa. Este intermetálico nucleia e cresce junto com a fase $\alpha$-aluminio, denominado de crescimento eutético acoplado.

\subsection{Formação da lama}

Quando ocorre a formação da fase $\alpha-\mathrm{Al}_{15}(\mathrm{Fe}, \mathrm{Mn})_{3} \mathrm{Si}_{2}$ primaria, como por exemplo na liga Al-7\%Si-1,40\%Fe-0,3\% Mn, como mostra a sequência de solidificação da tabela 4 e o ponto " $G$ " da figura 29, a morfologia da fase $\beta$ passa a ser poligonal [7] (figura 30). Esta fase apresenta um elevado peso específico e em circunstâncias específicas, como por exemplo, quando o metal é mantido a baixas temperaturas em fornos de espera, podem se precipitar no fundo do recipiente formando um depósito de compostos intermetálicos, sendo denominadas de "lama" ou "sludge". Esta fase, de elevada temperatura de fusão, não pode ser reincorporada no metal líquido, a não ser que se aqueça o material a temperaturas muito elevadas. Se o metal líquido sofre agitação, estas fases podem ficar em suspensão no banho e serem incorporadas no produto fundido, dificultando a usinagem e comprometendo a resistência mecânica do fundido [40]. 


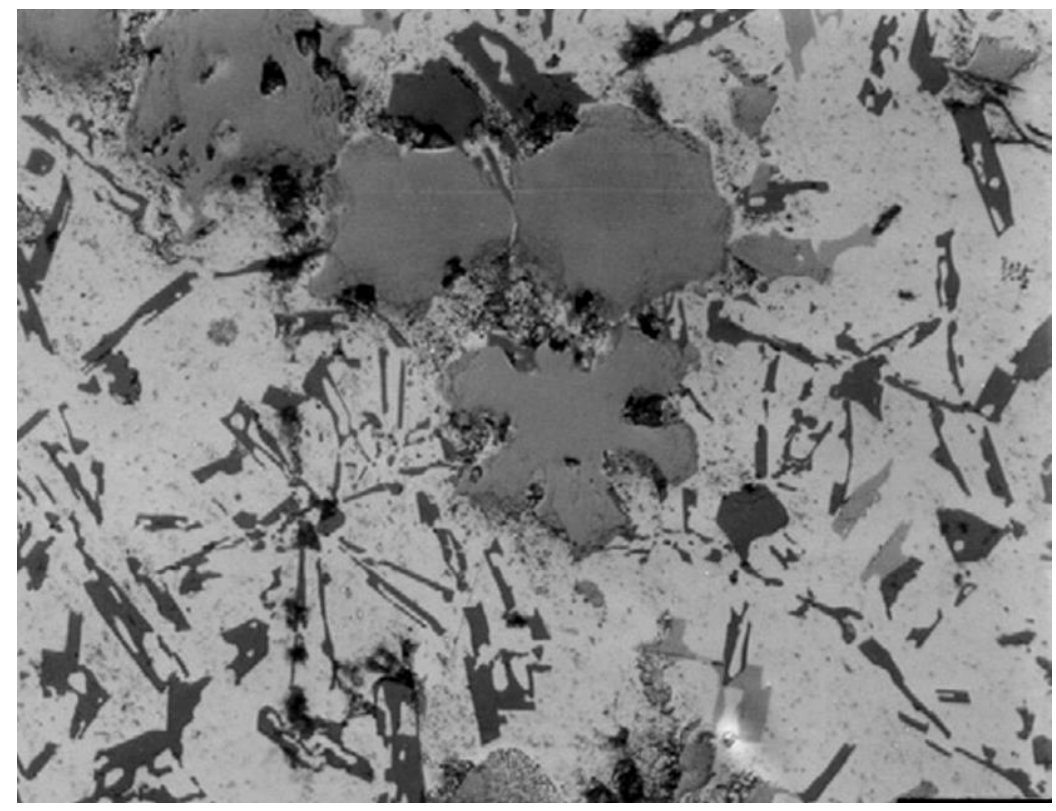

Figura 30 - Fase $\alpha-\mathrm{Al}_{15}(\mathrm{Fe}, \mathrm{Mn})_{3} \mathrm{Si}_{2}$ com morfologia poligonal em uma liga de $\mathrm{Al}-13 \% \mathrm{Si}$ com $2,5 \%$ de Fe e $1,25 \%$ de $\mathrm{Mn}$ [7].

A formação dos compostos intermetálicos ocorre com mais frequência no processo de fundição sob pressão, que utiliza ligas com altos teores de ferro, como a liga A380, cujo teor de ferro é da ordem de $1,3 \%$ e manganês em torno $0,4 \%$. No processo de injeção desta liga, quando adicionadas à câmara, sofrem um superresfriamento reduzindo o limite de solubilidade do $\mathrm{Fe}, \mathrm{Mn}$ e $\mathrm{Cr}$ no metal líquido [38, 41, 42]. Jorstad [40] definiu o limite de solubilidade destas fases em função da temperatura para a liga A380. Este fator, denominado de Fator de segregação (Fs), é calculado pela fórmula [40] (Eq.1).

$$
\mathbf{F S}=\% \mathbf{F e}+\mathbf{2} \% \mathrm{Mn}+3 \% \mathbf{C r} \quad \text { Eq.1. }
$$

A figura 31 mostra a correlação entre a temperatura e o fator de segregação para a liga A380 realizada por Jorstad em comparação com aquela realizada por Gobrecht. Se, por exemplo, Fs for igual a 1,4, a temperatura mínima para que não ocorra a sedimentação é de aproximadamente $618^{\circ} \mathrm{C}$ segundo Gobrecht e $628^{\circ} \mathrm{C}$ segundo Jorstad [41]. 


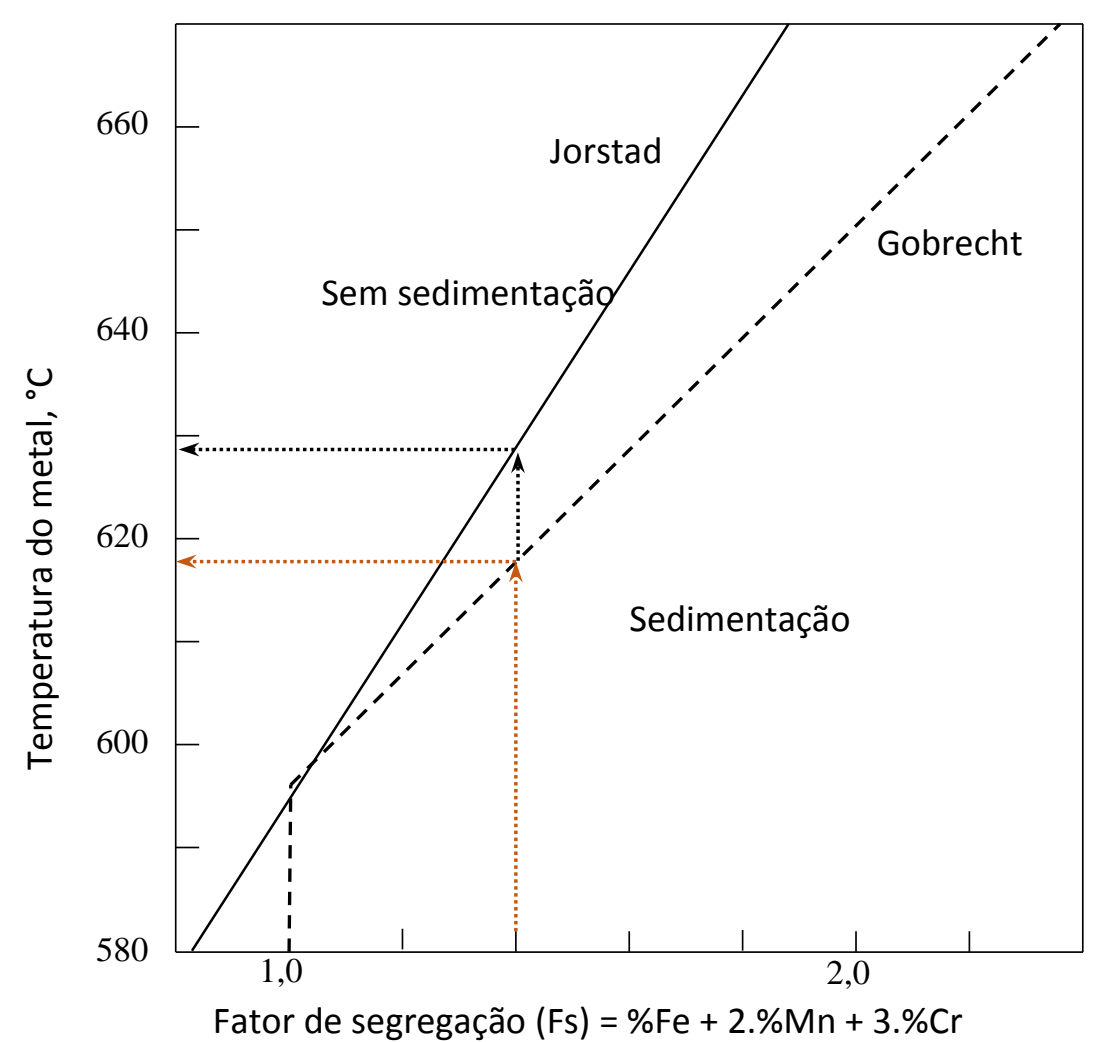

Figura 31 - Correlação entre a temperatura e o fator de segregação para a liga A380 mostrando a temperatura mínima para que não acorra a sedimentação é de $618^{\circ} \mathrm{C}$ segundo Gobrecht e $628^{\circ} \mathrm{C}$ segundo Jorstad para um Fs $=1,4$ [41].

\subsection{Modificação das ligas Al-Si}

A modificação das ligas de alumínio com silício é uma prática extensiva na indústria com o objetivo de melhorar as propriedades mecânicas, particularmente a dutilidade. As ligas de alumínio mais comuns utilizadas em fundição apresentam silício nos teores de 5 à $12 \%$ em peso e, portanto, uma fração de eutético, em volume, de 40 à 100\% [12]. Estas partículas de silício (figura 32) apresentam morfologia em plaquetas grosseiras que interrompe a continuidade da matriz induzindo à nucleação e crescimento de trincas quando submetido à solicitações mecânicas [10]. 


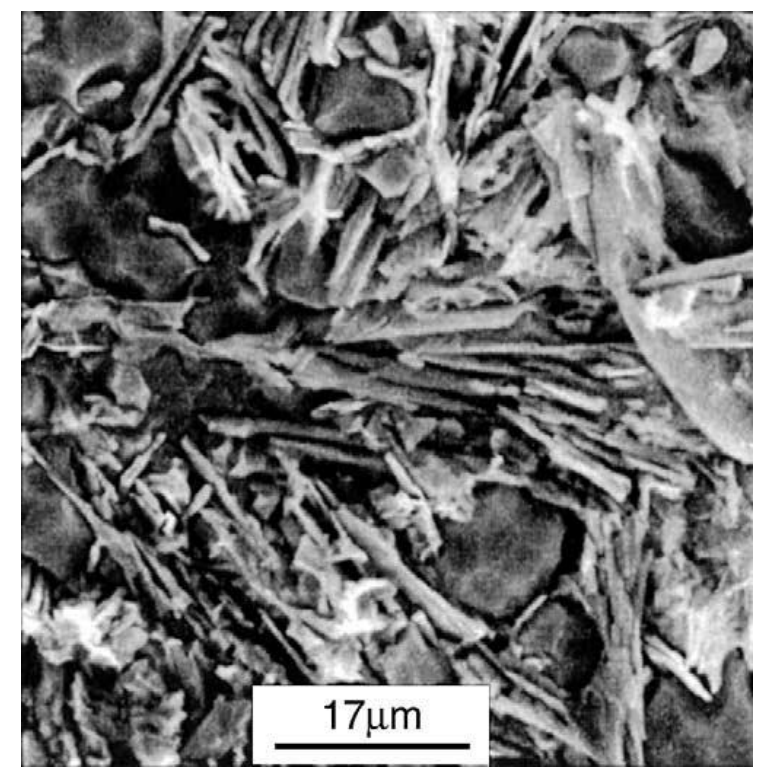

Figura 32 - Cristais de silício - fase beta- com morfologia em plaquetas [43].

O tratamento de modificação do eutético visa a alteração da morfologia das partículas de silício do eutético principal de plaquetas grossas para bastonetes [10] (Figura 33). Esta modificação do silício permite maior continuidade da matriz de a, aumentando a ductilidade das ligas Al-Si. Esta modificação pode ser feita com adição de elementos modificadores tais como o sódio ou estrôncio nos banhos momentos antes do vazamento [10].
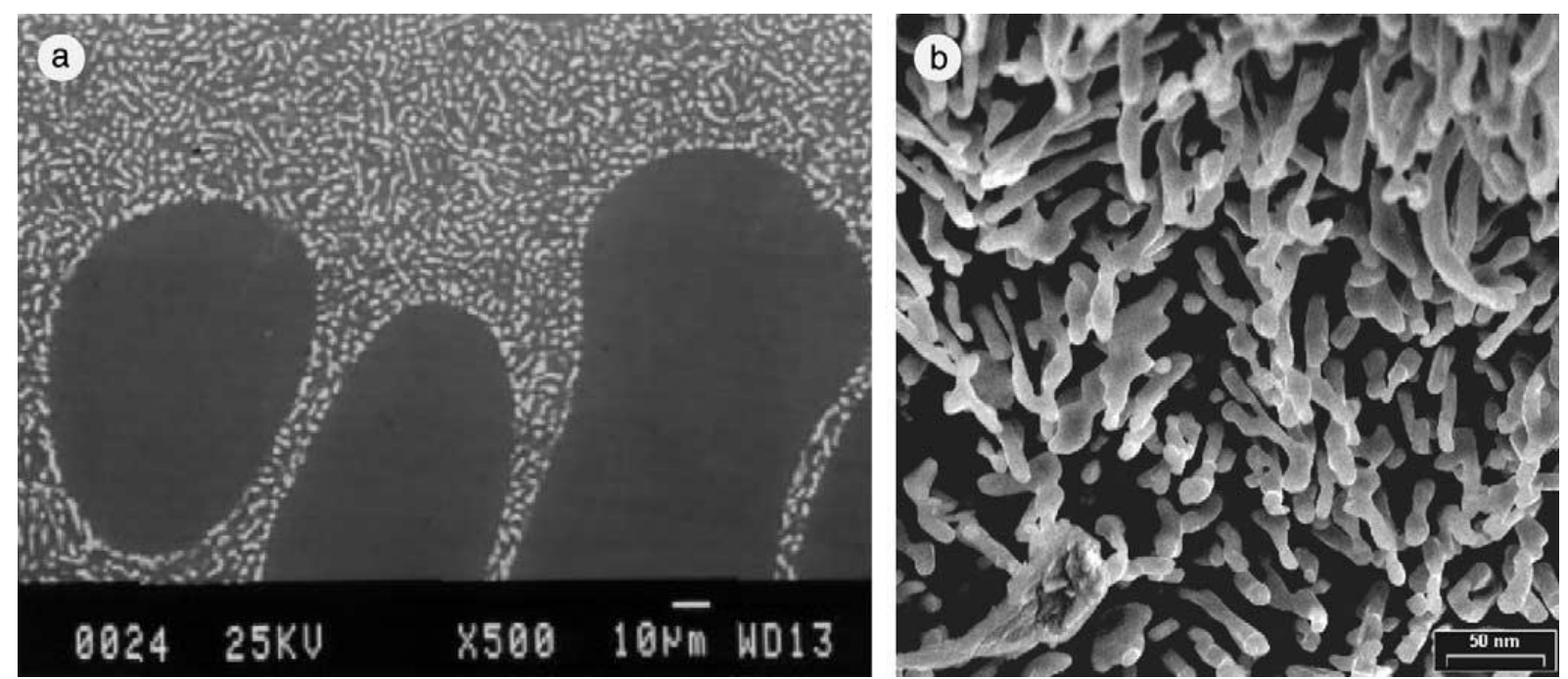

Figura 33 - Microestrutura de uma liga de Al-Si modificada com Sr em baixa resolução (a) e em alta resolução com ataque profundo (b) [43].

O tratamento de modificação tende a destacar a presença dos eutéticos secundários ricos em ferro (figura 34), seja pelo maior tamanho das plaquetas de $\beta$ AlsFeSi em relação às partículas de $\mathrm{Si}$, seja pelo aumento do tamanho das células 
eutéticas que intensificam a segregação intercelular [10].

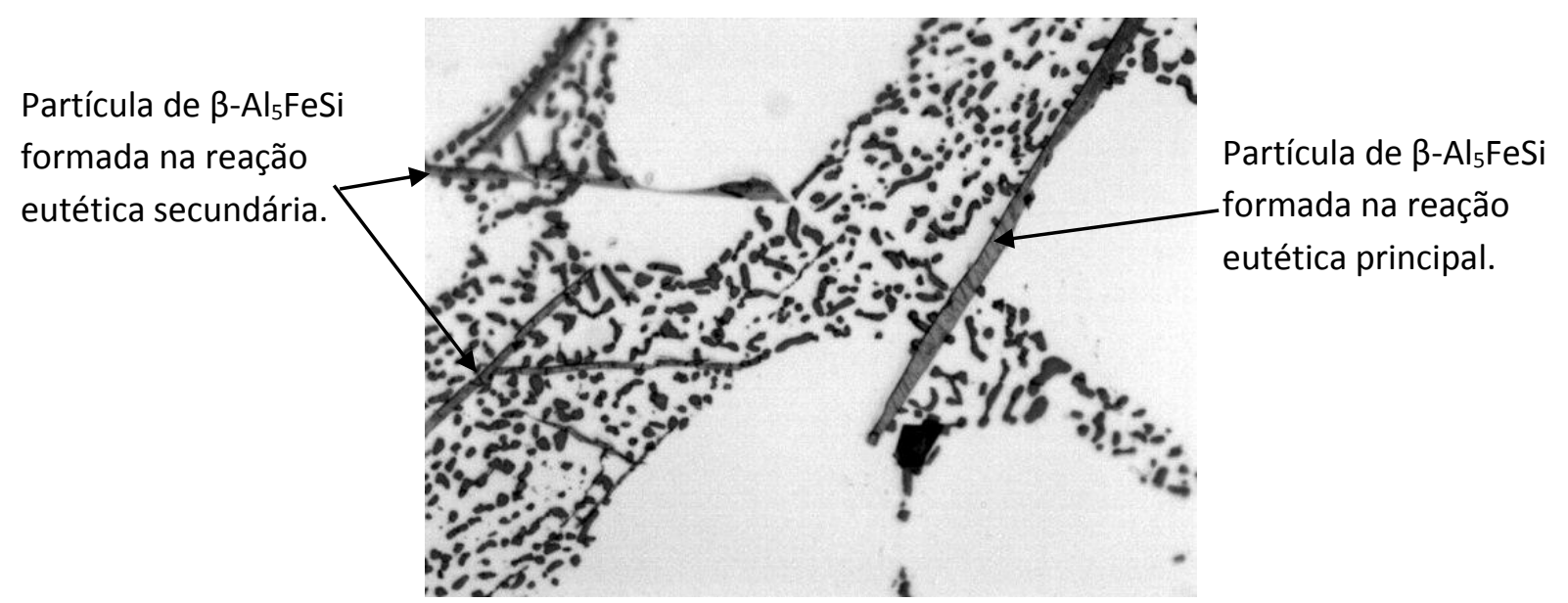

Figura 34 - Microestrutura de uma liga Al-7\%Si-1,0\%Fe mostra as partículas de $\beta-\mathrm{Al}_{5} \mathrm{FeSi}$ formadas nas reações eutéticas principal e secundária [13] facilmente identificadas em função da modificação das partículas de silício que se apresentam morfologia fibrosa entre as dendritas [10]. 


\section{MATERIAIS E MÉTODOS}

Para a realização deste trabalho, foi necessária inicialmente, a fabricação de uma coquilha em aço H13 (figura 35) segundo a norma ASTM B108 [44].

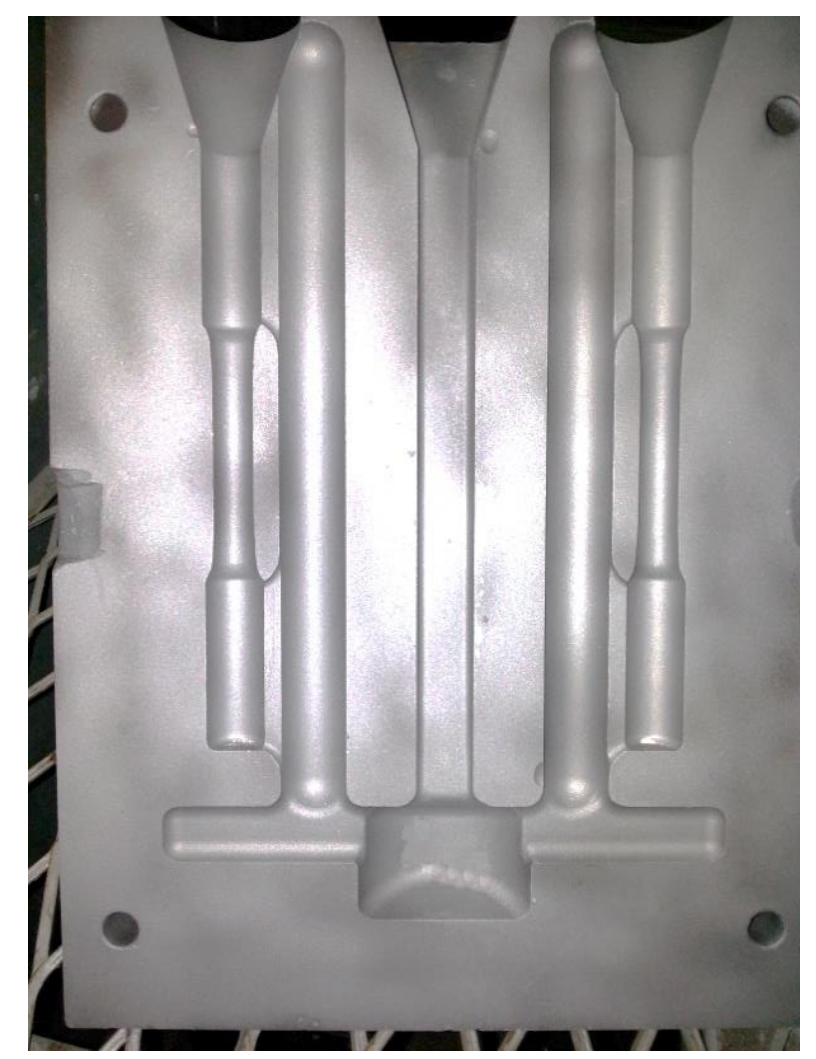

Figura 35 - Coquilha confeccionada em aço H13, conforme norma ASTM B108 [44].

As ligas foram elaboradas em um forno de indução a cadinho com capacidade para $30 \mathrm{~kg}$ de material. Foi utilizado alumínio puro (99,94\% em peso), silício metálico (98\% em peso) e pré-ligas de Al-Fe (1,8\%Fe em peso) e Al-Mn (1,6\% em peso). Em uma primeira etapa da elaboração foram obtidos corpos de prova em liga de $\mathrm{Al}-9 \% \mathrm{Si}$ para servir como referência. Em seguida foi adicionada a liga de AlFe 1,8\% com a finalidade de se obter ligas com teores de Fe na ordem de 0,4\%, 0,8\% e 1,2\% em peso. Na segunda etapa de elaboração foram obtidos corpos de prova com adição de Al-Mn em teores crescentes em uma liga de $\mathrm{Al}-9 \% \mathrm{Si}-0,8 \% \mathrm{Fe}$, de tal maneira a atingir $0,2 \%, 0,4 \%$ e $0,7 \%$ de $\mathrm{Mn}$ em peso.

As ligas fundidas foram desgaseificadas com nitrogênio por 5 minutos no próprio forno para remoção de inclusões de óxidos e hidrogênio. O equipamento utilizado foi um rotor cuja rotação foi de 300 RPM e vazão de gás de $15 \mathrm{l} / \mathrm{min}$. Após 
esta etapa foi realizada a escorificação para remoção da escória superficial e em seguida modificadas com 200 ppm de estrôncio com adição de Al-10\% Sr. A modificação visa facilitar a identificação das plaquetas da fase $\beta$-AlsFeSi devido à sua morfologia ser muito parecida com a fase $\beta$-Silício. A temperatura de vazamento foi de $760^{\circ} \mathrm{C}$.

A coquilha foi pintada por aspersão com uma tinta Dycote (fornecida pela Foseco e utilizada conforme recomendação do fornecedor) para garantir o preenchimento da cavidade e facilitar a extração do produto, que foi posteriormente preaquecida em torno de $300^{\circ} \mathrm{C}$. Os vazamentos foram realizados imediatamente após cada tratamento com o forno em baixa potência para evitar a reabsorção dos óxidos. Após o resfriamento, os corpos de prova foram separados do sistema de canais por corte em serra de fita e também remoção das rebarbas.

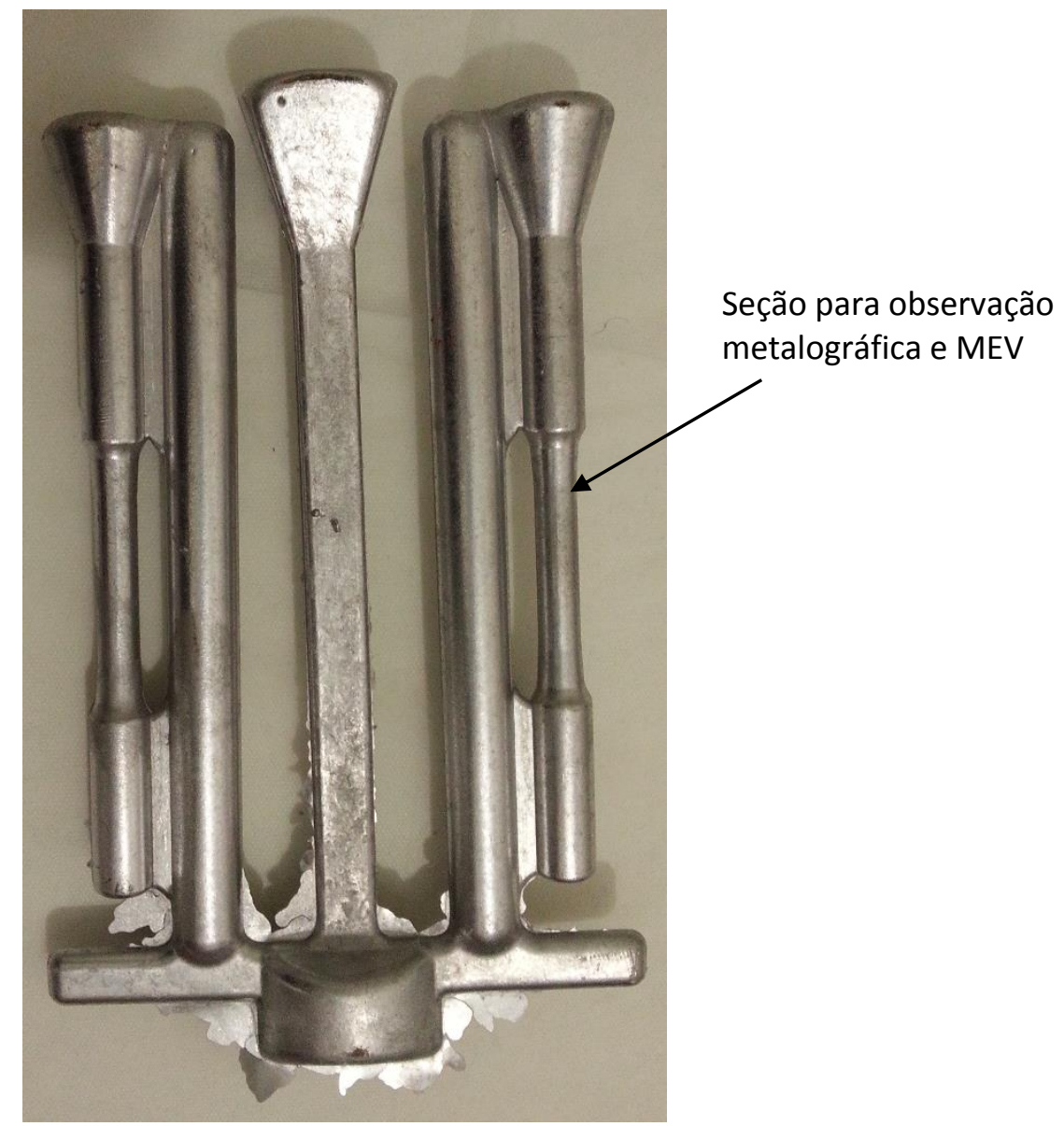

Figura 36 - Corpos de prova obtidos com o uso da coquilha segundo a norma ASTM B108 [44] indicando onde foram retiradas as amostras para observação metalográfica e MEV. 
Nos testes de tração, foram utilizados 5 (cinco) corpos de prova para cada experimento, realizadas em uma máquina Universal EMIC DL-60000 de $600 \mathrm{KN}$ no laboratório de Ensaios Metalúrgicos do SENAI. As micrografias, de cada uma das ligas, bem como as análises químicas, foram realizadas neste laboratório. As análises químicas foram realizadas em cada sequência de elaboração em um espectrômetro de emissão ótica GNR Metallab 75-80J para controle dos teores de Si, Fe e Mn a fim de que se garantisse a composição prevista. Demais elementos de ligas foram considerados residuais uma vez que a somatória destes não ultrapassou à $0,4 \%$ em peso. As amostras para metalografia foram obtidas dos corpos de prova ensaiados na seção transversal (figura 36) com diâmetro de $10 \mathrm{~mm}$, embutidas, identificadas, lixadas (na sequência de lixas: 120, 240, 260, 400, 600 e 1200), polidas com diamante em pasta (3 e 1 micra respectivamente) e sílica coloidal de 0,02 micra e atacadas com HF $0,5 \%$ por 30 segundo obtidas no microscópio ótico e 1 minuto para as imagens obtidas no microscópio eletrônico de varredura - MEV. Algumas amostras foram submetidas ao ataque profundo com uso de uma solução de $\mathrm{NaOH} 20 \%$ por 3 minutos. O microscópio utilizado foi um Olympus BX 60M com sistema de aquisição de imagem Micrometrics SE Premium. Em algumas amostras foi utilizado o microscópio eletrônico de varredura EDAX XL 30 da PHILIPS, visando a melhor identificação dos intermetálicos. 


\section{RESULTADOS E DISCUSSÃO}

\subsection{Ligas de Al-9\%Si com adições de ferro}

Na tabela 5 são apresentadas as composições, analisadas via espectrômetro de emissão ótica, das ligas obtidas com adição de ferro. Apesar da adição do estrôncio não ocorreu a modificação como esperado em função da constante agitação do metal, acelerando a perda de eficiência do modificador. Este fato, no entanto, não invalida o experimento já que as mesmas condições operacionais foram mantidas ao longo de sua execução.

Tabela 5 - Composição química das ligas obtidas da série Al-9\%Si.

\begin{tabular}{|c|c|c|c|c|}
\hline \multirow{2}{*}{$\begin{array}{c}\text { Elementos } \\
\text { químicos }\end{array}$} & \multicolumn{4}{|c|}{ Al-9\%Si } \\
\cline { 2 - 5 } & $0,1 \% \mathrm{Fe}$ & $0,4 \% \mathrm{Fe}$ & $0,81 \% \mathrm{Fe}$ & $1,2 \% \mathrm{Fe}$ \\
\hline $\mathrm{Si}$ & 9,257 & 8,759 & 8,988 & 9,104 \\
\hline $\mathrm{Cu}$ & 0,055 & 0,054 & 0,106 & 0,109 \\
\hline $\mathrm{Fe}$ & 0,092 & 0,455 & 0,842 & 1,246 \\
\hline $\mathrm{Mg}$ & 0,020 & 0,019 & 0,016 & 0,016 \\
\hline $\mathrm{Zn}$ & 0,021 & 0,022 & 0,008 & 0,014 \\
\hline $\mathrm{Ni}$ & 0,000 & 0,000 & 0,000 & 0,000 \\
\hline $\mathrm{Mn}$ & 0,038 & 0,039 & 0,031 & 0,035 \\
\hline $\mathrm{Ti}$ & 0,000 & 0,000 & 0,000 & 0,000 \\
\hline $\mathrm{Ca}$ & 0,003 & 0,004 & 0,005 & 0,003 \\
\hline $\mathrm{Na}$ & 0,001 & 0,001 & 0,001 & 0,001 \\
\hline $\mathrm{Pb}$ & 0,000 & 0,000 & 0,000 & 0,000 \\
\hline $\mathrm{Sn}$ & 0,015 & 0,004 & 0,003 & 0,005 \\
\hline $\mathrm{Cr}$ & 0,000 & 0,000 & 0,000 & 0,000 \\
\hline $\mathrm{V}$ & 0,007 & 0,004 & 0,004 & 0,003 \\
\hline $\mathrm{Be}$ & 0,000 & 0,000 & 0,000 & 0,000 \\
\hline $\mathrm{Cd}$ & 0,000 & 0,000 & 0,000 & 0,000 \\
\hline $\mathrm{Co}$ & 0,001 & 0,000 & 0,000 & 0,000 \\
\hline $\mathrm{Sr}$ & 0,011 & 0,001 & 0,010 & 0,008 \\
\hline $\mathrm{Sb}$ & 0,077 & 0,023 & 0,043 & 0,045 \\
\hline $\mathrm{B}$ & 0,002 & 0,001 & 0,001 & 0,001 \\
\hline $\mathrm{Zr}$ & 0,000 & 0,000 & 0,000 & 0,000 \\
\hline $\mathrm{Al}$ & 90,41 & 90,614 & 89,944 & 89,410 \\
\hline & & & & \\
\hline
\end{tabular}

$\mathrm{Na}$ tabela 6 são apresentados os resultados obtidos dos testes de tração em cada um dos experimentos das referidas ligas. 
Tabela 6- propriedades mecânicas obtidas do ensaio de tração nas ligas da série Al-9\%Si em função do ferro.

\begin{tabular}{|l|c|c|c|c|}
\hline \multirow{2}{*}{\multicolumn{1}{|c|}{ Propriedades }} & \multicolumn{4}{c|}{ Teor de Fe, \% em peso } \\
\cline { 2 - 5 } & 0,1 & 0,40 & 0,8 & 1,2 \\
\hline Resistência à tração, MPa & $157,3 \pm 12,4$ & $187,0 \pm 4,5$ & $185,5 \pm 7,1$ & $141,6 \pm 17,2$ \\
\hline Limite de escoamento, MPa & $68,7 \pm 4,7$ & $81,0 \pm 2,6$ & $81,5 \pm 12,2$ & $74,0 \pm 9,6$ \\
\hline Alongamento, \% & $5,5 \pm 2,8$ & $7,2 \pm 2,6$ & $6,3 \pm 2,7$ & $2,1 \pm 1,3$ \\
\hline
\end{tabular}

A figura 37 mostra os gráficos da resistência à tração e do limite de escoamento em função do teor de ferro apresentados na tabela 6. Verifica-se um aumento da resistência para $0,4 \%$ de $\mathrm{Fe}$ e que se mantem até $0,8 \%$ e a partir deste percentual, diminui com $1,2 \%$ de $\mathrm{Fe}$. Na figura 38 pode ser observado que o alongamento decresce a partir de $0,4 \%$.

\section{Limite de resistência e escoamento (MPa) X Teor de Fe (\% em} peso)

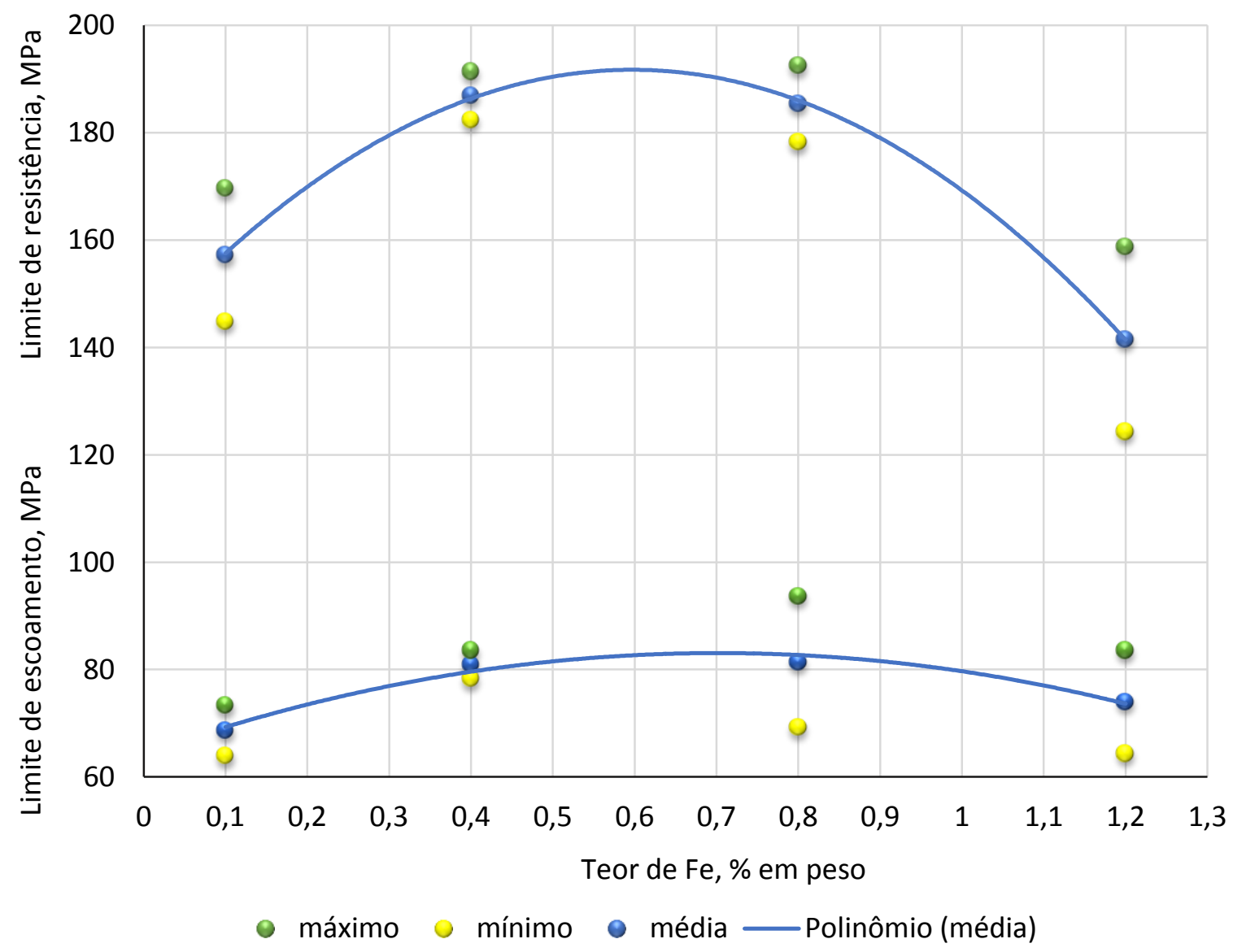

Figura 37 - Gráfico de resistência à tração em função do teor de ferro, \% em peso. 


\section{Alongamento (\%) $X$ teor de Fe (\% em peso)}

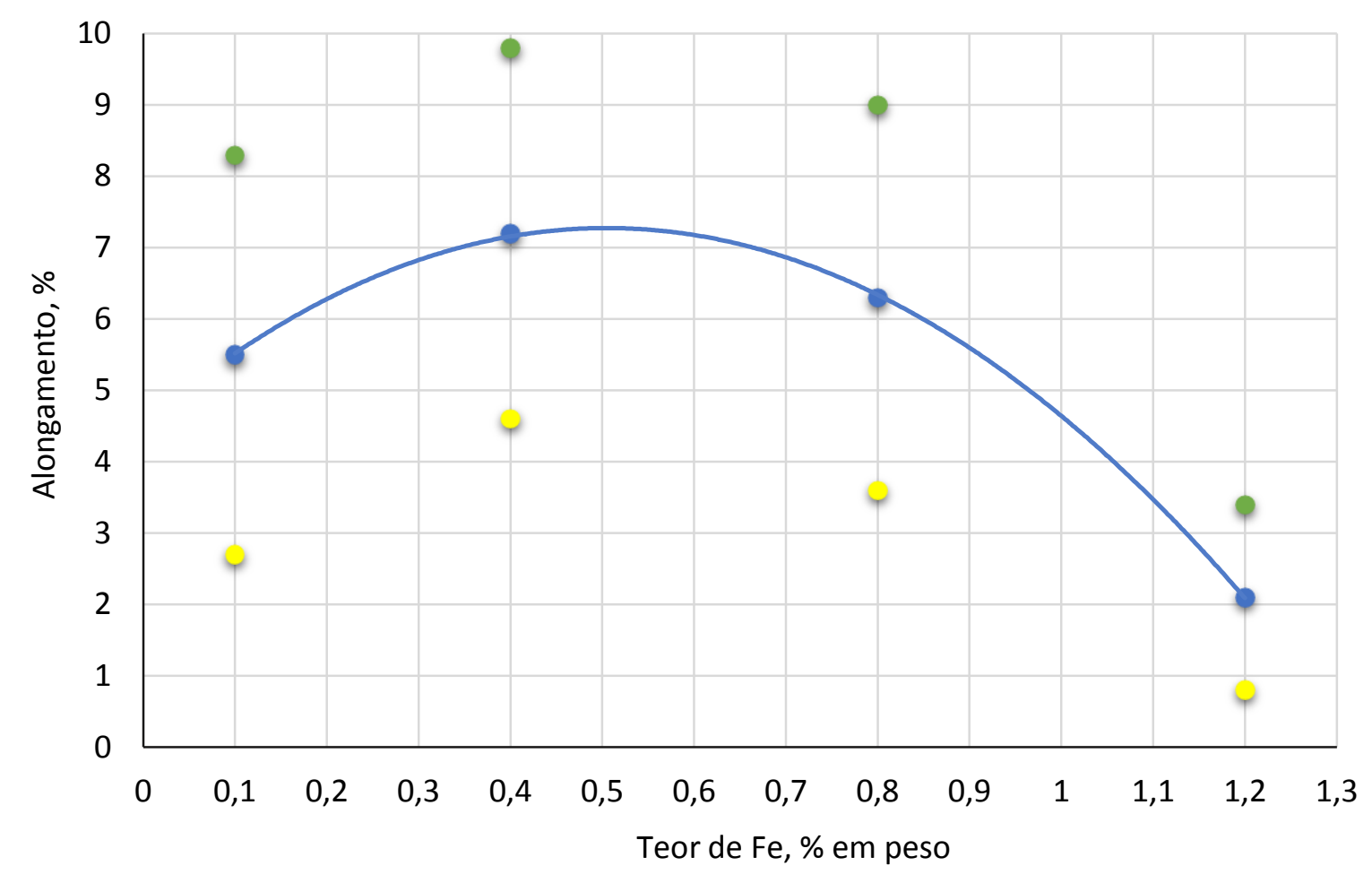

Série1

- Série2

- Série3 —Polinômio (Série2)

Figura 38 - Gráfico do alongamento em função do teor de ferro, \% em peso.

\subsubsection{Ligas de Al-9\%Si-0,1\% Fe}

A liga $\mathrm{Al}-9 \% \mathrm{Si}$ foi tomada como referência por conter o menor teor de $\mathrm{Fe}$, que neste caso foi por contaminação proveniente do silício metálico $(0,64 \%$ de $\mathrm{Fe})$. As micrografias realizadas na seção transversal do corpo de prova submetido à tração mostram a distribuição do silício, com morfologia acicular, entre as dendritas de alumínio (figura 39). Verifica-se que, em algumas regiões, as partículas de silício apresentam dimensões menores, que comprova alguma modificação.

Apesar da pequena quantidade de ferro presente nesta liga e a elevada velocidade de resfriamento, ainda assim foi possível constatar a presença de intermetálicos, só que com uma morfologia em "escrita chinesa" (figuras 40 e 41), característico de elevado super-resfriamento, formando a fase $\alpha-\mathrm{Al}_{8} \mathrm{Fe}_{2} \mathrm{Si}$ [45]. A fase $\beta$-Al $5 \mathrm{FeSi}$ não foi detectada. A caracterização da fase $\alpha-\mathrm{Al}_{8} \mathrm{Fe}_{2} \mathrm{Si}$ para esta liga com baixo teor de ferro é facilitada com o uso do MEV (figura 41). Por meio deste recurso verifica-se que a fase $\alpha-\mathrm{Al}_{8} \mathrm{Fe}_{2} \mathrm{Si}$ se forma próxima das partículas de silício, não sendo observado qualquer indício a respeito deste fato na literatura. 


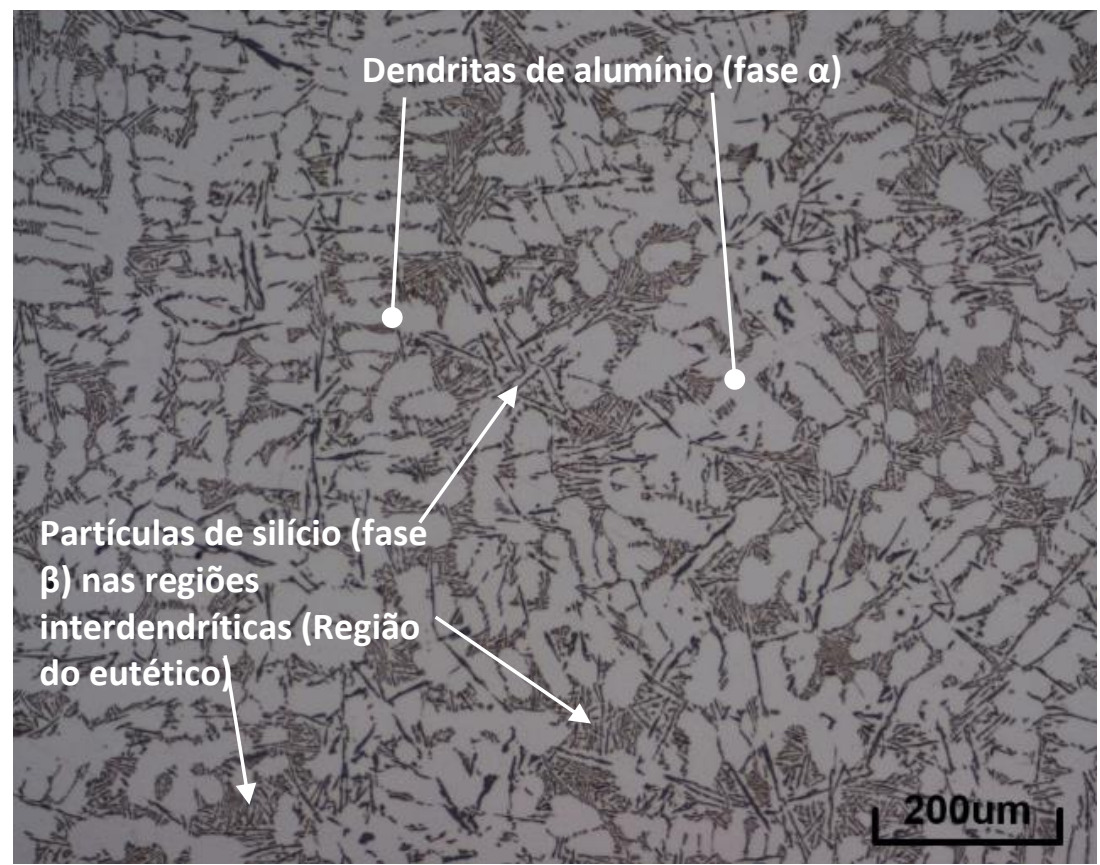

Figura 39 - Liga Al-9\%Si com 0,1\% de Fe mostrando as dendritas de alumínio e as partículas de silício eutético nas regiões interdendríticas.

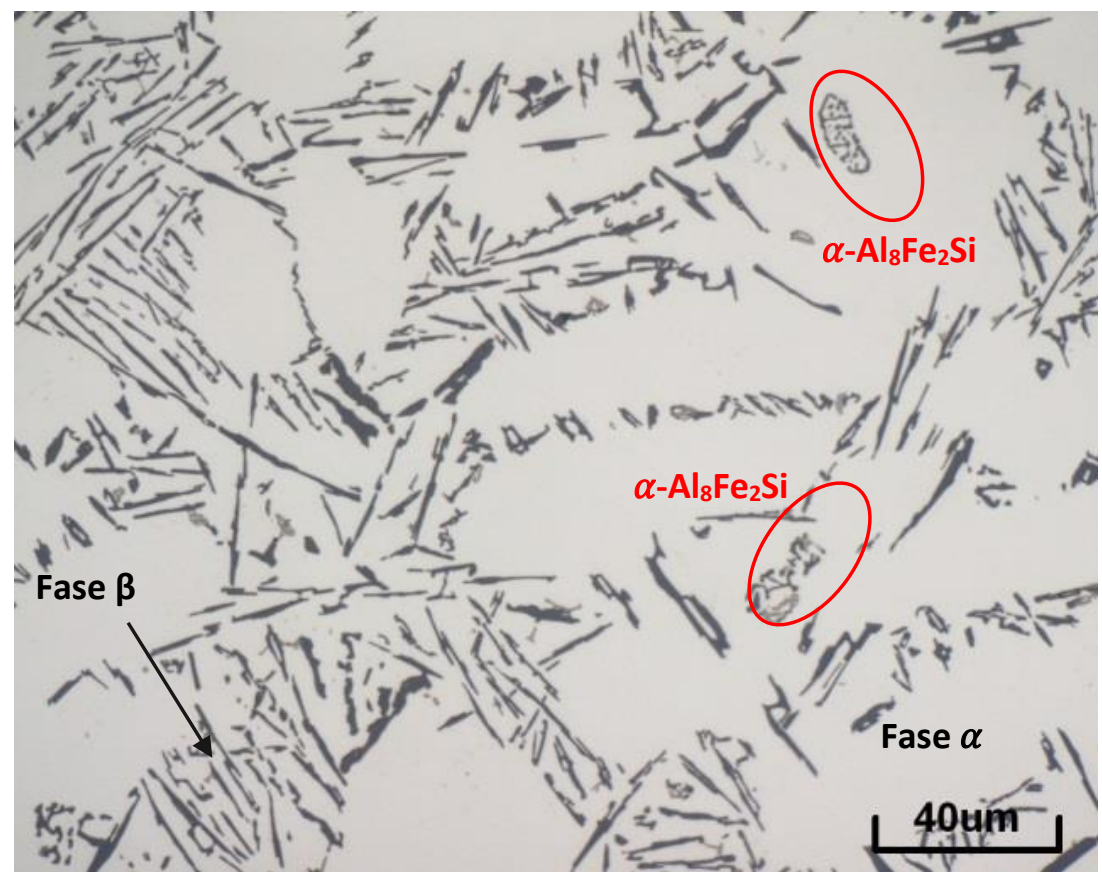

Figura 40 - Micrografia da liga Al-9\%Si com 0,1\% Fe mostrando as partículas de silício de formação eutética entre os braços das dendritas de alumínio e em destaque partículas do intermetálico $\alpha-\mathrm{Al}_{8} \mathrm{Fe}_{2} \mathrm{Si}$. 


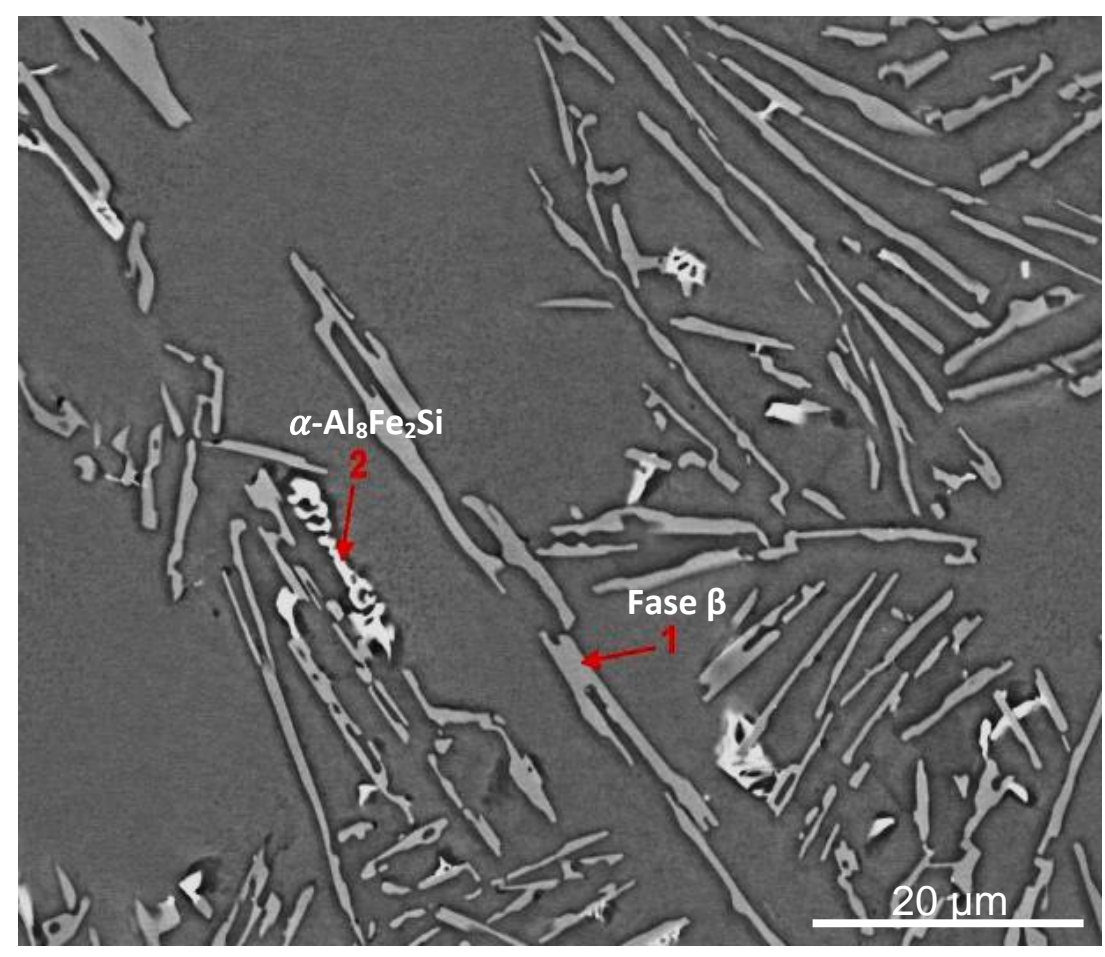

Figura 41 - Micrografia da liga Al-9\%Si-0,1\% Fe obtida pelo MEV mostrando as partículas do intermetálico $\alpha-\mathrm{Al}_{8} \mathrm{Fe}_{2} \mathrm{Si}$ de coloração mais clara (2). A fase (1) se refere à partícula de silício.

A fase cinza se refere ao silício do eutético (1), enquanto a mais clara (2) se refere ao intermetálico $\alpha-\mathrm{Al}_{8} \mathrm{Fe}_{2} \mathrm{Si}$. As microanálises obtidas por EDS (tabela 7) nas regiões apontadas da figura 41 confirmam as composições das respectivas fases.

Tabela 7 - Composição química das partículas apontadas na figura 41.

\begin{tabular}{c|cc}
\hline Elementos & \multicolumn{2}{|c}{ Partícula (\% em peso) } \\
& 1 & 2 \\
O K & 1,47 & 7,23 \\
Al K & 20,71 & 54,81 \\
Si K & 77,81 & 9,80 \\
Fe K & - & 28,15 \\
Total & 100,00 & 100,00
\end{tabular}

\subsubsection{Ligas de Al-9\%Si-0,4\%Fe}

$\mathrm{Na}$ amostra Al-9\%Si com teor $0,4 \%$ de ferro verifica-se um aumento significativo na quantidade e dimensões da fase $\alpha-\mathrm{Al}_{8} \mathrm{Fe}_{2} \mathrm{Si}$ formada, além de uma distribuição 
mais homogênea na microestrutura, bem como a presença pequenas quantidades da fase $\beta-A l_{5} F e S i$ (figuras 42 e 43).

De acordo com os resultados, a presença do ferro até $0,4 \%$ promove um discreto aumento da resistência à tração, bem como do limite de escoamento. Esse ligeiro aumento pode ser atribuído ao intermetálico $\alpha-\mathrm{Al}_{8} \mathrm{Fe} 2 \mathrm{Si}$, cuja morfologia em escrita chinesa não interrompe a continuidade da matriz. Além disso, esta fase remove o silício, que na ausência do ferro deveria se apresentar como uma fase de silício acicular que contribui para a redução das propriedades mecânicas em função de atuarem como concentradores de tensões.

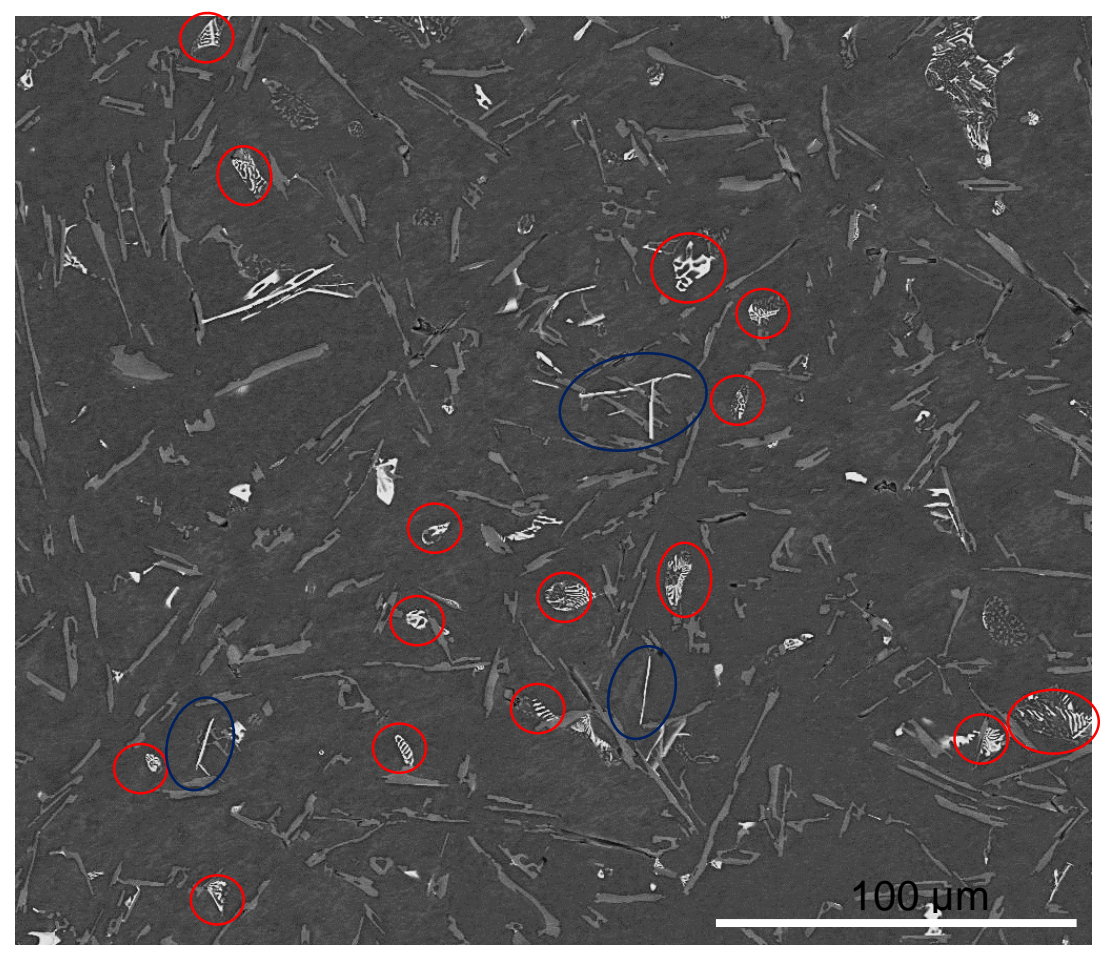

Figura 42 - Micrografia da liga Al-9\%Si-0,4\% Fe obtida pelo MEV mostrando as partículas da fase $\alpha-\mathrm{Al}_{8} \mathrm{Fe}_{2} \mathrm{Si}$ destacado em vermelho e $\beta-\mathrm{Al}_{5} \mathrm{FeSi}$ destacado em azul. 


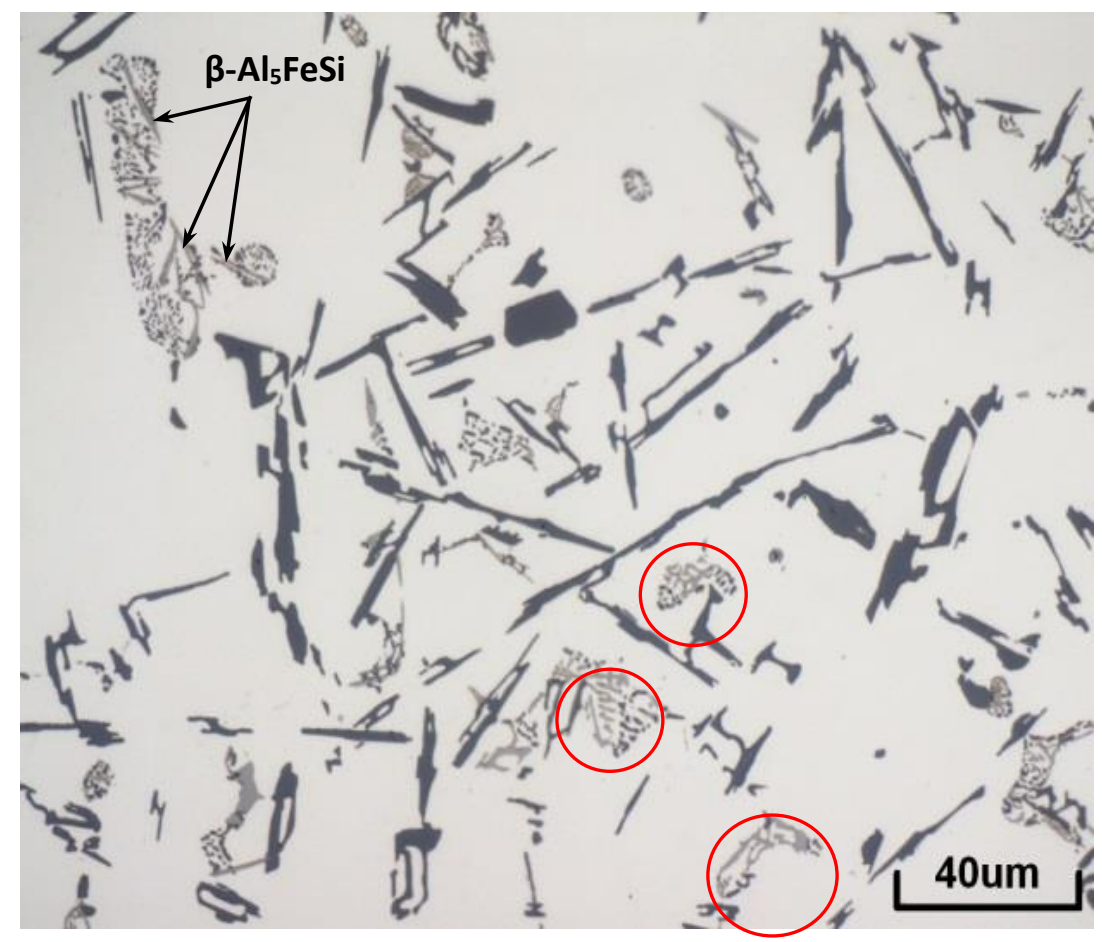

Figura 43 - Presença de partículas de $\alpha-\mathrm{Al}_{8} \mathrm{Fe}_{2} \mathrm{Si}$ situada entre as dendritas de alumínio e de partículas da fase $\beta-A I_{5} F e S i$ formando agulhas refinadas.

A tabela 8 mostra a microanálise do intermetálico enumerado na figura 44 . $\mathrm{Na}$ comparação com os resultados obtidos na tabela 7, verifica-se uma redução no teor de $\mathrm{Fe}$, que pode ser atribuído à imprecisão do sistema de medição.

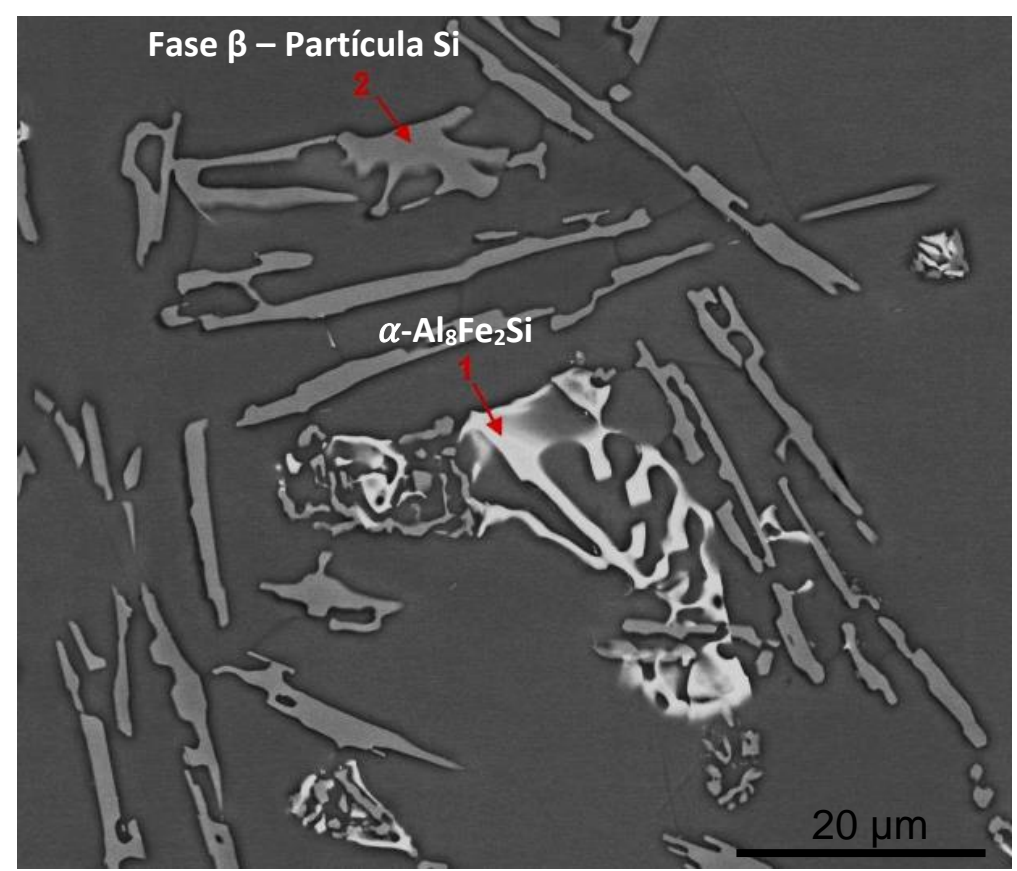

Figura 44 - Micrografia da liga Al-9\%Si- 0,4\% Fe obtidas pelo MEV mostrando as partículas do intermetálico $\alpha-\mathrm{Al}_{8} \mathrm{Fe}_{2} \mathrm{Si}$ de coloração mais clara (2). A fase (1) se refere à partícula de silício. 
Tabela 8 - Microanálise do ponto 1 referente a partícula $\alpha-\mathrm{Al}_{8} \mathrm{Fe}_{2} \mathrm{Si}$ e 2 partícula de silício.

\begin{tabular}{c|cc}
\hline Elementos & \multicolumn{2}{|c}{ Partícula (\% em peso) } \\
O K & 1 & 2 \\
Al K & 3,07 & 1,71 \\
Si K & 67,32 & 17,64 \\
Fe K & 9,15 & 80,64 \\
Total & 20,46 & - \\
\hline
\end{tabular}

A figura 45 mostra a projeção da superfície liquidus do diagrama ternário Al-SiFe onde estão representadas as sequências de fases formadas na solidificação das ligas $\mathrm{Al}-9 \% \mathrm{Si}$ com $0,1 \% \mathrm{Fe}$ e 0,4\%Fe em que ambas apresentam os mesmos caminhos de solidificação. A tabela 9 mostra a sequência de solidificação para as referidas ligas.

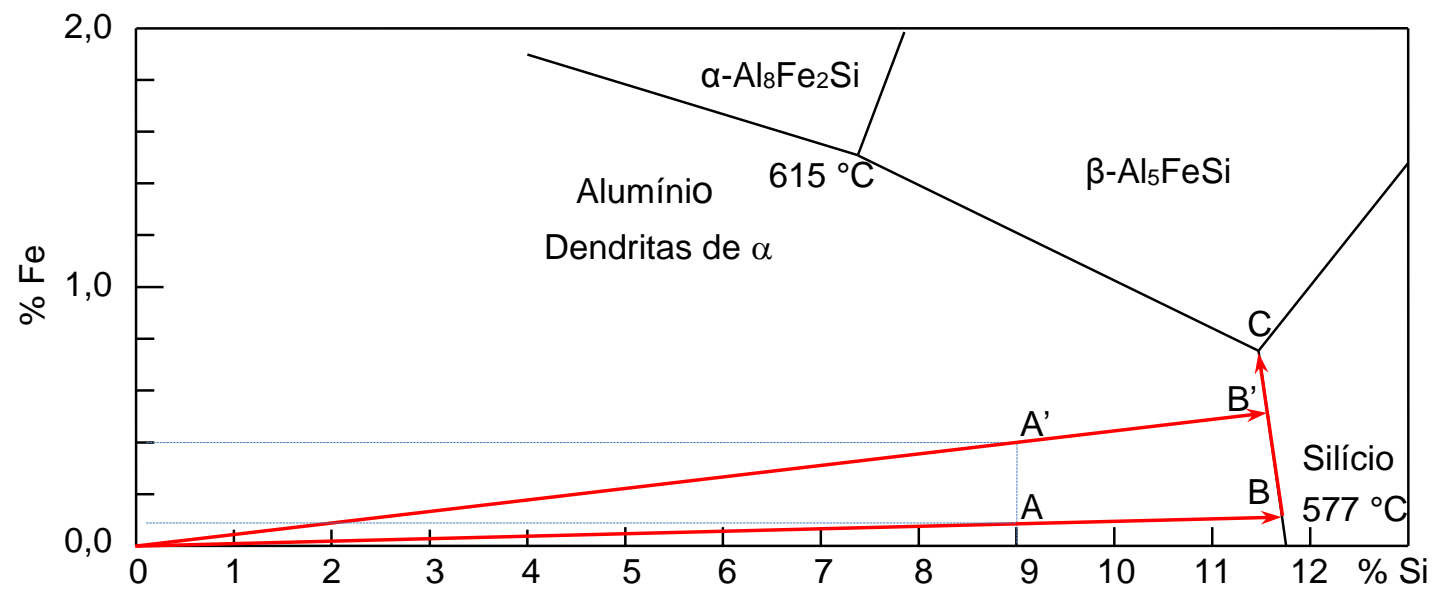

Figura 45 - Projeção da superfície liquidus do diagrama ternário Al-Si-Fe onde estão representadas as sequências de fases formadas na solidificação das ligas Al-9\%Si com $0,1 \%$ e $0,4 \%$ de ferro respectivamente. Adaptado [14].

Tabela 9 - Sequência de solidificação das ligas Al-9\%Si e com teores de ferro de 0,1\%, e $0,4 \%$ como representadas na figura 45 .

\begin{tabular}{|c|c|c|}
\hline Liga & Região & Fases formadas na solidificação \\
\hline \multirow{3}{*}{$\begin{array}{l}\text { Al-9\%Si-0,10\%Fe } \\
\text { Al-9\%Si-0,40\%Fe }\end{array}$} & $\begin{array}{l}A-B \\
A^{\prime}-B^{\prime}\end{array}$ & $\mathrm{L} \rightarrow$ Dendritas de Fase $\alpha$ \\
\hline & $\begin{array}{l}B-C \\
B^{\prime}-C\end{array}$ & $\mathrm{~L} \rightarrow$ Eutético principal $(\alpha+\mathrm{Si})$ \\
\hline & $\mathrm{C}$ & $\mathrm{L} \rightarrow$ Eutético secundário $\left(\alpha+\mathrm{Si}+\beta-\mathrm{Al}{ }_{5} \mathrm{FeSi}\right)$ \\
\hline
\end{tabular}


A fase $\beta$-AlsFeSi é formada em condições de estabilidade, conforme previsto pelo diagrama Al-Si-Fe simplificado e decorre de uma reação eutética secundária se formando nas regiões interdendríticas. Não foi encontrada qualquer referência quanto à formação da fase $\alpha-\mathrm{Al}_{8} \mathrm{Fe}_{2} \mathrm{Si}$ em tal quantidade como mostrada na figura 42 e não há qualquer informação quanto à formação direta desta fase durante a solidificação de ligas semelhantes. As referências existentes são relacionadas às ligas destinadas a processos de transformação mecânica, onde a formação da fase $\alpha-\mathrm{Al}_{8} \mathrm{Fe} 2 \mathrm{Si}$ metaestável decorre da precipitação do ferro por um mecanismo de difusão a curtas distâncias. Como a temperatura de vazamento foi em torno de $760^{\circ} \mathrm{C}$ e com $0,4 \%$ de $\mathrm{Fe}$, verifica-se que os resultados obtidos estão em concordância com os dados da figura 22 obtidos por Awamo e Shimizu [20].

\subsubsection{Ligas de Al-9\%Si-0,8\%Fe}

Nas amostras com 0,8\% de Fe pode-se constatar um aumento acentuado na formação das partículas da fase $\beta$-AlsFeSi. Verifica-se na superfície a formação de partículas menores (figura 46) decorrentes da maior velocidade de resfriamento. No centro (figura 47) as partículas são maiores em função da menor velocidade de resfriamento e, consequentemente, maiores tempos para a difusão e o crescimento da partícula.

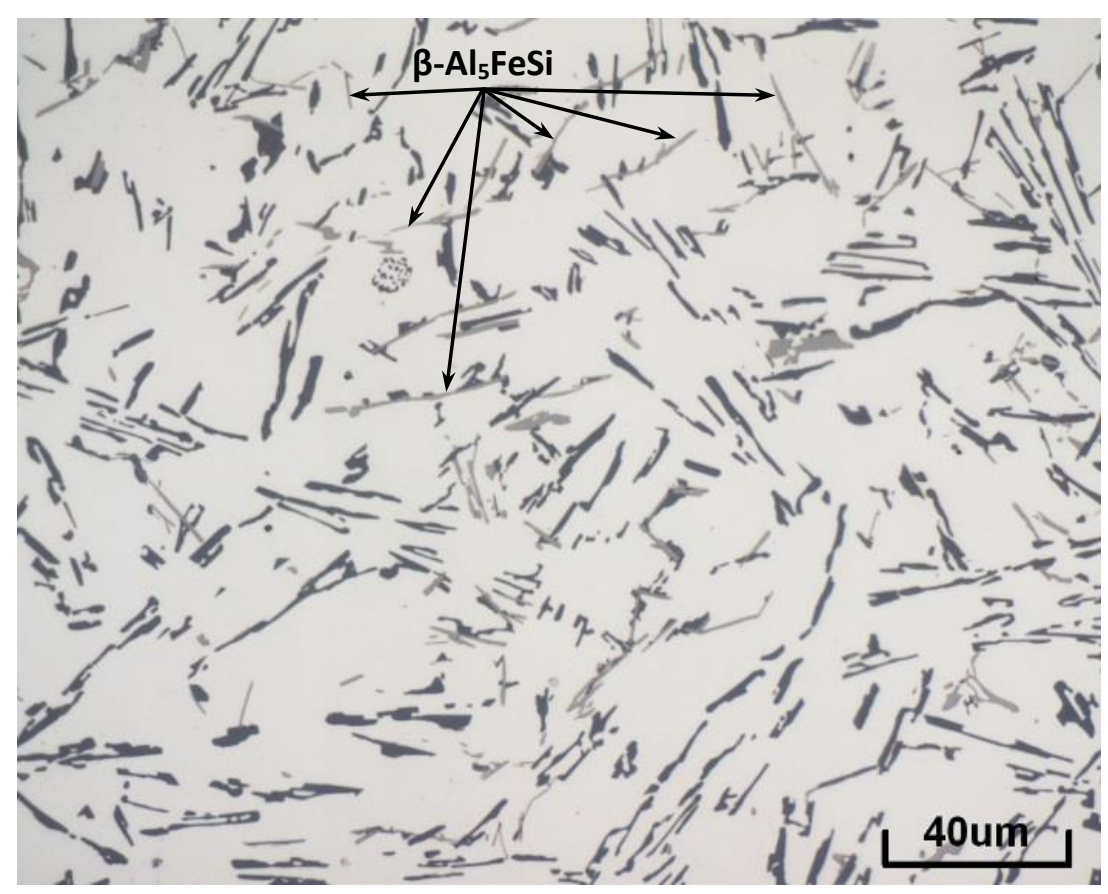

Figura 46 - Microestrutura da liga Al-9\%Si-0,8\%Fe próxima a superfície da amostra. 


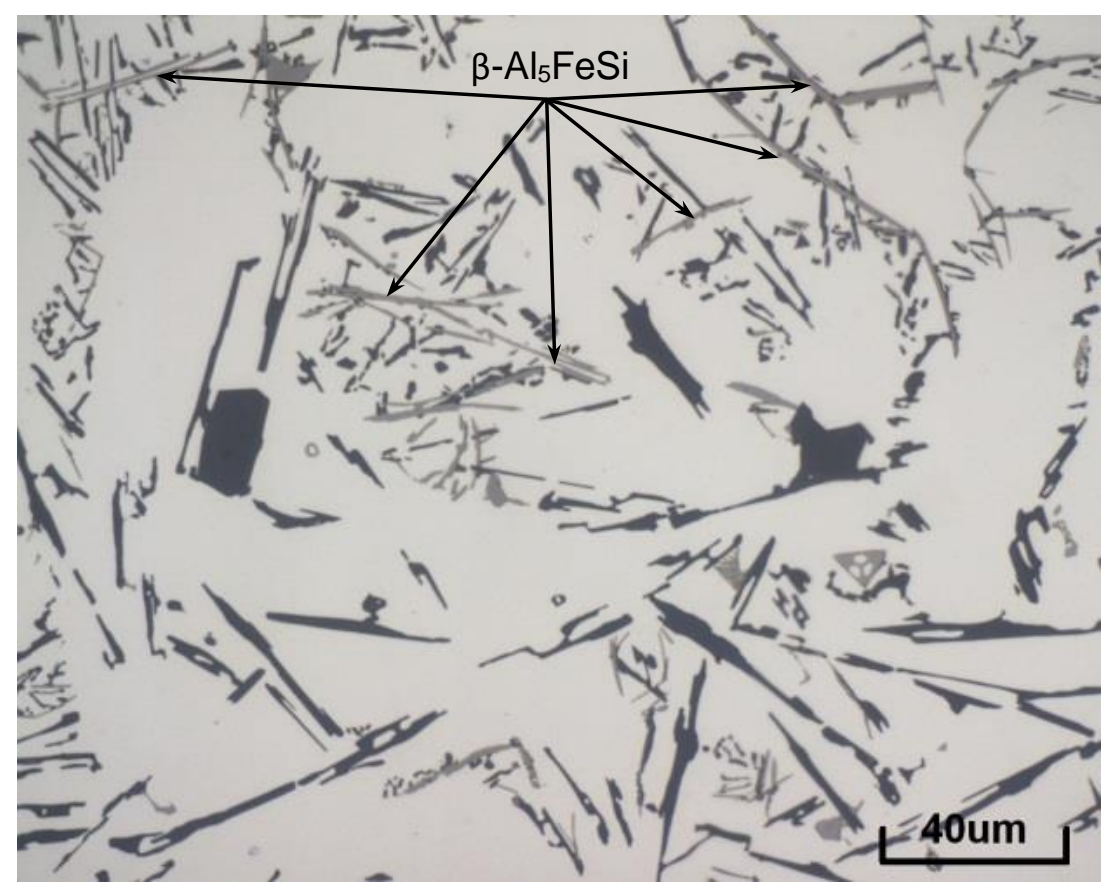

Figura 47 - Microestrutura da liga Al-9\%Si-0,8\%Fe no centro da amostra.

A observação no MEV mostra grandes partículas da fase $\beta$-Als $F$ FeSi na região central em função da menor velocidade de resfriamento, favorecendo a difusão do ferro. Na figura 48 nota-se que uma partícula da fase $\beta$-Al $5 \mathrm{FeSi}$ encontra-se encurvada. Esta curvatura pode ser explicada pela possível presença da alumina que atua como substrato para nucleação do intermetálico [23]. Na solidificação, esta lamina de alumina se deforma devido à contração, enquanto que, simultaneamente, ocorre a nucleação da fase intermetálica. As microanálises, mostradas na tabela 10, dos pontos (1) e (2), da figura 49 mostram que se trata de partículas de $\beta-\mathrm{Al}_{5} \mathrm{FeSi}$ e silício respectivamente. 


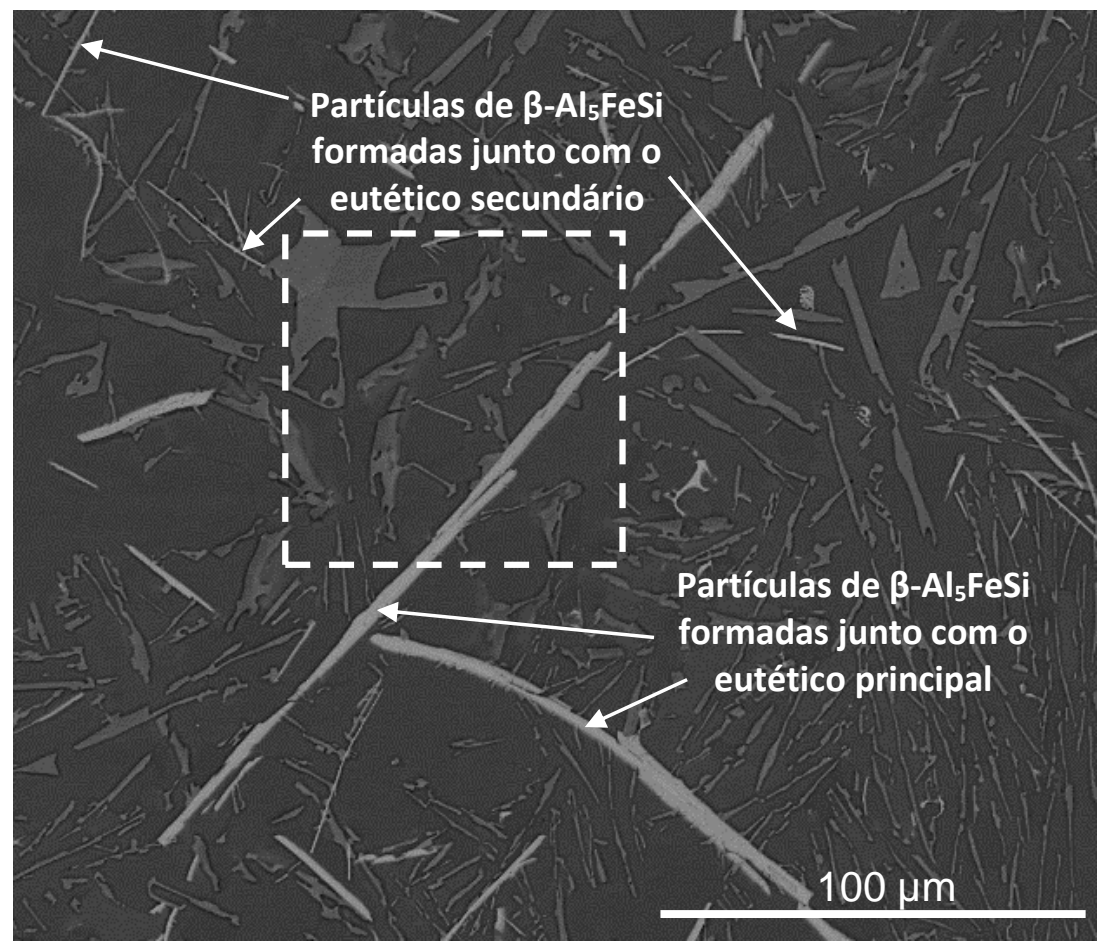

Figura 48 - Micrografia da liga Al-9\%Si-0,8\% Fe obtidas pelo MEV mostra as partículas de $\beta$-Al ${ }_{5} \mathrm{FeSi}$ formadas junto ao eutético principal, em dimensões maiores e aquelas formadas junto ao eutético secundário, com menor dimensão. Esta figura mostra ainda uma partícula de $\beta-\mathrm{Al}_{5} \mathrm{FeSi}$ que nucleou formando uma curvatura.

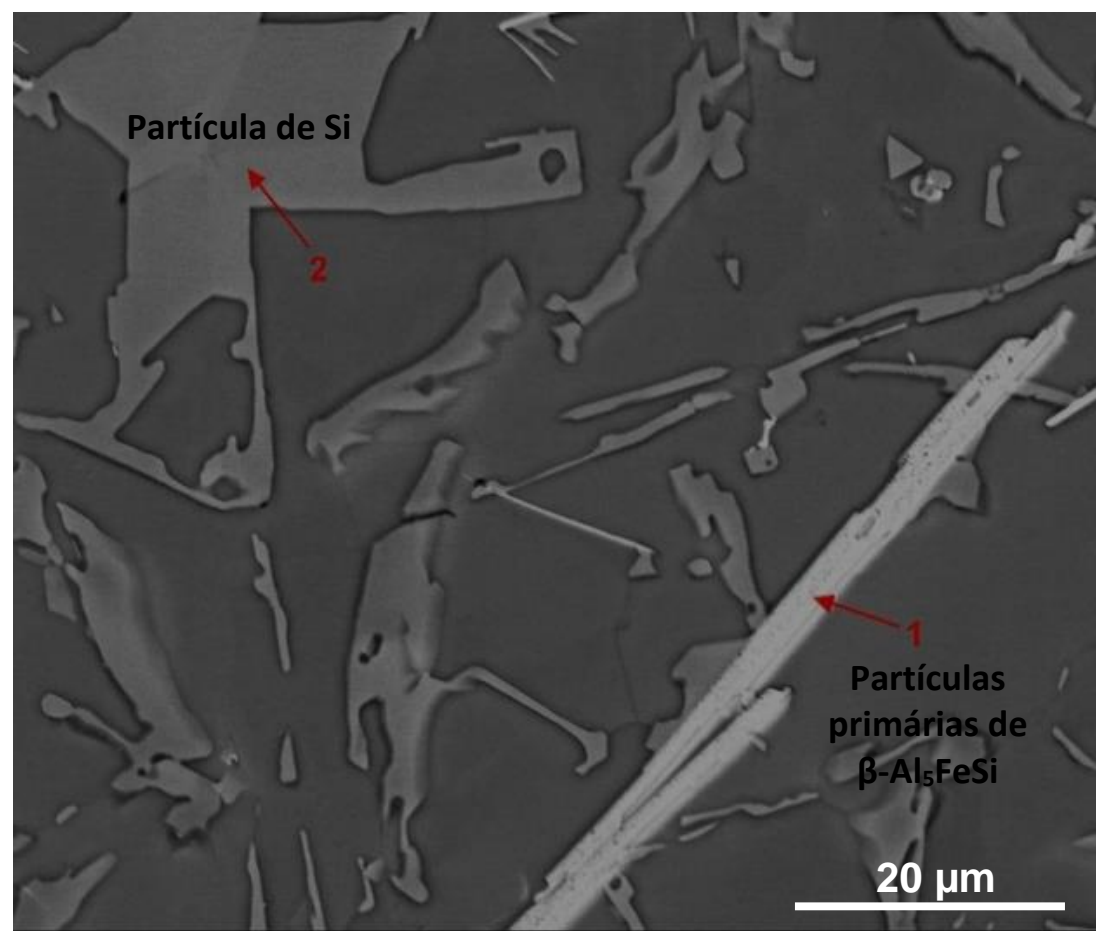

Figura 49 - Ampliação do detalhe da figura anterior obtida pelo MEV mostrando as partículas do intermetálico $\beta$-Al ${ }_{5} \mathrm{SiFe}$ de coloração mais clara (1) e partículas de silício de coloração mais escura (2). 
Tabela 10 - Microanálise das partículas da fase $\beta-\mathrm{Al}_{5} \mathrm{FeSi}$ e silício.

\begin{tabular}{c|cc}
\hline Elementos & \multicolumn{2}{|c}{ Partícula (\% em peso) } \\
& 1 & 2 \\
O K & 11,55 & 0,85 \\
Al K & 46,86 & 10,54 \\
Si K & 15,01 & 88,62 \\
Fe K & 26,57 & - \\
Total & 100,00 & 100,00 \\
\hline
\end{tabular}

Pelo fato da utilização de uma liga de alumínio-silício hipoeutética, cujo modo de solidificação é pastoso, admite-se certo nível de microporosidades. Considerandose uma liga binária, a solidificação inicia com a formação das dendritas de alumínio que, após entrarem em coerência, aprisionariam o líquido de composição eutética que em seguida se solidifica e contraem formando microporosidades. O efeito das partículas da fase $\beta$-Als $\mathrm{FeSi}$ é o de ampliar o volume destas microporosidades uma vez que interrompem o fluxo dos líquidos eutéticos para o interior destes vazios e, consequentemente, ocorre uma redução das propriedades mecânicas da liga, o que está de acordo as referências [30,46]. O volume das microporosidades aumentam a partir do ferro crítico no ponto " $\mathrm{C}$ " do diagrama Al-Fe-Si simplificado, quando a formação da fase $\beta$-AlsFeSi passa a ocorrer junto com o eutético principal. A figura 50 mostra que o intermetálico $\beta-\mathrm{Al}_{5} \mathrm{FeSi}$, formado junto com o eutético principal, interrompe o fluxo do líquido eutético, contribuindo para a formação das microporosidades na liga Al-9\%Si-0,8\%Fe.

A formação de $\beta$-AlsFeSi decorrente da reação eutética secundária pode ser observada na figura 51 , que mostra as partículas de intermetálicos entre as dendritas que formaram protrusões durante a solidificação. Muito provavelmente, estas partículas de $\beta$-Als $\mathrm{FeSi}$ se formaram enquanto o vazio estava parcialmente preenchido com o liquido eutético secundário e que, na solidificação desta, nuclearam e cresceram ao longo das ramificações da dendrita. Evidentemente, com a maior formação de microporosidades, a resistência mecânica diminui bem como o alongamento, como foi verificado nas figuras 37 e 38 , respectivamente. 


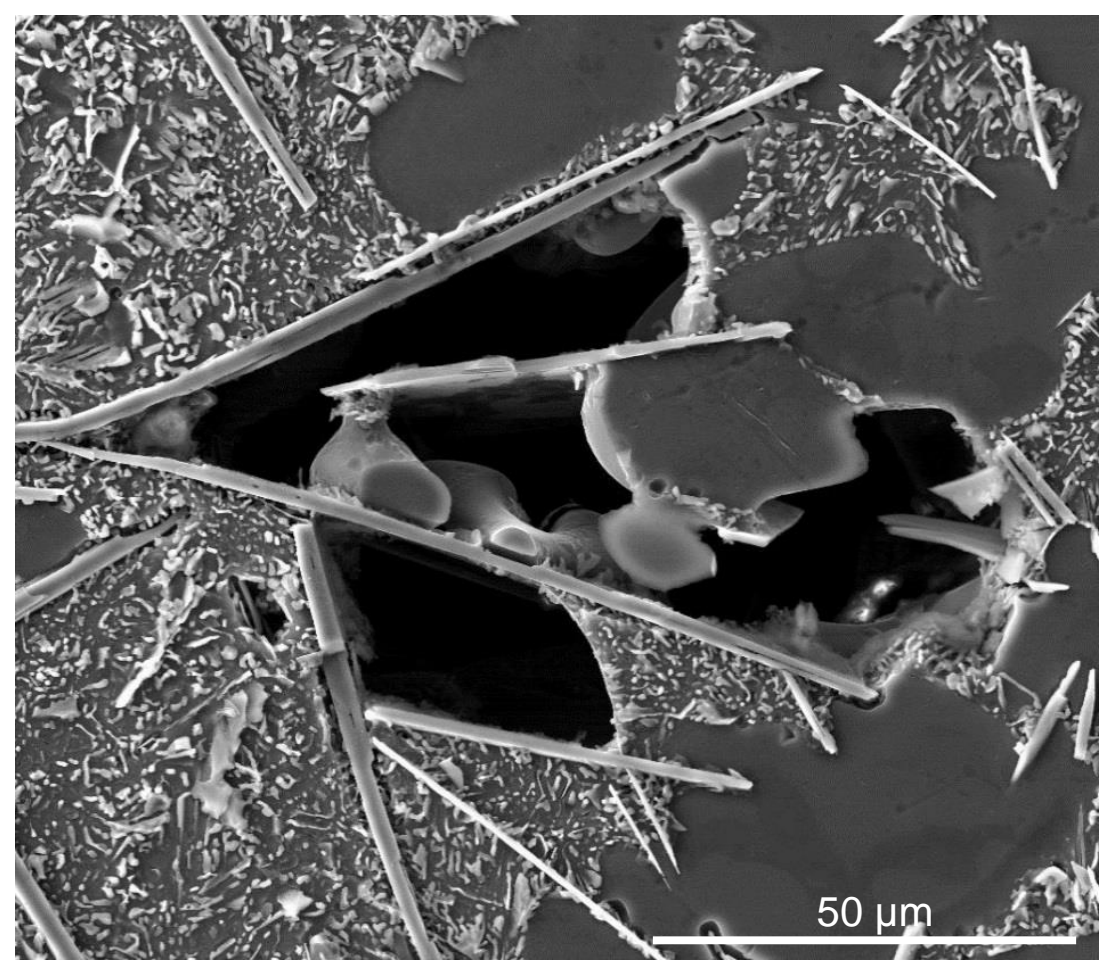

Figura 50 - Microporosidade limitada pelas partículas da fase $\beta-\mathrm{Al}{ }_{5} \mathrm{FeSi}$ restringindo o fluxo de material interdendrítico. Liga Al-9\%Si-0,8\%Fe

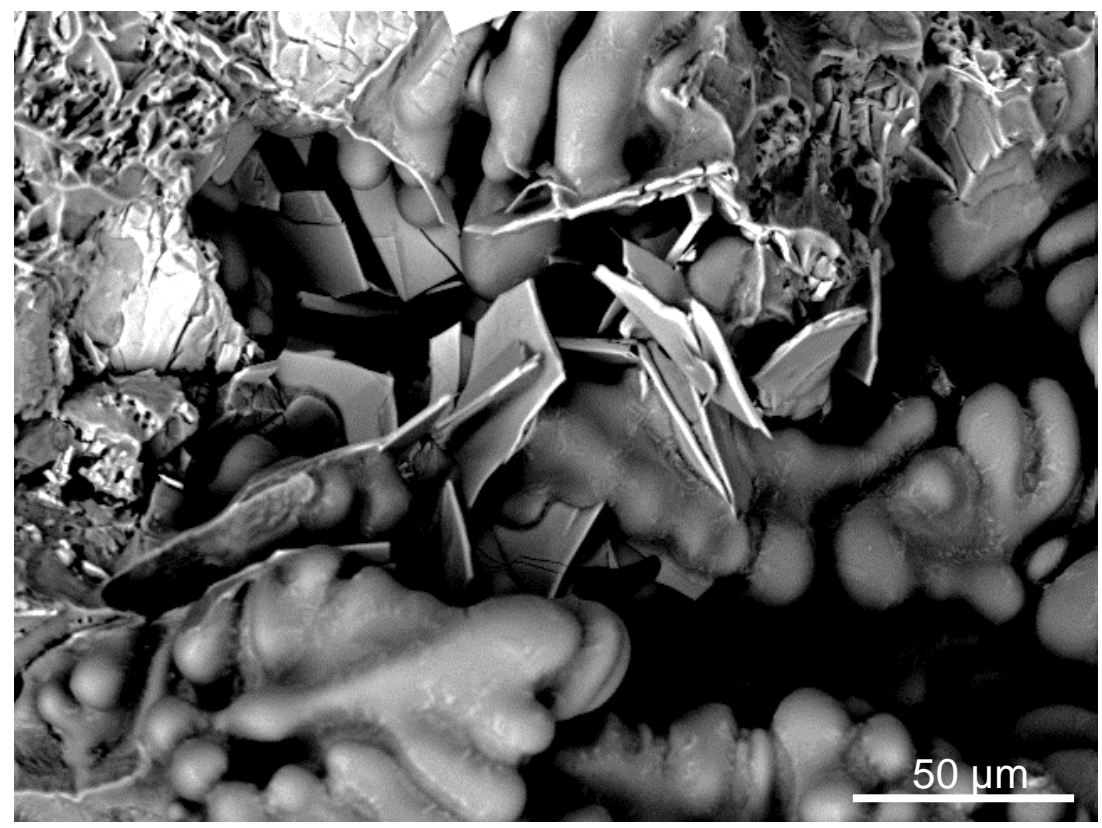

Figura 51 - Fase $\beta$-Al ${ }_{5} F e S i$ formada junto com o eutético secundário sobre os braços da dendrita no interior de uma microporosidade.

A fase $\beta$-Als $\mathrm{FeSi}$ atua como um concentrador de tensões, onde as trincas preexistentes, provavelmente decorrentes do processo de nucleação e crescimento sobre o bi-filme de óxidos, crescem quando submetidas às solicitações mecânicas 
[21]. A figura 52 mostra a micrografia de uma amostra de Al- $9 \% \mathrm{Si}-0,8 \% \mathrm{Fe}$ submetida ao ensaio de tração, mas com interrupção do teste momentos após atingir o limite de escoamento. Verifica-se que a trinca se propaga entre a partícula de fase $\beta-\mathrm{Al}_{5} \mathrm{FeSi}$, mas não é possível afirmar que esta se propagou sobre uma fissura provocada pelo bi-filme de óxido.

As fissuras que podem ocorrer no interior do intermetálico e observadas no microscópio ótico podem ser provenientes do processo de contração de solidificação ou da própria preparação da amostra nas etapas de lixamento e polimento, que promovem a fratura do intermetálico [21]. Não se tentou, neste trabalho, encontrar evidências mais claras quanto à propagação das trincas sobre os intermetálicos, ficando como uma sugestão para novos trabalhos. A observação fractográfica da mesma amostra mostra que a fratura apresenta aspecto frágil (figura 53).

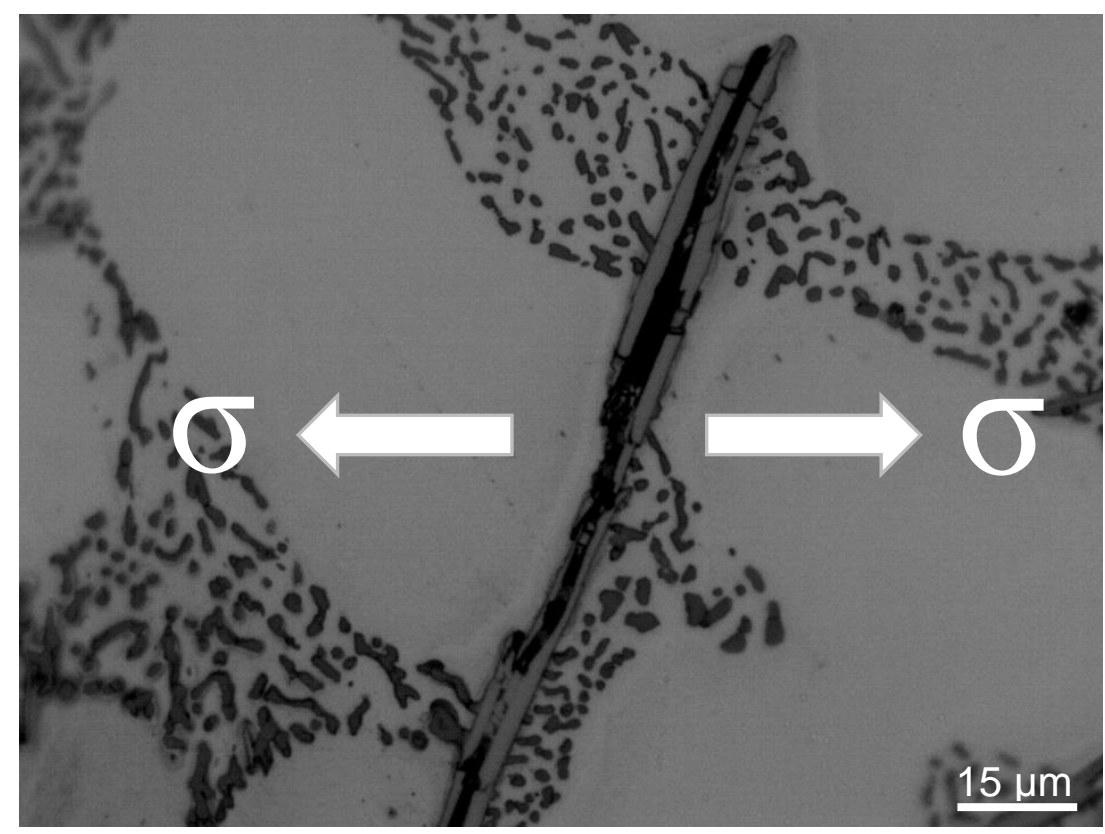

Figura 52 - Trinca nucleada no interior da partícula de $\beta-\mathrm{Al}_{5} \mathrm{FeSi}$. 


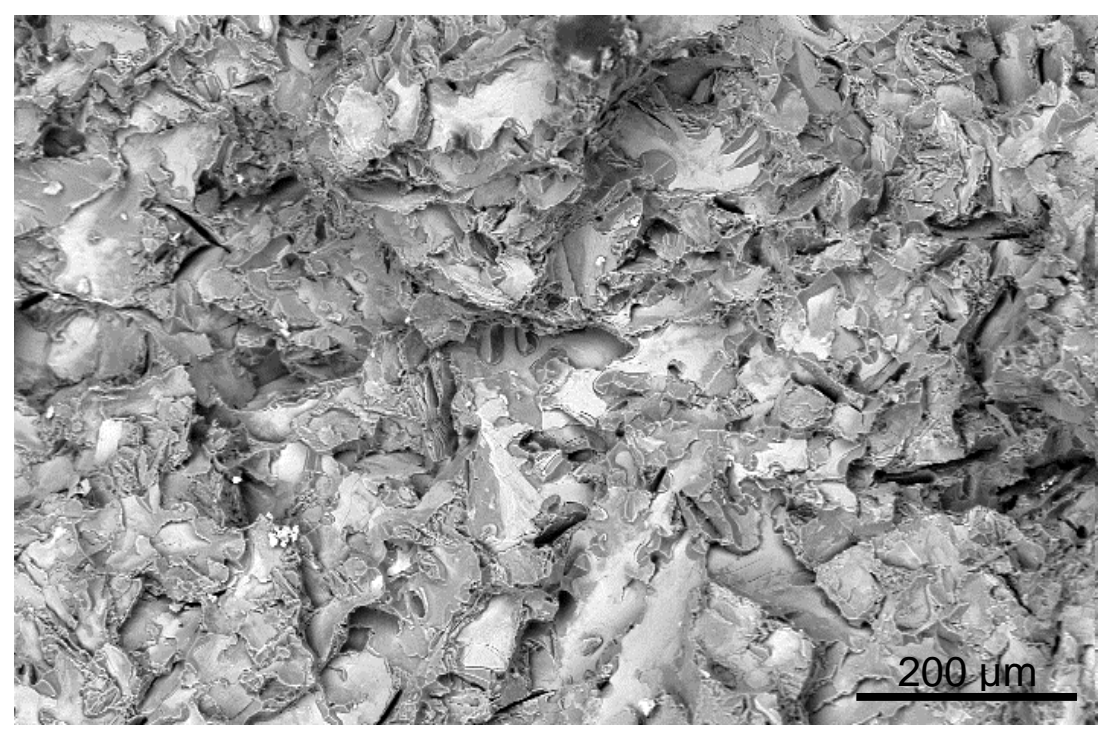

Figura 53 - MEV de uma fratura mostrando os planos de clivagem decorrentes da decoesão das partículas de $\beta$-Al ${ }_{5} F e S i$ [13].

\subsubsection{Ligas de Al-9\%Si-1,2\%Fe}

Maiores teores de ferro promovem uma intensificação na formação da fase $\beta$ $\mathrm{Al} 5 \mathrm{FeSi}$, como pode ser observado nas figuras 54 e 55, cujo teor de ferro na amostra é de $1,2 \%$. Nestas figuras nota-se que os intermetálicos com ferro são mais grosseiros e de maior comprimento, o que contribui significativamente para a redução das propriedades mecânicas, principalmente o alongamento, conforme mostrado na tabela 6. Não se observou a presença da fase $\alpha-\mathrm{Al}_{8} \mathrm{Fe}_{2} \mathrm{Si}$, que está de acordo com a figura 22, em que a formação da fase $\beta-\mathrm{Al}_{5} \mathrm{FeSi}$ predomina para maiores teores de ferro e silício. 


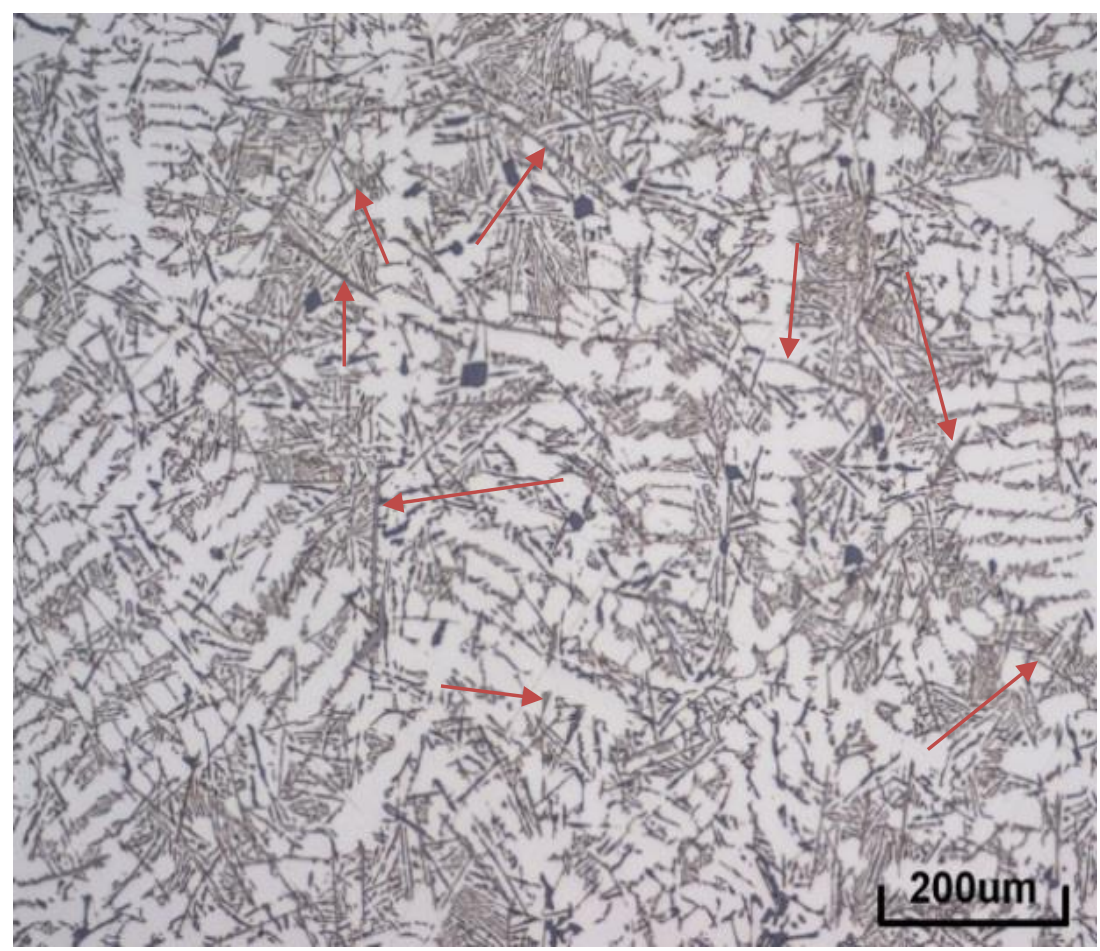

Figura 54 - Micrografia da liga Al-9\%Si-1,2\% Fe mostrando a distribuição das partículas da fase $\beta-\mathrm{Al}_{5} \mathrm{FeSi}$ formadas junto com as dendríticas de $\alpha$.

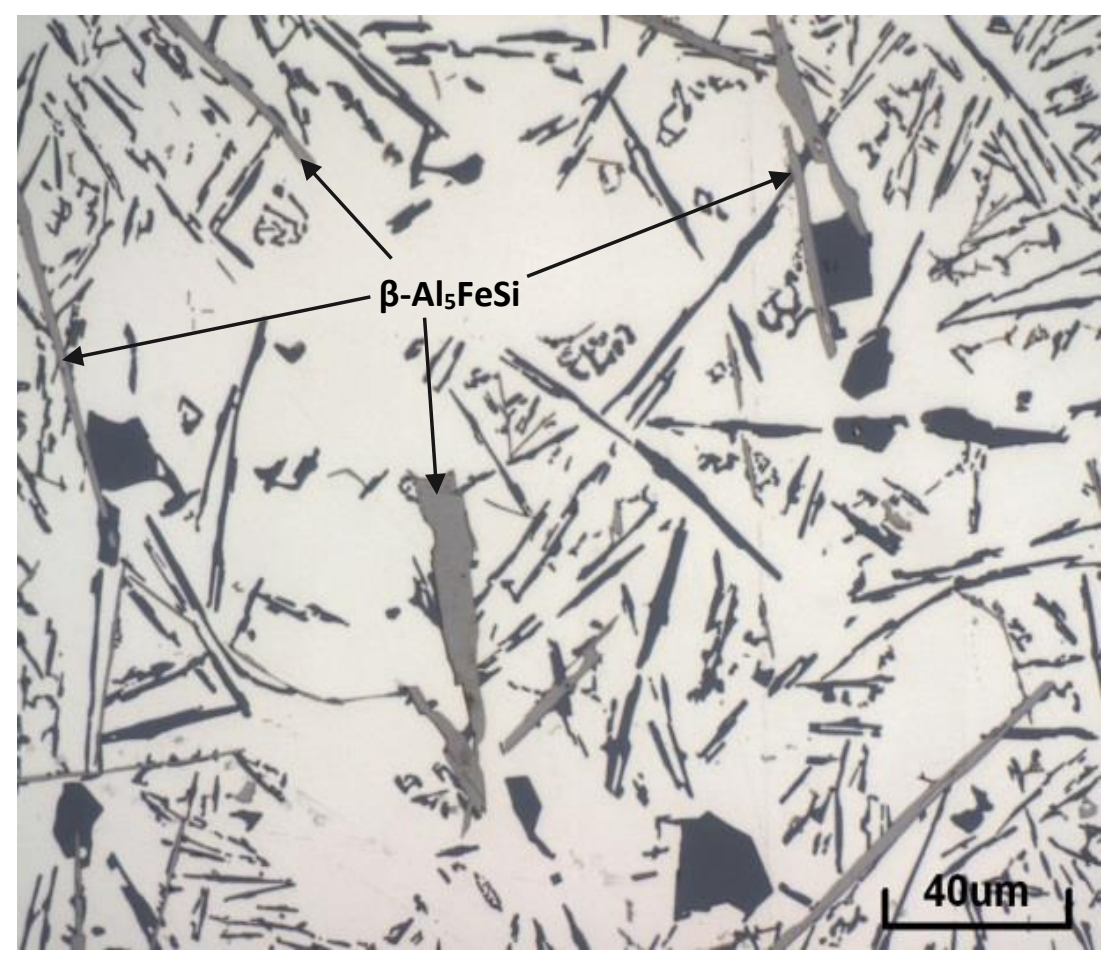

Figura 55 - Micrografia da liga Al-9\%Si-1,2\% Fe mostrando respectivamente as partículas de silício de formação eutética entre os braços das dendritas de alumínio e a fase $\beta$ $\mathrm{Al}_{5} \mathrm{FeSi}$ de grandes dimensões formadas junto com o eutético principal. 
O diagrama ternário Al-Fe-Si (figura 56) simplificado mostra as sequências de solidificação para as ligas Al-9\%Si com 0,8 e 1,2\% de Fe. Apesar das sequências de solidificação serem iguais (tabela11), constata-se grandes diferenças em relação às dimensões dos intermetálicos formados. Na observação dos intermetálicos com a utilização do MEV, nas figuras 57 e 58, fica evidente as diferenças dimensionais entre as partículas da fase $\beta-A l_{5} F e S i$ decorrentes da formação junto ao eutético principal daquelas formadas junto com o eutético secundário. A microanálise dos pontos 1 e 2 da figura 58 , apresentada na tabela 11 , confirma as composições das partículas de $\beta$ AlsFeSi e silício, respectivamente.

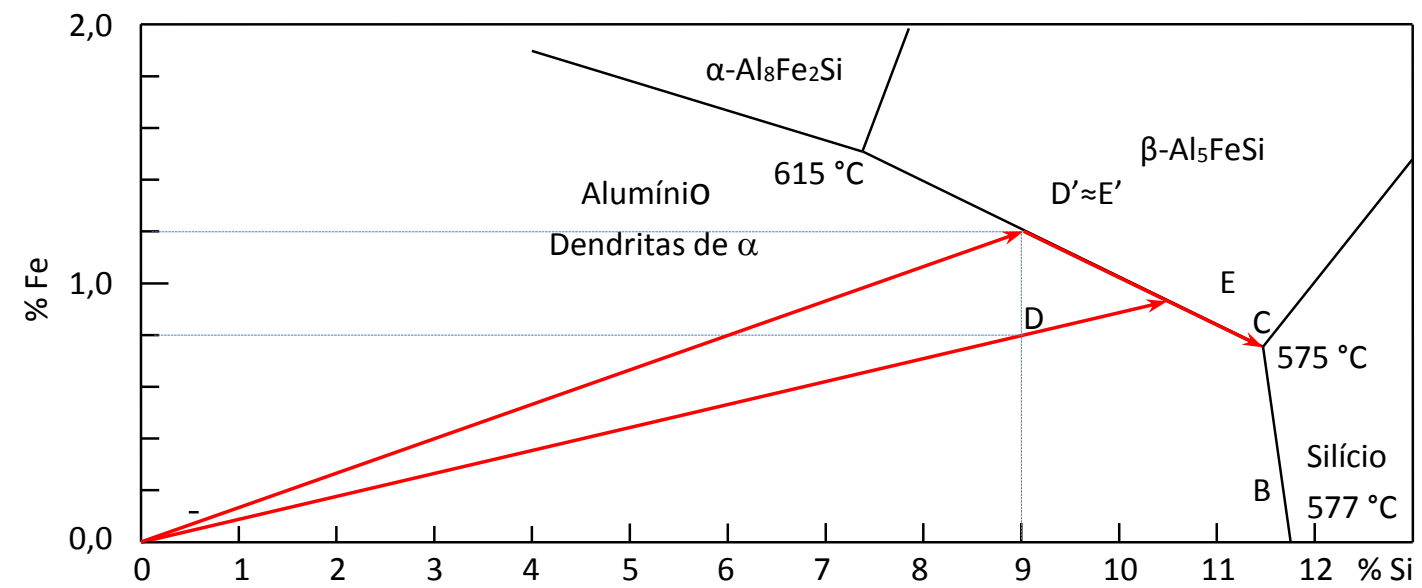

Figura 56 - Projeção da superfície liquidus do diagrama ternário Al-Si-Fe onde estão representadas as sequencias de fases formadas na solidificação das ligas Al-9\%Si com $0,8 \%$ e $1,2 \%$ de ferro respectivamente. Adaptado [14].

Tabela 11 - Sequência de solidificação das ligas AI-9\%Si com teores de ferro em 0,8\%, e $1,2 \%$ como representadas na figura 56 .

\begin{tabular}{|l|c|l|}
\hline \multicolumn{1}{|c|}{ Liga } & Região & \multicolumn{1}{c|}{ Fases formadas na solidificação } \\
\hline & D-E & L $\rightarrow$ Dendritas de Fase $\alpha$ \\
& D'- E' & L \\
\cline { 2 - 3 } Al-9\%Si-0,80\%Fe & E - C & L $\rightarrow$ Eutético $\left(\alpha+\beta-A l_{5} F e S i\right)$ \\
Al-9\%Si-1,20\%Fe & E'-C & \\
\cline { 2 - 3 } & C & L $\rightarrow$ Eutético secundário $\left(\alpha+\mathrm{Si}+\beta-\mathrm{Al}_{5} \mathrm{FeSi}\right)$ \\
\hline
\end{tabular}




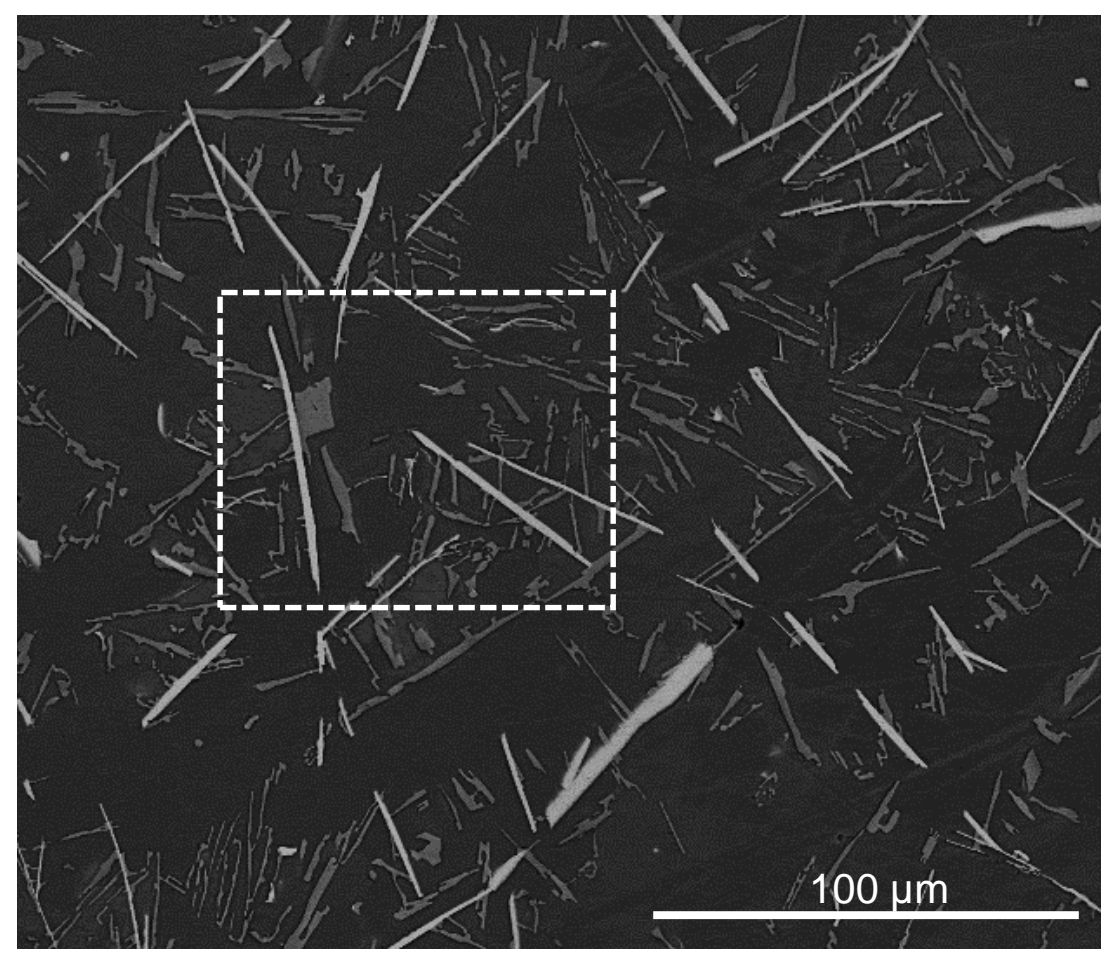

Figura 57 - Micrografia obtida por Mev na região central da amostra mostrando as partículas de intermetálicos formadas junto ao eutético principal (partículas maiores) e aquelas formadas junto ao eutético secundário (partículas menores).

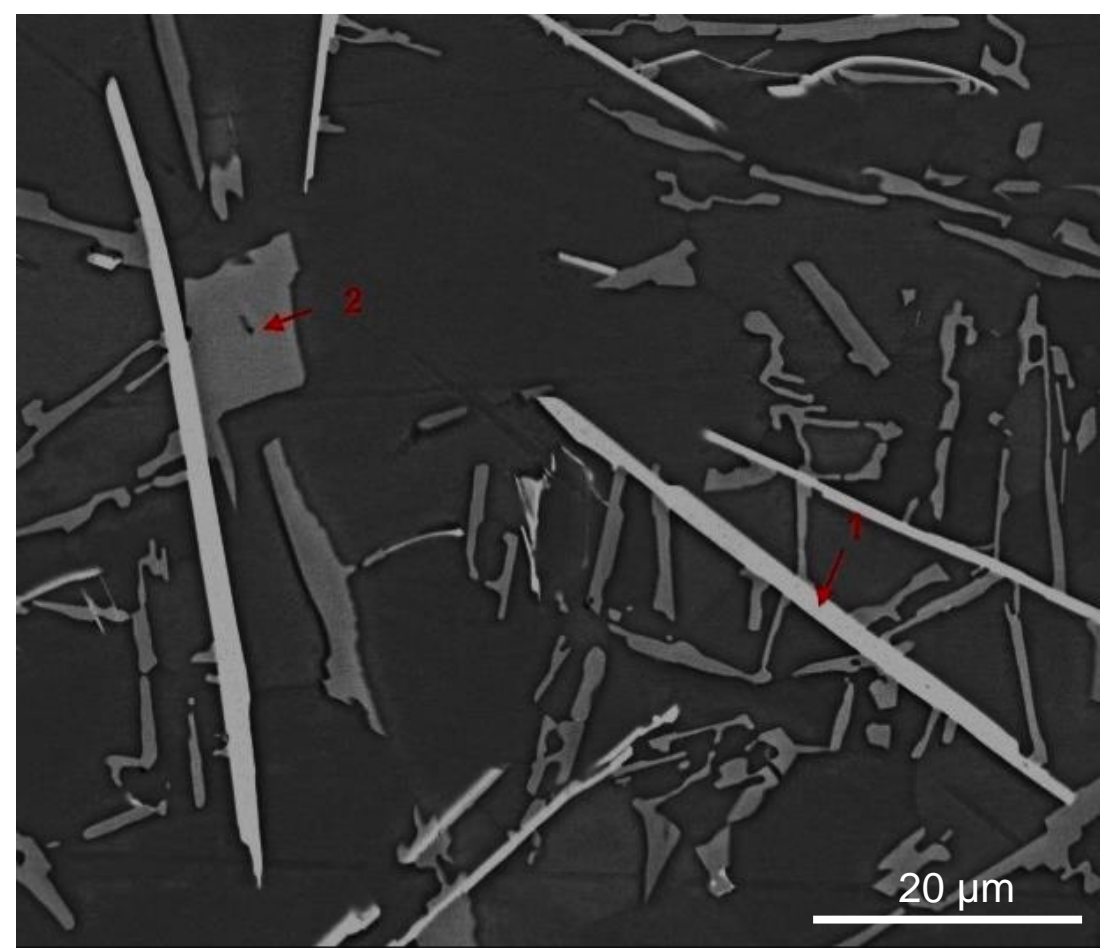

Figura 58 - Ampliação do destaque da figura 57 para microanálise nas partículas enumeradas de 1 e 
Tabela 12 - Microanálise das partículas da fase $\beta-\mathrm{Al}_{5} \mathrm{FeSi}$ e silício referente à figura 58.

\begin{tabular}{c|cc}
\hline Elementos & \multicolumn{2}{|c}{ Partícula (\% em peso) } \\
& 1 & 2 \\
O K & 7,48 & 1,45 \\
Al K & 52,42 & 12,02 \\
Si K & 16,05 & 86,53 \\
Fe K & 24,04 & - \\
Total & 100,00 & 100,00 \\
\hline
\end{tabular}

\subsubsection{Fractografia nas ligas Al-9\%Si com Fe}

Após os ensaios de tração nas ligas desta série, as superfícies fraturadas foram observadas no MEV, conforme mostra a sequência de figuras a seguir (figuras 59 a 62). Nesta sequência de fractografias pode-se constatar que a fratura tem aspecto tanto mais frágil quanto maior o teor de ferro presente na liga. Isto ocorre em função da presença das plaquetas de $\beta-A l_{5} F e S i$ que favorecem a propagação das trincas durante as solicitações mecânicas.

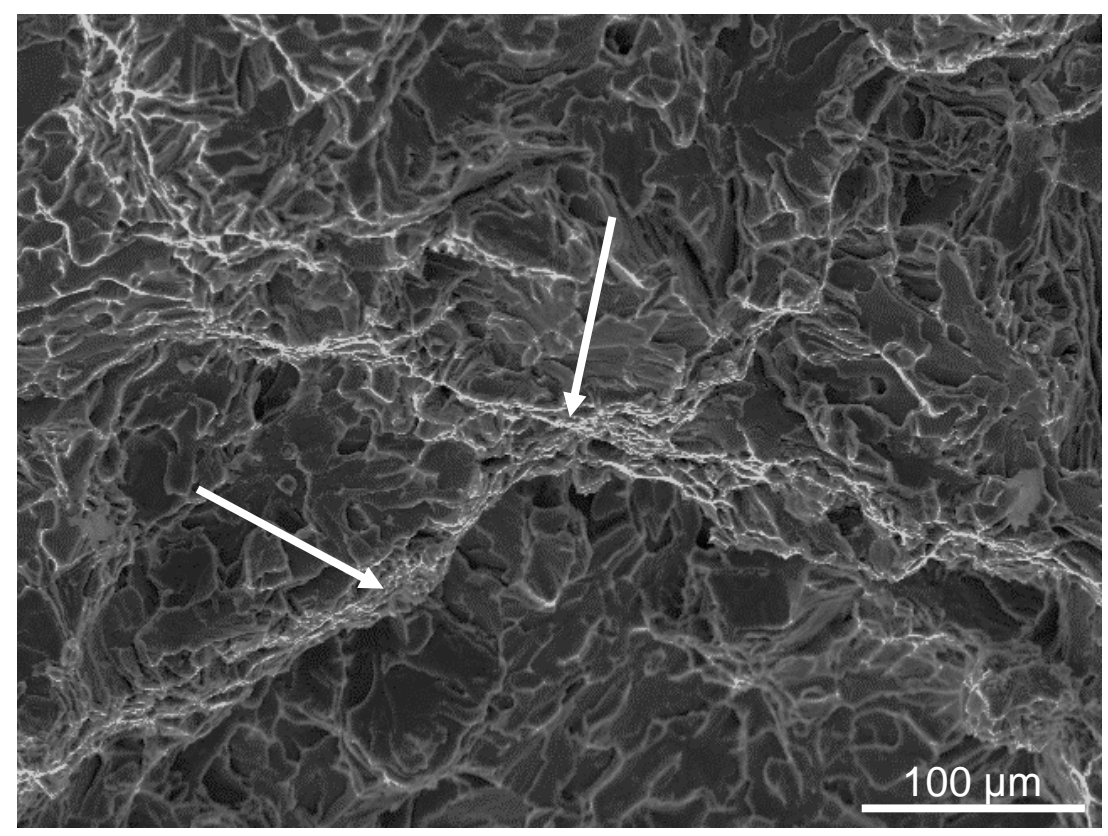

Figura 59 - Aspecto da fratura da liga Al-9\%Si-0,1\%Fe. O aspecto frágil é decorrente da presença das partículas de Si com morfologia acicular. Verifica-se algumas regiões com aspecto alveolar como indicados na figura. 


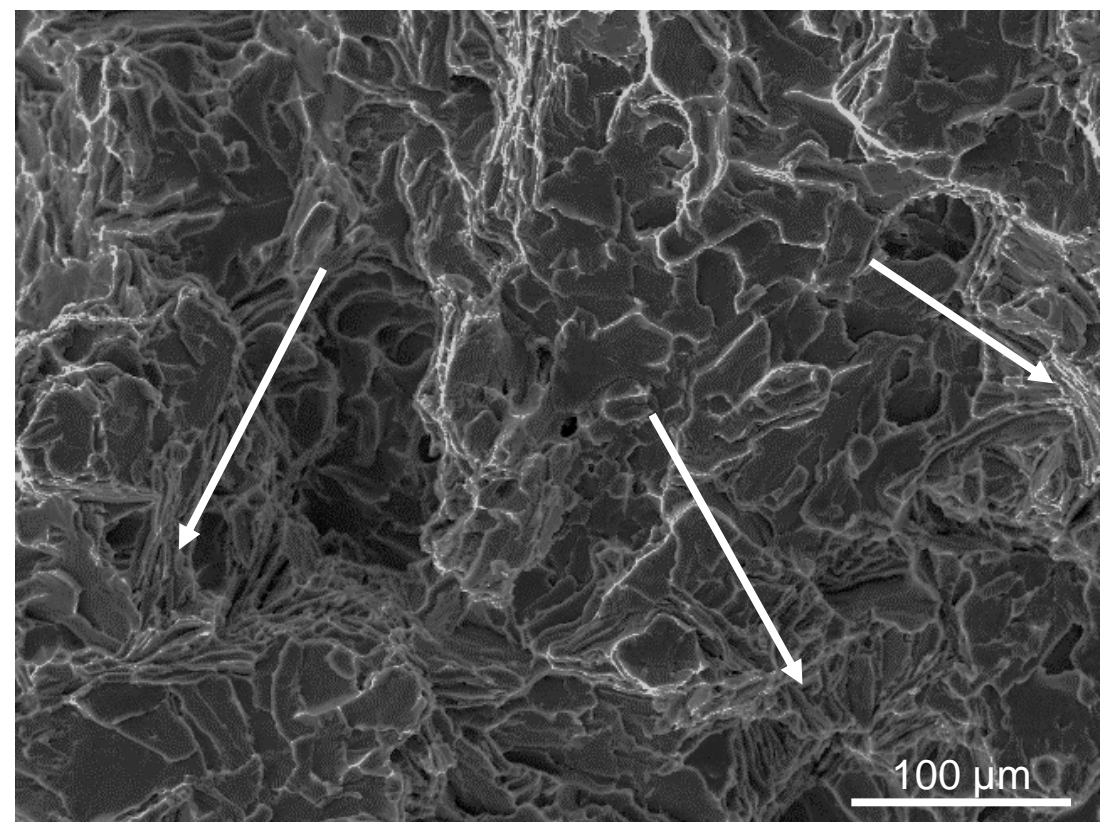

Figura 60 - Fratura da liga Al-9\%Si-0,4\%Fe mostrando a presença de regiões alveolares alongadas como indicados na figura.

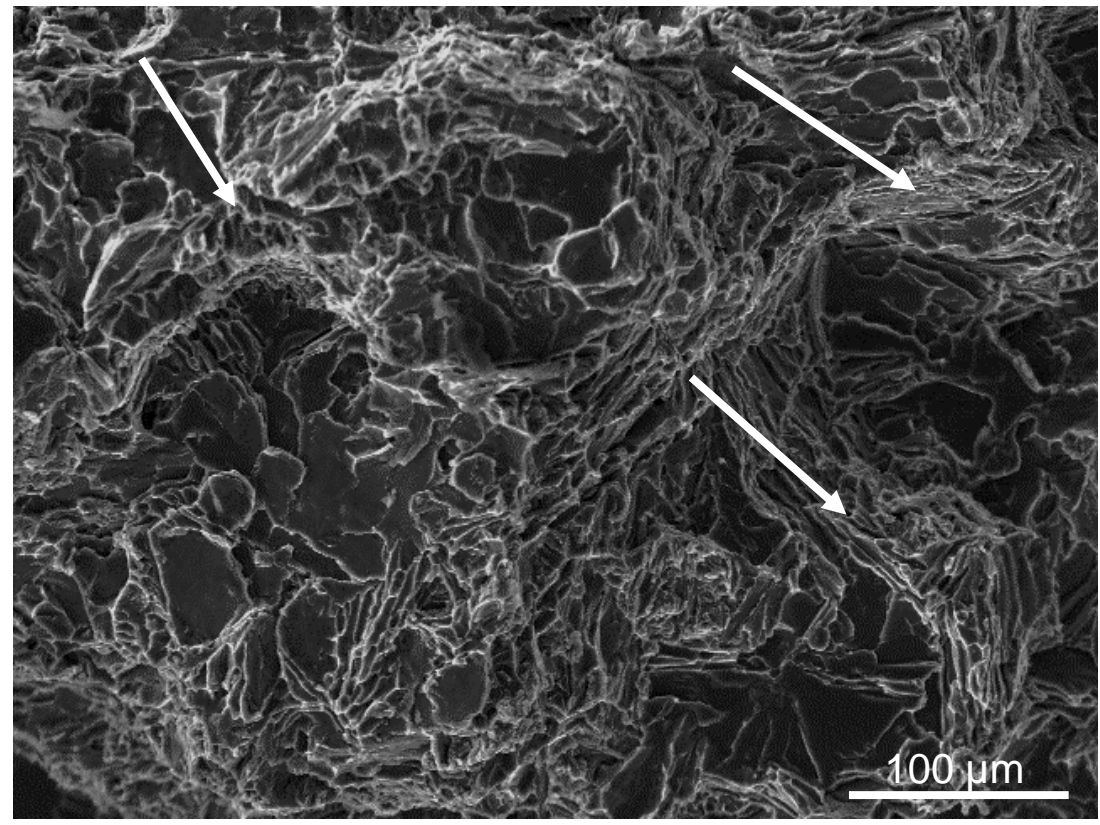

Figura 61 - Fratura referente ao corpo de prova tracionado da liga Al-9\%Si-0,8\% Fe. Aspecto frágil provocada pela presença das partículas de $\beta$-Al ${ }_{5} \mathrm{FeSi}$. Verifica-se a presença de regiões alveolares alongadas apontadas na figura. 


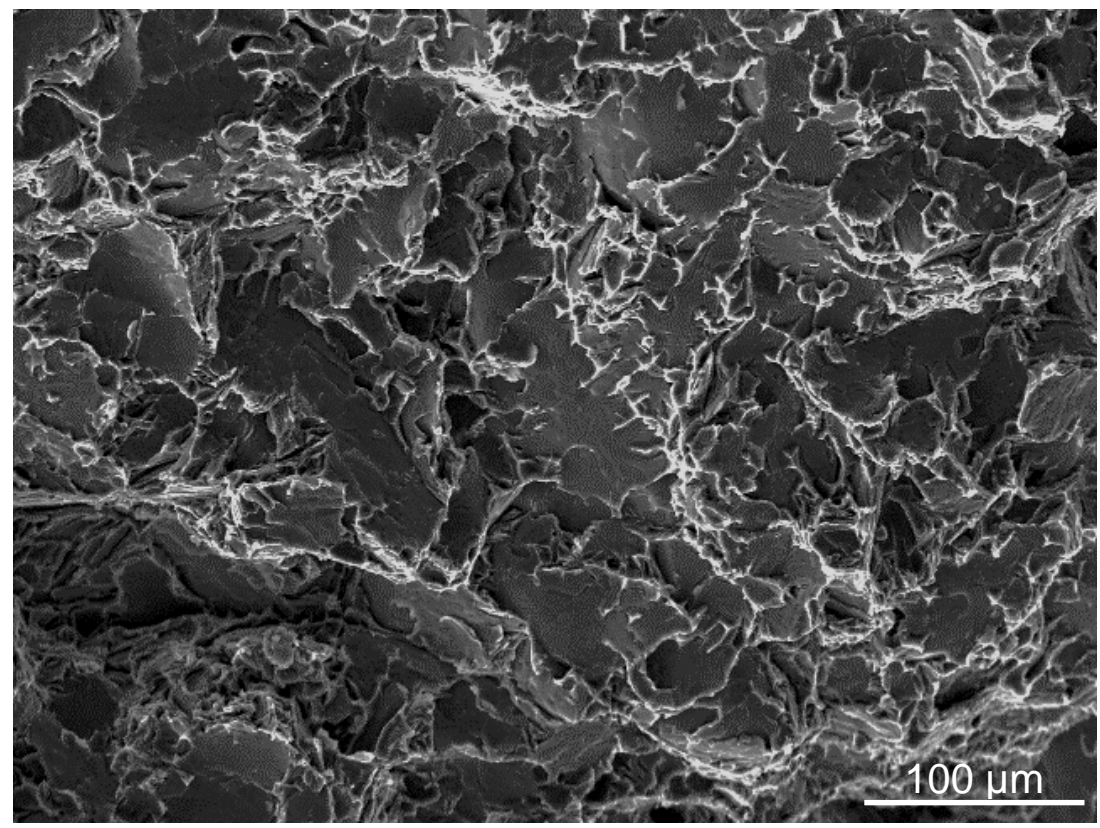

Figura 62 - Fratura da liga Al-9\%Si-1,2\%Fe com fratura predominantemente frágil provocada pela intensa formação das plaquetas de $\beta-\mathrm{Al}_{5} \mathrm{FeSi}$. 


\subsection{Ligas de Al-9\%Si-0,8\%Fe com adições de Mn}

A adição de manganês na liga $\mathrm{Al}-9 \% \mathrm{Si}-0,8 \% \mathrm{Fe}$ visa aumentar as propriedades mecânicas da liga via alteração da morfologia do intermetálico $\beta$-AlsFeSi em forma de plaquetas para $\alpha-\mathrm{Al}_{15}(\mathrm{Fe}, \mathrm{Mn})_{3} \mathrm{Si} \mathrm{i}_{2} \mathrm{com}$ morfologia em "escrita chinesa". Na tabela 13 são apresentadas as composições químicas, via espectrômetro por emissão ótica, nas ligas obtidas de Al-9\%Si-0,8\%Fe com teores de 0,$1 ; 0,2 ; 0,4$ e $0,7 \%$ em peso de manganês. A liga Al-9\%Si-0,8\%Fe foi tomada como referência, tanto para a execução dos testes de resistência à tração como para comparação metalográfica por apresentar a formação da fase $\beta$-AlsFeSi junto com a formação do eutético principal. Nesta sequência de testes tentou-se manter o teor de estrôncio em torno de 200 ppm no material fundido no forno de indução na tentativa de facilitar a identificação dos compostos intermetálicos.

Tabela 13 - Composição química das amostras obtidas.

\begin{tabular}{|c|c|c|c|c|c|}
\hline \multirow{2}{*}{$\begin{array}{c}\text { Elementos } \\
\text { químicos }\end{array}$} & \multicolumn{5}{|c|}{ Al-9\%Si-0,8\% } \\
\cline { 2 - 6 } & $0,0 \% \mathrm{Mn}$ & $0,1 \% \mathrm{Mn}$ & $0,2 \% \mathrm{Mn}$ & $0,4 \% \mathrm{Mn}$ & $0,7 \% \mathrm{Mn}$ \\
\hline $\mathrm{Si}$ & 8,991 & 8,987 & 9,153 & 8,748 & 8,793 \\
\hline $\mathrm{Cu}$ & 0,149 & 0,159 & 0,159 & 0,191 & 0,232 \\
\hline $\mathrm{Fe}$ & 0,806 & 0,861 & 0,867 & 0,845 & 0,801 \\
\hline $\mathrm{Mg}$ & 0,000 & 0,000 & 0,000 & 0,000 & 0,000 \\
\hline $\mathrm{Zn}$ & 0,000 & 0,000 & 0,000 & 0,000 & 0,000 \\
\hline $\mathrm{Ni}$ & 0,000 & 0,000 & 0,000 & 0,000 & 0,000 \\
\hline $\mathrm{Mn}$ & 0,008 & 0,116 & 0,226 & 0,482 & 0,730 \\
\hline $\mathrm{Ti}$ & 0,000 & 0,000 & 0,000 & 0,000 & 0,000 \\
\hline $\mathrm{Ca}$ & 0,006 & 0,000 & 0,012 & 0,005 & 0,006 \\
\hline $\mathrm{Na}$ & 0,000 & 0,000 & 0,000 & 0,000 & 0,000 \\
\hline $\mathrm{Pb}$ & 0,026 & 0,027 & 0,028 & 0,031 & 0,031 \\
\hline $\mathrm{Sn}$ & 0,000 & 0,000 & 0,000 & 0,000 & 0,000 \\
\hline $\mathrm{Cr}$ & 0,000 & 0,000 & 0,000 & 0,000 & 0,002 \\
\hline $\mathrm{V}$ & 0,000 & 0,000 & 0,000 & 0,000 & 0,000 \\
\hline $\mathrm{Be}$ & 0,000 & 0,000 & 0,000 & 0,000 & 0,000 \\
\hline $\mathrm{Cd}$ & 0,000 & 0,000 & 0,000 & 0,000 & 0,000 \\
\hline $\mathrm{Co}$ & 0,000 & 0,000 & 0,000 & 0,000 & 0,009 \\
\hline $\mathrm{Sr}$ & 0,020 & 0,027 & 0,023 & 0,023 & 0,031 \\
\hline $\mathrm{Sb}$ & 0,043 & 0,000 & 0,032 & 0,036 & 0,014 \\
\hline $\mathrm{B}$ & 0,000 & 0,000 & 0,000 & 0,000 & 0,000 \\
\hline $\mathrm{Zr}$ & 0,000 & 0,000 & 0,000 & 0,000 & 0,000 \\
\hline $\mathrm{Al}$ & 89,949 & 89,691 & 89,498 & 89,639 & 89,349 \\
\hline
\end{tabular}


$\mathrm{Na}$ tabela 14 são apresentados os resultados dos ensaios de tração. Com a adição do manganês verifica-se um ligeiro aumento da resistência mecânica, enquanto que o limite de escoamento apresenta uma leve oscilação, com tendência de uma queda suave, conforme mostrado na figura 63.

Tabela 14 - Resultados obtidos dos testes de tração em cada um dos experimentos.

\begin{tabular}{|l|c|c|c|c|c|}
\hline \multirow{2}{*}{ Propriedades } & \multicolumn{5}{|c|}{ Teor de Mn, \% } \\
\cline { 2 - 6 } & 0,0 & 0,1 & 0,2 & 0,4 & 0,7 \\
\hline Resistência à tração, MPa & $179,2 \pm 5,5$ & $181,7 \pm 13,5$ & $183,8 \pm 10,5$ & $179,8 \pm 8,9$ & $190,7 \pm 6,8$ \\
\hline $\begin{array}{l}\text { Limite de escoamento, } \\
\text { MPa }\end{array}$ & $79,4 \pm 9,3$ & $74,7 \pm 6,7$ & $78,8 \pm 7,0$ & $75,8 \pm 3,9$ & $76,7 \pm 2,5$ \\
\hline Alongamento, \% & $4,7 \pm 0,8$ & $4,5 \pm 0,9$ & $6,9 \pm 0,7$ & $5,8 \pm 1,6$ & $5,6 \pm 1,7$ \\
\hline
\end{tabular}

Limite de resistência e escoamento (MPa) X Teor de Mn (\% em peso)

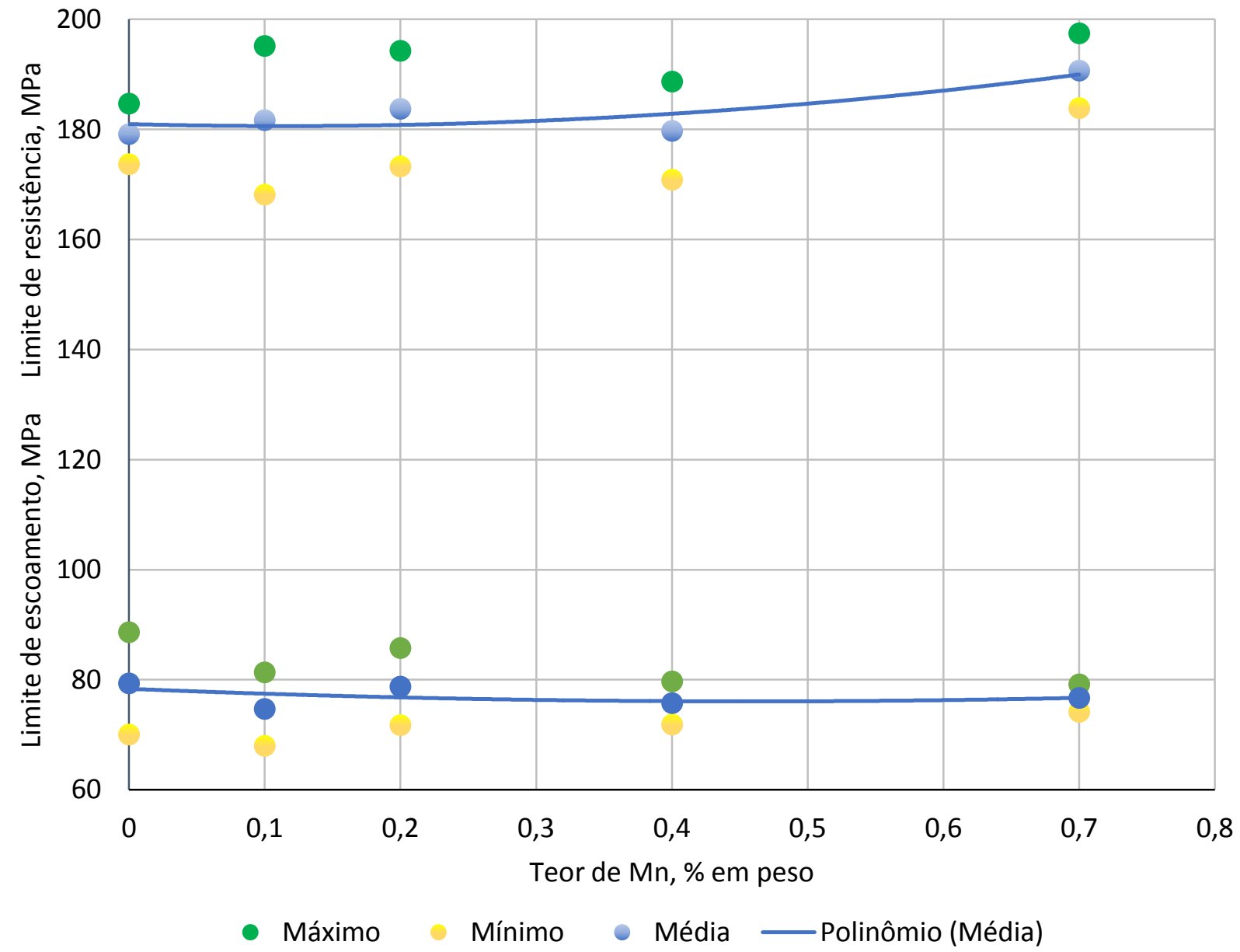

Figura 63 - Gráfico de Limite de resistência e escoamento em função do teor de Mn, \% em peso. 
Apesar da grande dispersão de resultados de alongamento apresentados a partir de $0,4 \%$ de $\mathrm{Mn}$, a figura 64 mostra uma tendência de queda desta propriedade em função do teor de Mn. Todos os resultados obtidos nestes ensaios estão em concordância com as referências [8, 39].

\section{Alongamento (\%) X Teor de $\mathrm{Mn}(\%$ em peso)}

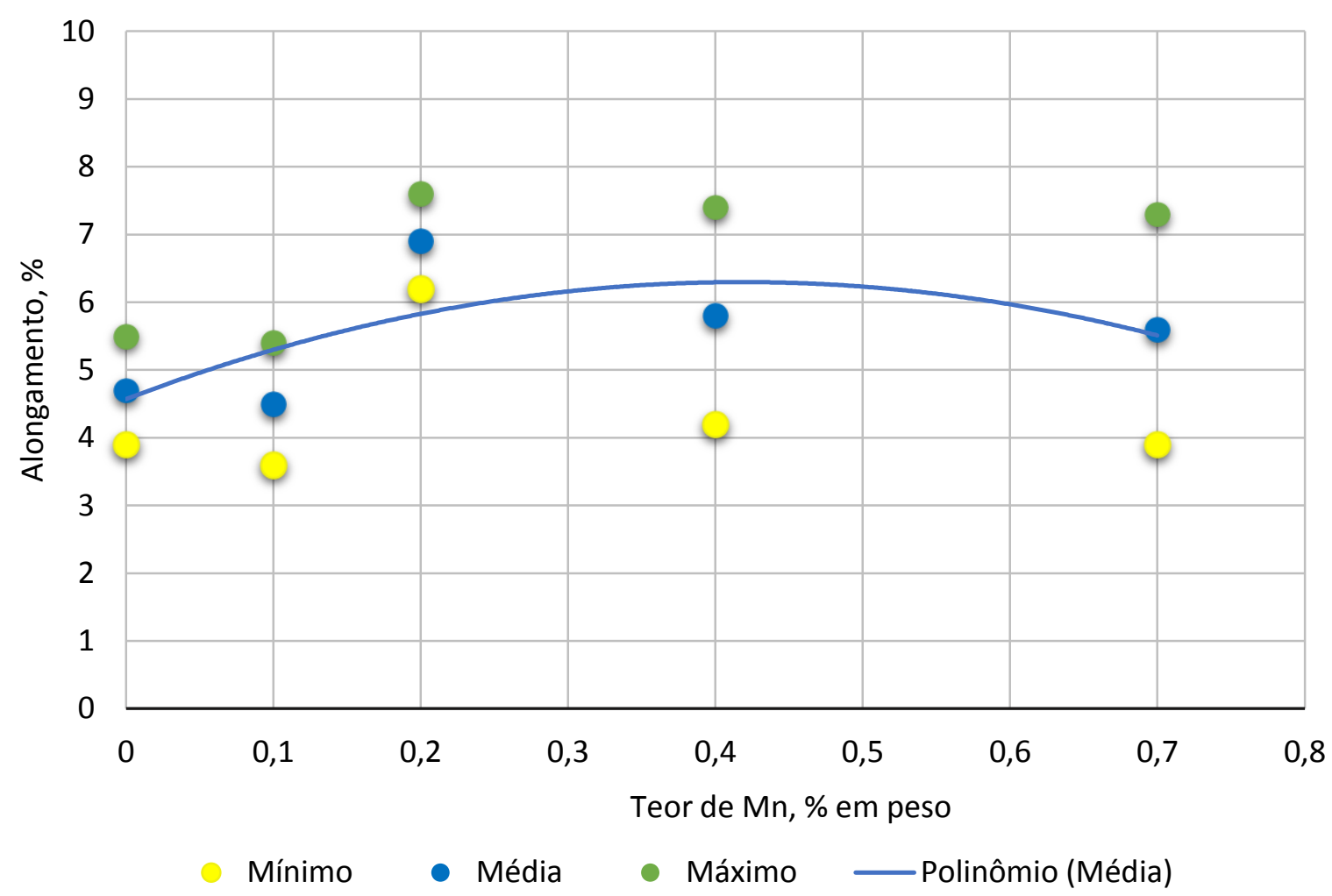

Figura 64 - Gráfico de alongamento em função do teor de Mn, \% em peso.

\subsubsection{Ligas de Al-9\%Si-0,8\%Fe-0,1\%Mn}

O diagrama da figura 65 mostra a sequência de solidificação para a liga Al$9 \% \mathrm{Si}-0,8 \% \mathrm{Fe}$ com $0,1 \%$ de Mn. Verifica-se, conforme mostrado na tabela 15 , que após a formação das dendritas de $\alpha$, ocorre a formação do intermetálico $\beta-\mathrm{Al}_{5} \mathrm{FeSi}$ no campo estreito B-D, seguido da formação da fase aalumínio mais $\mathrm{Al}_{15}(\mathrm{Fe}, \mathrm{Mn})_{3} \mathrm{Si}_{2}$ e a formação de eutético secundário de aalumínio mais $\beta-\mathrm{Al}_{5} \mathrm{FeSi}$. 


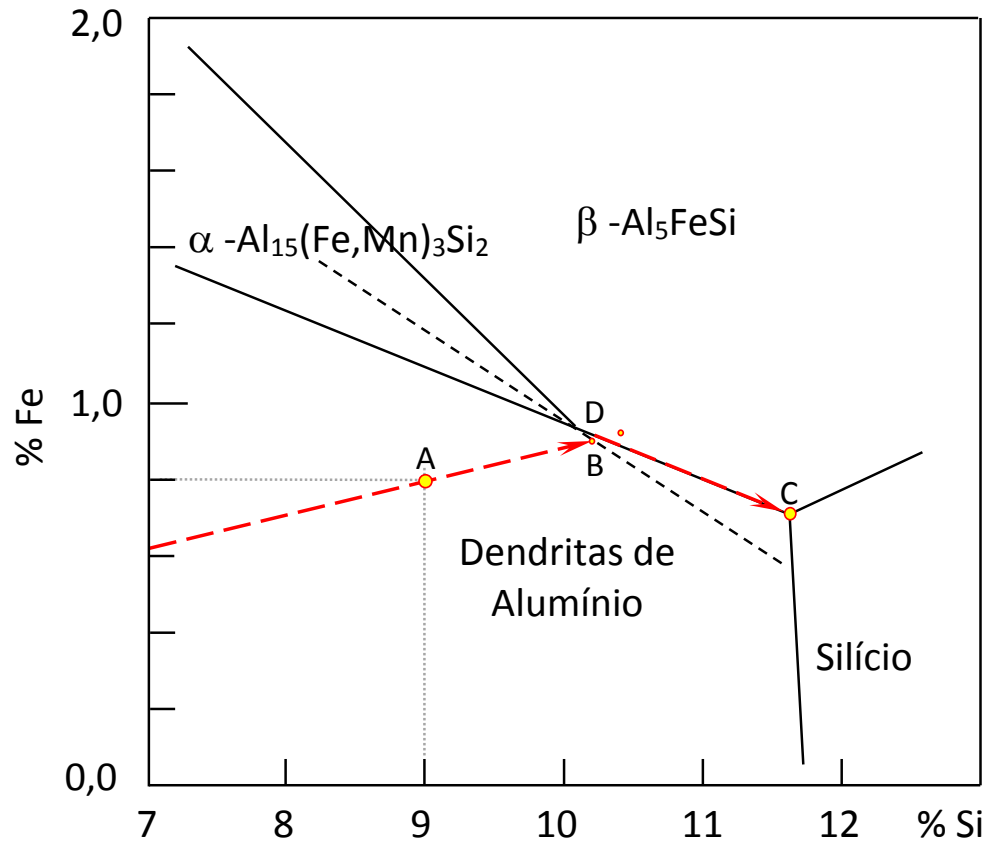

Figura 65 - Projeção da superfície liquidus do diagrama ternário Al-Si-Fe com 0,1\% de $\mathrm{Mn}$ onde estão representadas as sequencias de fases formadas na solidificação das ligas Al-9\%Si com 0,8\% e 0,1\%Mn. Adaptado [14]

Tabela 15 - Sequência de solidificação das ligas Al-9\%Si com teor de ferro em 0,8\% e $0,1 \% \mathrm{Mn}$ como representado na figura 65 .

\begin{tabular}{|c|c|l|}
\hline Liga & Região & \multicolumn{1}{|c|}{ Fases formadas na solidificação } \\
\hline \multirow{3}{*}{$\begin{array}{c}\text { Al-9\%Si-0,80\%Fe } \\
0,1 \% \mathrm{Mn}\end{array}$} & A - B & $\mathrm{L} \rightarrow$ Dendritas de $\alpha$ \\
\cline { 2 - 3 } & B - D & L $\rightarrow$ Eutético $\alpha+\beta-\mathrm{Al}_{5} \mathrm{FeSi}$ \\
\cline { 2 - 3 } & $\mathrm{D}-\mathrm{C}$ & $\mathrm{L} \rightarrow$ Eutético $\alpha+\alpha-\mathrm{Al}{ }_{15}(\mathrm{Fe}, \mathrm{Mn})_{3} \mathrm{Si}_{2}$ \\
\hline & $\mathrm{C}$ & $\mathrm{L} \rightarrow$ Eutético secundário $\alpha+\mathrm{Si}+\beta-\mathrm{Al}_{5} \mathrm{FeSi}$ \\
\hline
\end{tabular}

Com $0,1 \%$ de $\mathrm{Mn}$ constata-se a presença de grande quantidade da fase $\beta$ AlsFeSi conforme previsto pelo diagrama da figura 65. As composições aproximadas das fases enumeradas na figura 66 são mostradas na tabela 16 onde se constata grandes diferenças de teor de ferro entre os intermetálicos sem a presença de Mn. No campo analisado na figura 64 constata-se o predomínio da partícula $\beta$ - $\mathrm{Al} 5 \mathrm{FeSi}$, mas com a presença da fase $\alpha-\mathrm{Al}_{8} \mathrm{Fe}_{2} \mathrm{Si}$ com morfologia em escrita chinesa. Na figura 67, no ponto 1, já se verifica a presença da fase $\alpha-\mathrm{Al}_{15}(\mathrm{Fe}, \mathrm{Mn})_{3} \mathrm{Si}_{2}$ com morfologia em "escrita chinesa". O ponto 2 mostra um outro intermetálico também com a presença 
de cobre formando morfologia em plaqueta e o ponto 3 a partícula de silício. A tabela 17 mostra as composições aproximadas das referidas partículas.

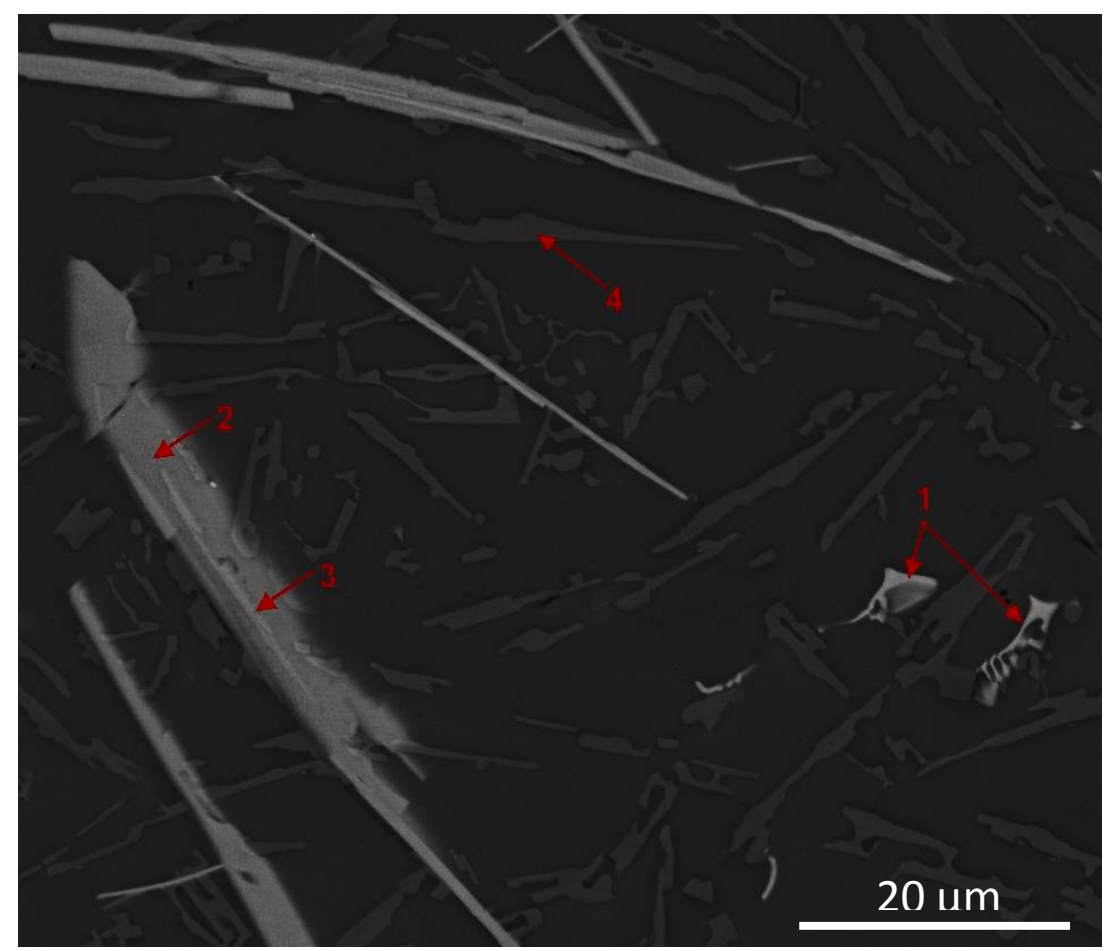

Figura 66 - Micrografia obtida pelo MEV da microestrutura da liga Al-9\%Si-0,8\%Fe-0,1\%Mn para determinar as composições químicas por microanálise nas regiões apontadas de 1 a 4 .

Tabela 16 - Microanálise das fases enumeradas na figura 66.

\begin{tabular}{l|cccc}
\hline \multirow{2}{*}{ Elementos } & \multicolumn{4}{|c}{ Partícula (\% em peso) } \\
& 1 & 2 & 3 & 4 \\
O K & 2,57 & 4,53 & 6,32 & 0,91 \\
Al K & 79,84 & 68,71 & 57,08 & 57,64 \\
Si K & 9,62 & 14,28 & 18,11 & 41,45 \\
Fe K & 7,97 & 12,48 & 18,49 & - \\
Total & 100,00 & 100,00 & 100,00 & 100,00 \\
\hline
\end{tabular}




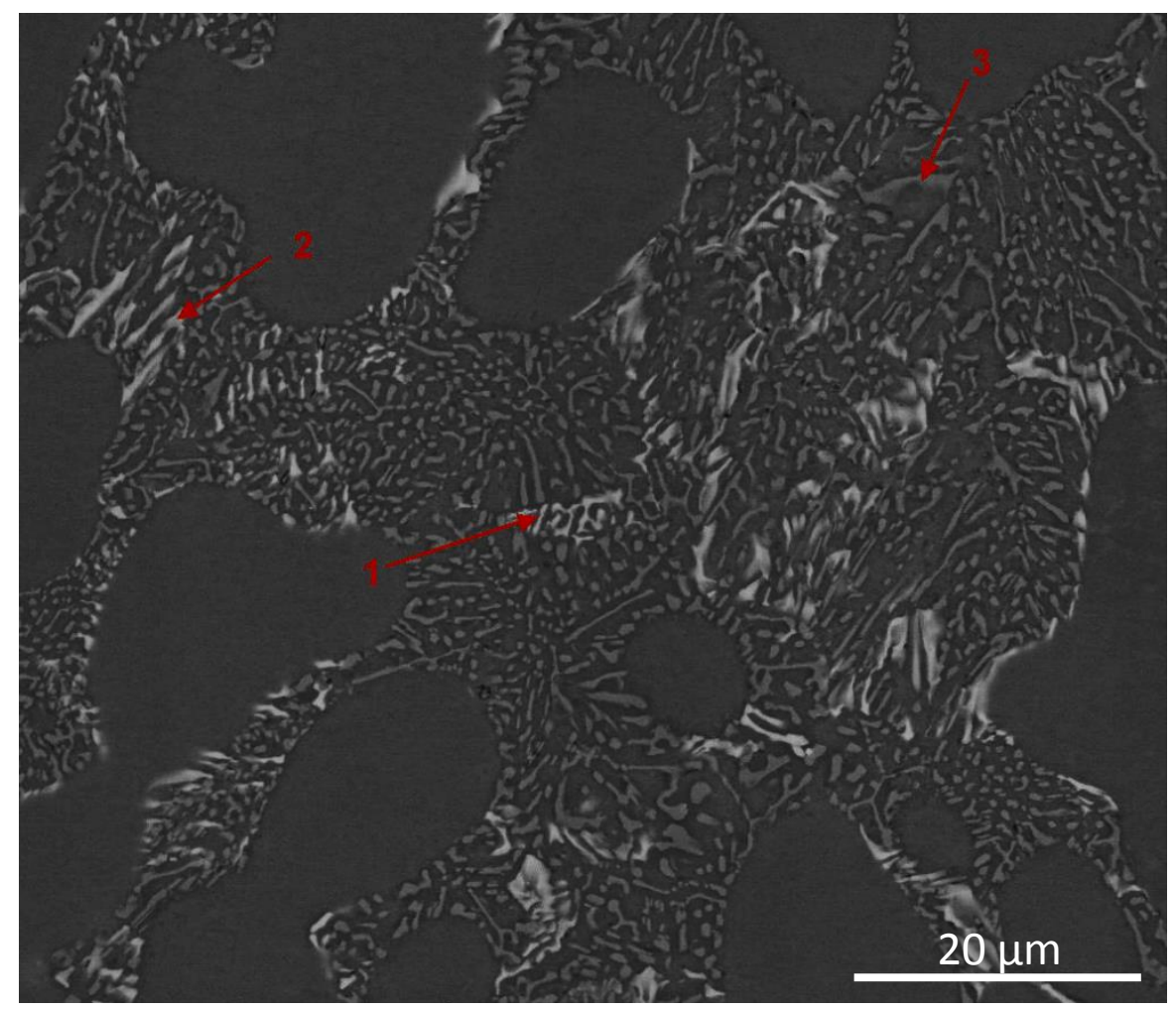

Figura 67 - $O$ ponto1 se refere a fase $\alpha-\mathrm{Al}_{15}(\mathrm{Fe}, \mathrm{Mn})_{3} \mathrm{Si}_{2}$, ponto 2 ao intermetálico com a presença de cobre e o ponto 3 a partícula de silício.

Tabela 17 - Microanálise dos pontos 1, 2 e 3 referente às fases $\alpha-\mathrm{Al}_{15}(\mathrm{Fe}, \mathrm{Mn})_{3} \mathrm{Si}_{2}$, intermetálico com cobre e partícula de silício respectivamente.

\begin{tabular}{l|ccc}
\hline \multirow{2}{*}{ Elementos } & \multicolumn{3}{|c}{ Partículas (\% peso) } \\
O K & 1 & 2 & 3 \\
Al K & 4,96 & 5,33 & 1,65 \\
Si K & 73,00 & 70,52 & 73,89 \\
Mn K & 11,61 & 10,23 & 24,46 \\
Fe K & 2,14 & 0,66 & - \\
CuK & 8,30 & 11,88 & - \\
Total & - & 1,38 & - \\
\hline
\end{tabular}

\subsubsection{Ligas de Al-9\%Si-0,8\%Fe-0,2\%Mn}

Com o aumento do teor de Mn ocorre a ampliação do campo da fase $\alpha$ $\mathrm{Al}_{15}(\mathrm{Fe}, \mathrm{Mn})_{3} \mathrm{Si}_{2}$, como pode ser verificado no diagrama simplificado Al-Si-Fe para $0,2 \%$ de manganês (figura 68 ). A tabela 18 mostra a sequência de solidificação das fases, onde se pode observar que a fase $\alpha-\mathrm{Al}_{15}(\mathrm{Fe}, \mathrm{Mn})_{3} \mathrm{Si}_{2}$ forma-se junto com a fase aalumínio, em um crescimento eutético acoplado. Este intermetálico fica inserido no 
interior da fase Calumínio, como pode ser observado na figura 69. A figura 70 mostra partículas de fase $\beta$-AlsFeSi com morfologia em plaquetas que também apresentam Mn em sua composição química, conforme tabela 19, concordando com [39].

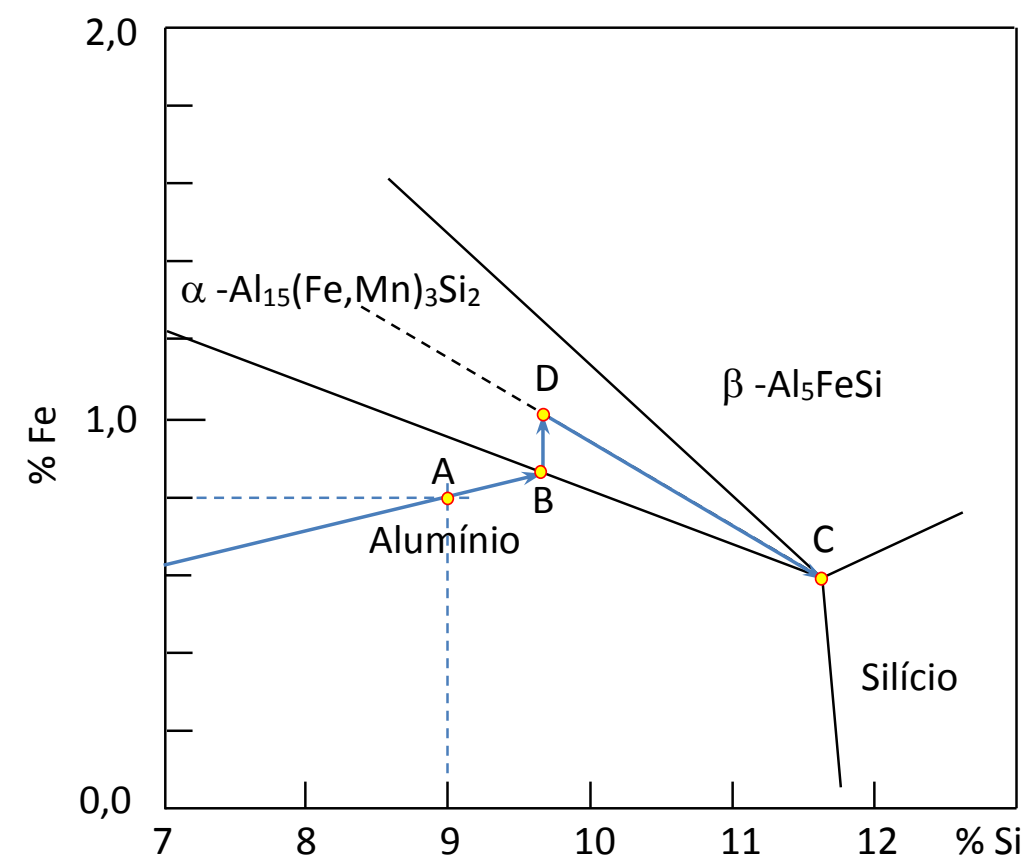

Figura 68 - Projeção da superfície liquidus do diagrama ternário Al-Si-Fe para 0,2\% de $\mathrm{Mn}$ onde estão representadas as sequencias de fases formadas na solidificação das ligas Al-9\%Si com 0,8\% Fe e 0,2\%Mn. Adaptado [14]

Tabela 18 - Sequência de solidificação das ligas AI-9\%Si com teor de ferro em 0,8\% e $0,2 \% \mathrm{Mn}$ como representado na figura 68 .

\begin{tabular}{|c|c|l||}
\hline Liga & Região & \multicolumn{1}{|c|}{ Fases formadas na solidificação } \\
\hline \multirow{2}{*}{$\begin{array}{c}\text { Al-9\%Si-0,80\%Fe } \\
0,2 \% \mathrm{Mn}\end{array}$} & A $-\mathrm{B}$ & $\mathrm{L} \rightarrow$ Dendritas de $\alpha$ \\
\hline & B $-\mathrm{D}$ & $\mathrm{L} \rightarrow$ Eutético $\left(\alpha+\alpha-\mathrm{Al}{ }_{15}(\mathrm{Fe}, \mathrm{Mn})_{3} \mathrm{Si}_{2}\right)$ \\
\hline & $\mathrm{D}-\mathrm{C}$ & $\mathrm{L} \rightarrow$ Eutético $\alpha+\mathrm{Al} 5 \mathrm{FeSi}$ \\
\hline & $\mathrm{C}$ & $\mathrm{L} \rightarrow$ Eutético secundário $\alpha+\mathrm{Si}+\mathrm{Al} 5 \mathrm{FeSi}$ \\
\hline
\end{tabular}




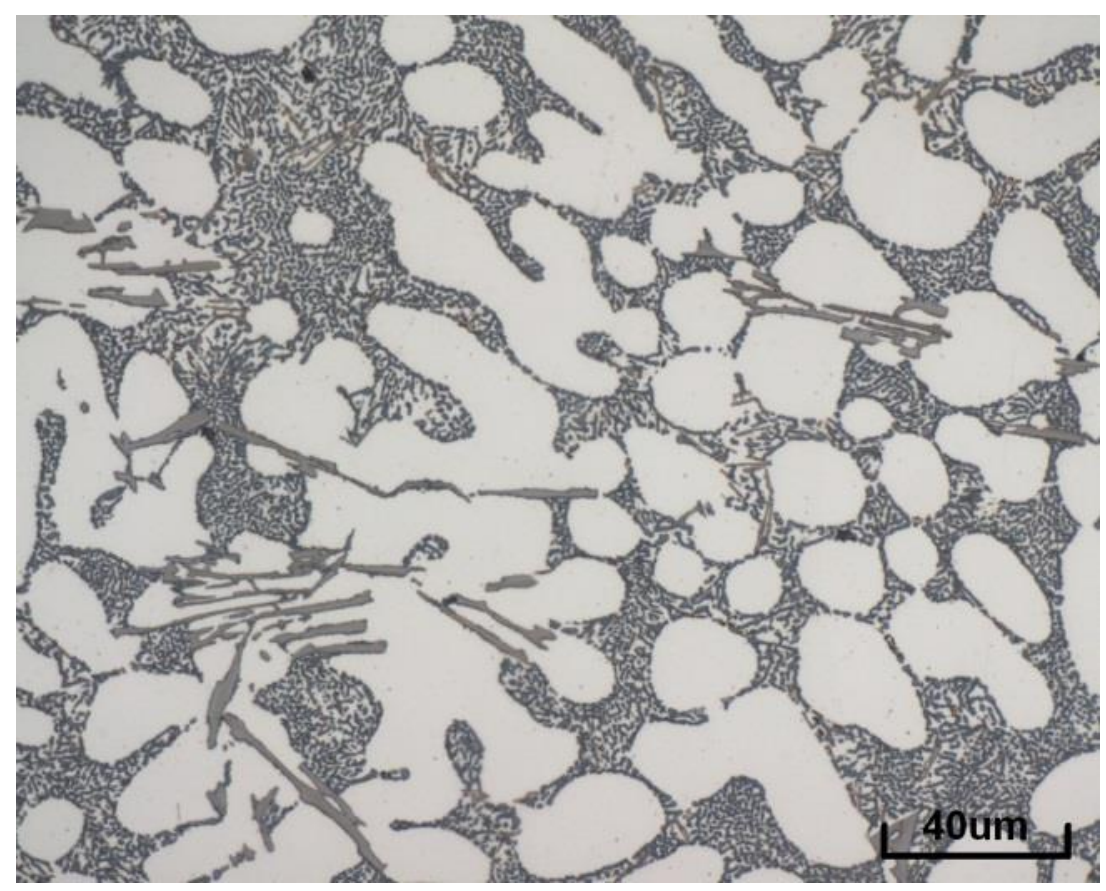

Figura 69 - Fase $\alpha$-Al ${ }_{15}(\mathrm{Fe}, \mathrm{Mn})_{3} \mathrm{Si}_{2}$ formada no interior da fase $\alpha$-alumínio que se formou decorrente de uma reação eutética acoplada.

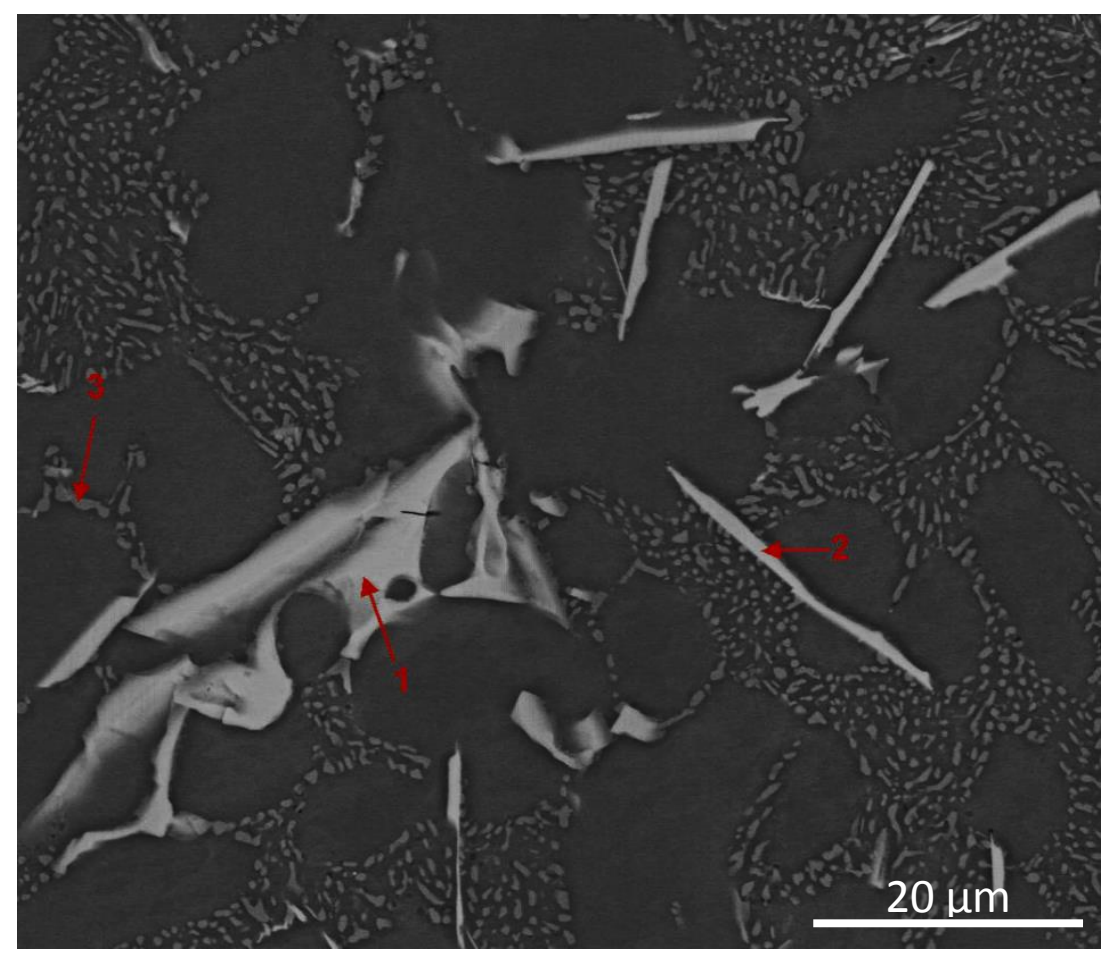

Figura 70 - Partículas de $\alpha-\mathrm{Al}_{15}(\mathrm{Fe}, \mathrm{Mn})_{3} \mathrm{Si}_{2}(1), \beta-\mathrm{Al}_{5} \mathrm{FeSi}(2)$ e silício(3) 
Tabela 19 - Composição química referente às partículas da figura 70.

\begin{tabular}{c|ccc}
\hline Elementos & \multicolumn{3}{|c}{ Partícula (\% em peso) } \\
O K & 1 & 2 & 3 \\
Al K & 2,99 & 3,10 & 2,00 \\
Si K & 60,24 & 55,73 & 67,95 \\
Mn K & 21,68 & 24,78 & 30,05 \\
Fe K & 3,24 & 3,33 & - \\
Total & 11,84 & 13,05 & - \\
\hline
\end{tabular}

\subsubsection{Ligas de Al-9\%Si-0,8\%Fe-0,4\%Mn}

As sequências de solidificação da liga Al-9\%Si-0,8\%-Fe e 0,4\% de Mn são mostradas no diagrama simplificado Al-Si-Fe para 0,4\% de manganês (figura 71). Com essa composição é atingida a proporção recomendada de 2:1 de ferro em relação ao manganês, onde a formação da fase $\alpha-\mathrm{Al}_{15}(\mathrm{Fe}, \mathrm{Mn})_{3} \mathrm{Si}_{2}$ se intensifica e ocorre acoplada às dendritas de alumínio. Verifica-se grande quantidade da fase $\alpha$ $\mathrm{Al}_{15}(\mathrm{Fe}, \mathrm{Mn})_{3} \mathrm{Si}_{2}$ no interior das dendritas de alumínio, conforme mostra a figura 72 . A tabela 20 mostra a sequência de formação das fases.

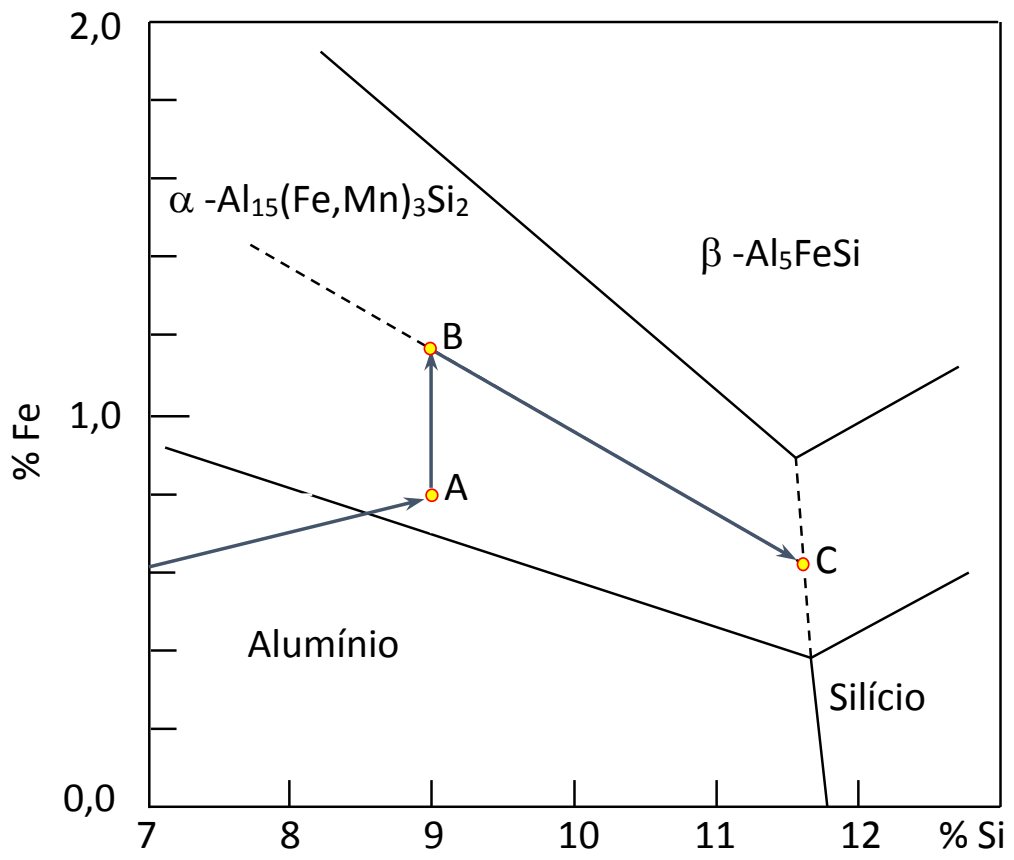

Figura 71 - Projeção da superfície liquidus do diagrama ternário Al-Si-Fe para 0,4\% de $\mathrm{Mn}$ onde estão representadas as sequencias de fases formadas na solidificação das ligas Al-9\%Si-0,8\% Fe e 0,4\%Mn. Adaptado [14] 
Tabela 20 - Sequência de solidificação das ligas Al-9\%Si-0,8\% e 0,4\%Mn como representado na figura 71 .

\begin{tabular}{|c|c|l|}
\hline Liga & Região & Fases formadas solidificação \\
\hline \multirow{2}{*}{$\begin{array}{c}\text { Al-9\%Si-0,80\%Fe } \\
0,4 \% \mathrm{Mn}\end{array}$} & A $-\mathrm{B}$ & $\mathrm{L} \rightarrow$ Dendritas de $\alpha+\left(\alpha-\mathrm{Al}_{15}(\mathrm{Fe}, \mathrm{Mn})_{3} \mathrm{Si} 2\right)$ \\
\cline { 2 - 3 } & B-C & $\mathrm{L} \rightarrow$ Eutético $\alpha+\beta-\mathrm{Al}_{5} \mathrm{FeSi}$ \\
\hline & $\mathrm{C}$ & $\mathrm{L} \rightarrow$ Eutético secundário $\alpha+\mathrm{Si}+\mathrm{Al}_{5} \mathrm{FeSi}$ \\
\hline
\end{tabular}

A partir deste teor também se verifica a formação da fase $\alpha-\mathrm{Al}_{15}(\mathrm{Fe}, \mathrm{Mn})_{3} \mathrm{Si}_{2}$ com morfologia poligonal. Este tipo de morfologia é decorrente do elevado super resfriamento bem como do elevado do teor de Mn na liga, conforme [8]. Sua formação é de origem primária no início da solidificação, que pode explicar seu crescimento exagerado em relação à escrita chinesa adjacente (figura 73). A composição química aproximada da fase poligonal é mostrada na tabela 21 em comparação com a escrita chinesa adjacente conforme enumerada na figura 74 .

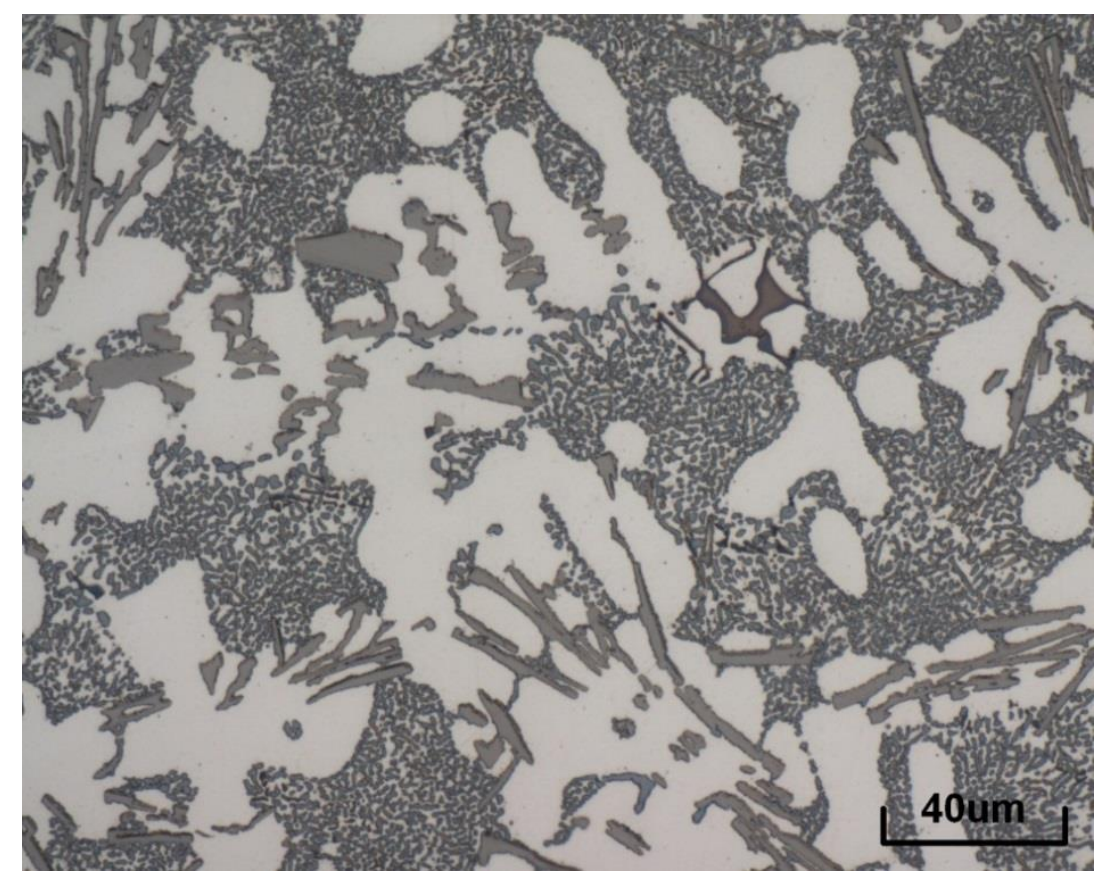

Figura 72 - A micrografia mostra as partículas da fase $\beta-\mathrm{Al}_{15}(\mathrm{Fe}, \mathrm{Mn})_{3} \mathrm{Si}_{2}$. 


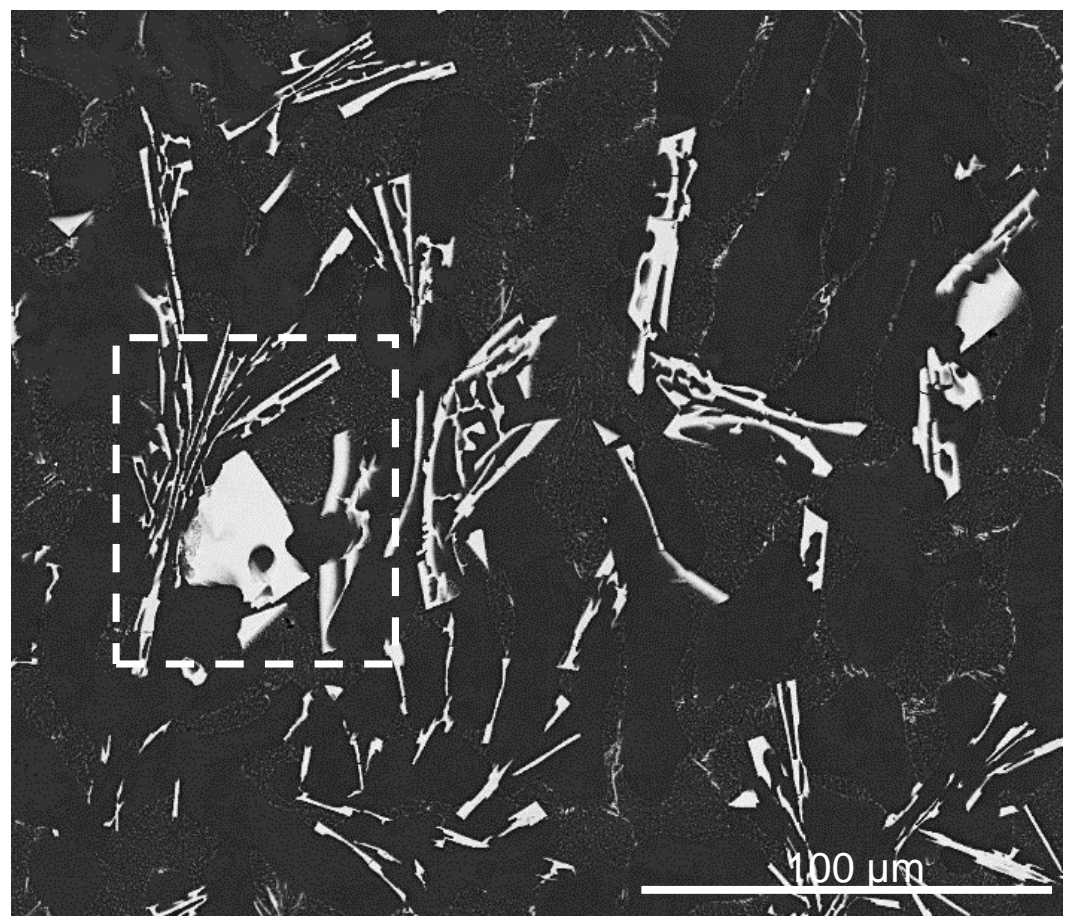

Figura 73 - Fase $\alpha-\mathrm{Al}_{15}(\mathrm{Fe}, \mathrm{Mn})_{3} \mathrm{Si}_{2}$ com morfologia poligonal formada junto com a dendrita de alumínio.

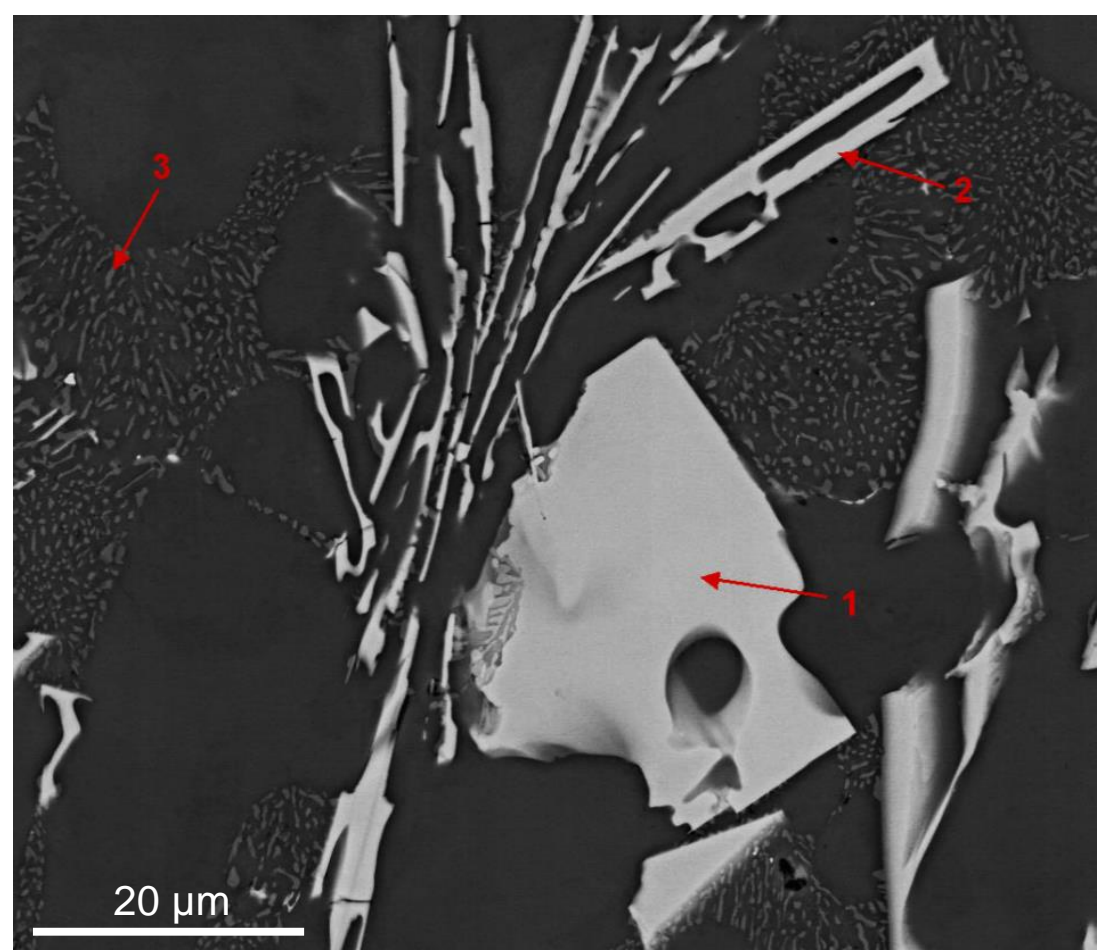

Figura 74 - Ampliação da região destacada na figura 73 mostra as fases: 1- $\alpha$ $\mathrm{Al}_{15}(\mathrm{Fe}, \mathrm{Mn})_{3} \mathrm{Si}_{2}$ com morfologia poligonal; $2-\alpha-\mathrm{Al}_{15}(\mathrm{Fe}, \mathrm{Mn})_{3} \mathrm{Si}_{2}$ com morfologia em escrita chinesa e 3 - partículas de silício com morfologia fibrosa (modificada). 
Tabela 21 - Composição química aproximada da fase $1\left(\alpha-\mathrm{Al}_{15}(\mathrm{Fe}, \mathrm{Mn})_{3} \mathrm{Si}_{2}\right)$ poligonal e fase 2 escrita chinesa apontada na figura 74.

\begin{tabular}{c|ccc}
\hline \multirow{2}{*}{ Elementos } & \multicolumn{3}{|c}{ Partículas (\% peso) } \\
O K & 1 & 2 & 3 \\
Al K & 2,16 & 2,24 & - \\
Si K & 41,62 & 43,29 & 65,50 \\
Mn K & 32,09 & 30,81 & 34,50 \\
Fe K & 6,87 & 8,43 & - \\
Total & 17,25 & 15,24 & - \\
\hline
\end{tabular}

A partícula poligonal de $\alpha-\mathrm{Al}_{15}\left(\mathrm{Fe}, \mathrm{Mn}_{3} \mathrm{Si}_{2}\right.$ (1) apresenta uma estrutura poliédrica como uma fase preliminar, isto é, antes da solidificação das dendritas de alumínio. Esta partícula apresenta um crescimento facetado com uma forma aproximadamente hexagonal, na secção transversal, com o mostra a figura 75. A partícula 2, mostrada na figura 74 , se formou decorrente de uma reação eutética com crescimento acoplado com ramificações mais complexas [47].

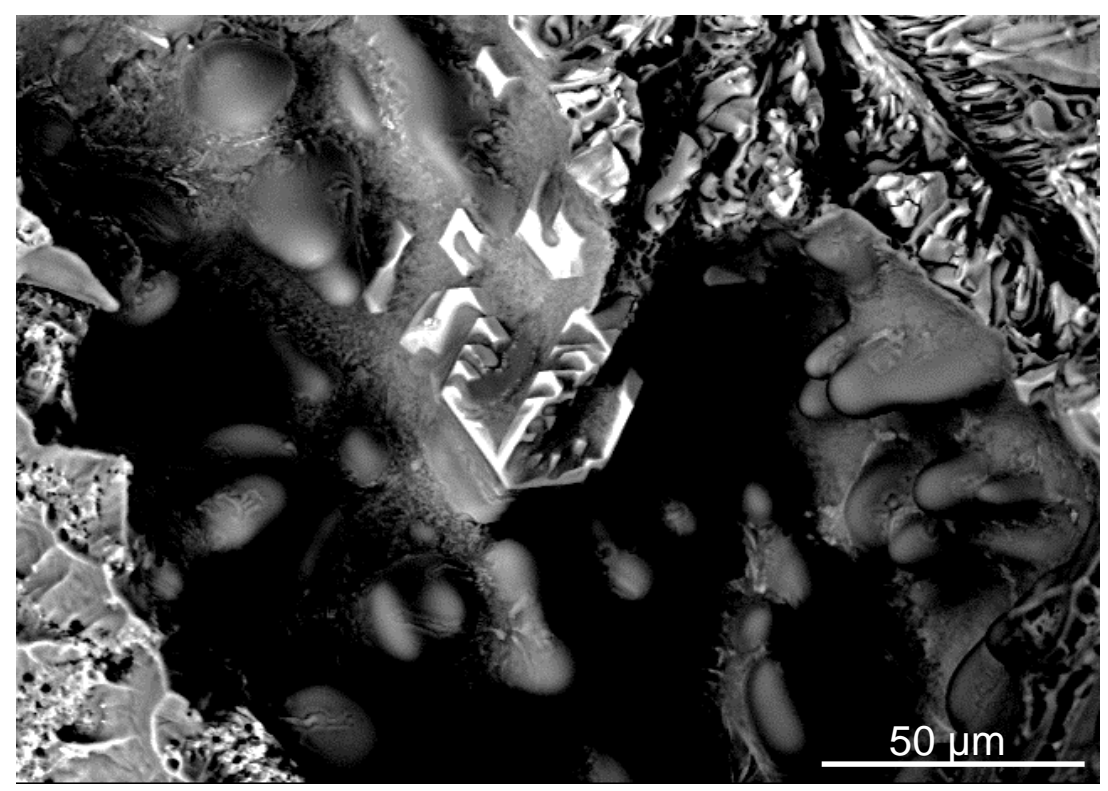

Figura 75 - Fase $\alpha-\mathrm{Al}_{15}(\mathrm{Fe}, \mathrm{Mn})_{3} \mathrm{Si}_{2}$ com morfologia poliédrica na interfase de um braço dendrítico no interior de uma microporosidade.

$\mathrm{O}$ crescimento da fase $\alpha-\mathrm{Al}{ }_{15}(\mathrm{Fe}, \mathrm{Mn})_{3} \mathrm{Si}_{2}$ ocorreu por longas distâncias, como pode ser observado na superfície fraturada após teste de tração da figura 76 . Verificase que os intermetálicos se apresentam alinhados na direção de extração de calor. 


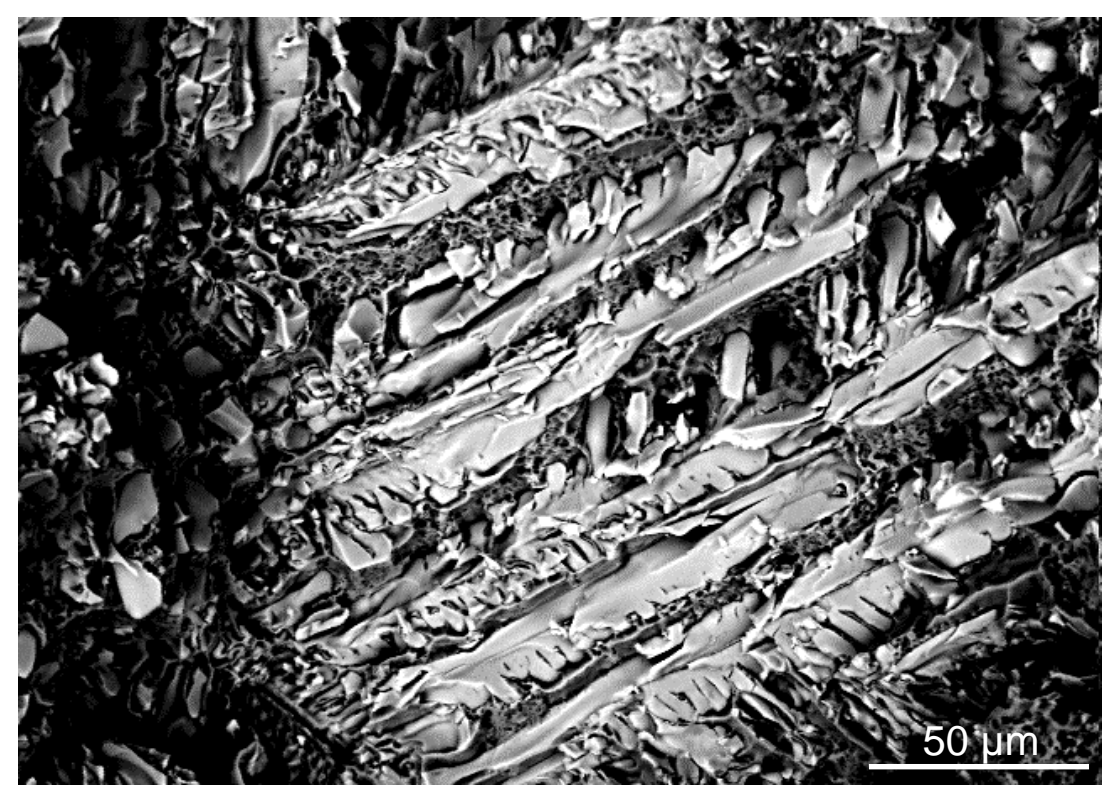

Figura 76 - Intermetálicos alinhados na superfície de um corpo de prova tracionado.

\subsubsection{Ligas de Al-9\%Si-0,8\%Fe-0,7\%Mn}

Com adição de manganês próxima do teor de ferro, a fase $\alpha-\mathrm{Al}_{15}(\mathrm{Fe}, \mathrm{Mn})_{3} \mathrm{Si}_{2}$ poliédrica se apresenta mais grosseira, conforme figura 77 . Vale ressaltar que ao longo da partícula 3 (partícula contendo $\mathrm{Mn}$ ) ocorreu a nucleação e crescimento de uma partícula de silício decorrente da reação eutética secundária. Não foi encontrada qualquer observação na literatura a respeito desta nucleação do silício sobre a partícula do intermetálico. A composição dos constituintes enumerados na figura 77 é mostrada na tabela 22. Maiores teores de Mn não inibem totalmente a formação da fase $\beta$-Als $\mathrm{FeSi}$ (figura 78 - partícula 2). A literatura não faz qualquer referência à formação desta fase em que o Mn faça parte na composição química, como se verifica na tabela 23. A figura 79 apresenta uma partícula de $\alpha-\mathrm{Al}_{15}(\mathrm{Fe}, \mathrm{Mn})_{3} \mathrm{Si}_{2}$, atacada com $\mathrm{NaOH}$ na concentração de $20 \%$, onde pode-se constatar suas ramificações com a morfologia escrita chinesa. 


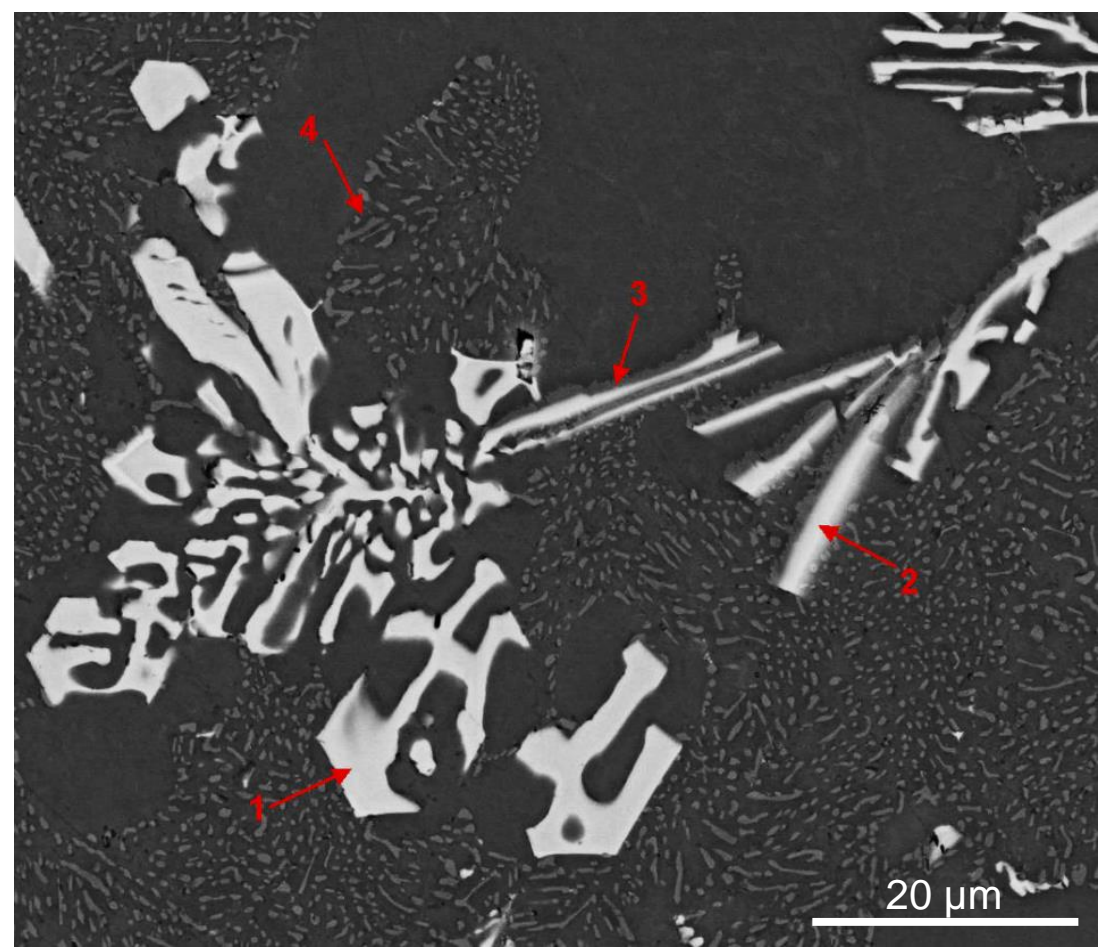

Figura 77 - Micrografia obtida no Mev mostra a nucleação da partícula de silício (3) sobre a partícula de $\alpha-A l_{15}(\mathrm{Fe}, \mathrm{Mn})_{3} \mathrm{Si}_{2}$.

Tabela 22 - Microanálise dos constituintes enumerados na figura 77.

\begin{tabular}{c|cccc}
\hline \multirow{2}{*}{ Elementos } & \multicolumn{4}{|c}{ Partícula (\% em peso) } \\
O K & 1 & 2 & 3 & 4 \\
Al K & 4,30 & - & - & - \\
Si K & 60,49 & 53,24 & 92,73 & 61,95 \\
Mn K & 11,73 & 28,42 & 7,27 & 38,05 \\
Fe K & 12,28 & 7,67 & - & - \\
Total & 11,21 & 10,66 & - & - \\
\hline
\end{tabular}




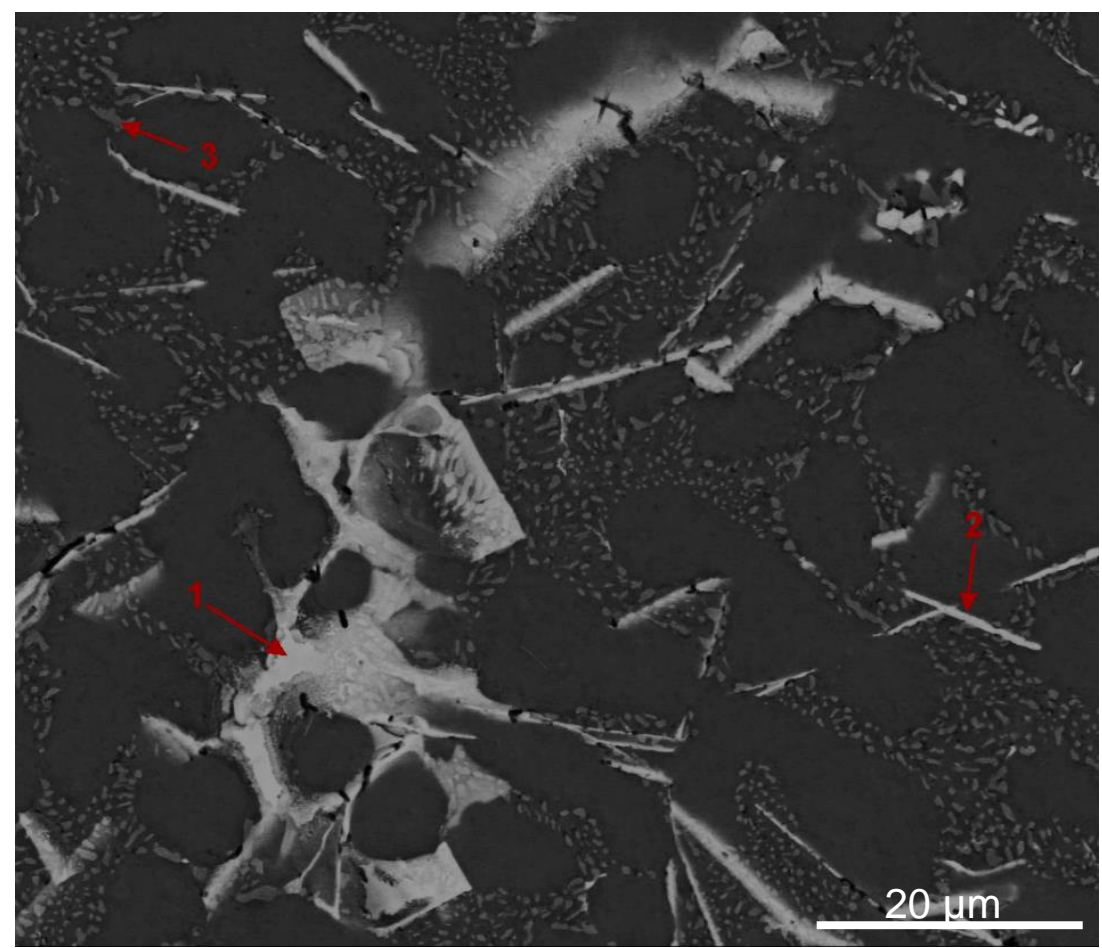

Figura 78 - Fase $\alpha-\mathrm{Al}_{15}(\mathrm{Fe}, \mathrm{Mn})_{3} \mathrm{Si}_{2}$ (1) grosseira, partículas de $\beta-\mathrm{Al}_{5} \mathrm{FeSi}$ (2) e silício(3).

Tabela 23 - Microanálise das fases enumeradas na figura 78.

\begin{tabular}{l|ccc}
\hline \multirow{2}{*}{ Elementos } & \multicolumn{3}{|c}{ Partícula (\% em peso) } \\
O K & 1 & 2 & 3 \\
Al K & 2,30 & 3,99 & - \\
Si K & 54,77 & 67,22 & 58,86 \\
Mn K & 22,99 & 13,13 & 41,14 \\
Fe K & 8,92 & 6,52 & - \\
& 11,02 & 9,13 & - \\
Total & 100,00 & 100,00 & 100,0 \\
\hline
\end{tabular}




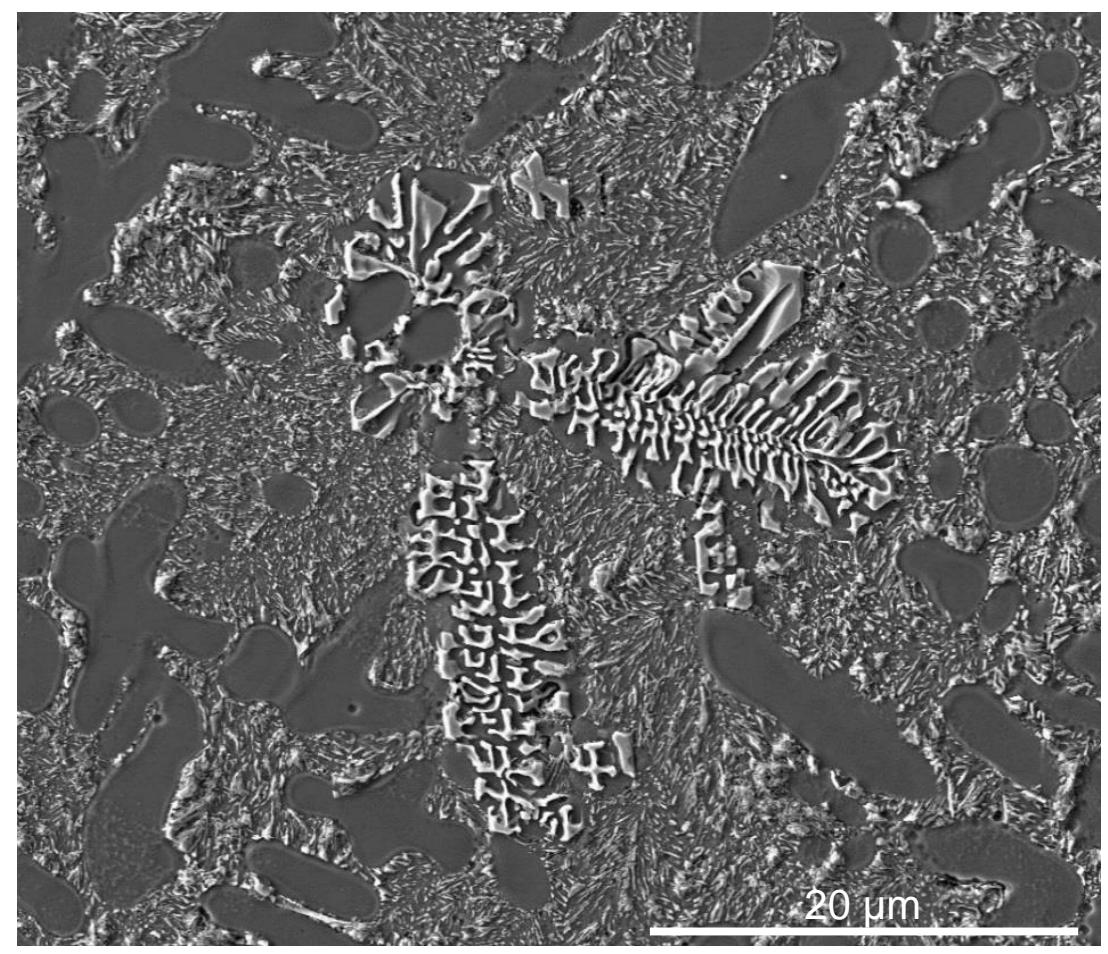

Figura 79 - Ataque profundo com NaOH 20\% em amostra de Al-9\%Si-0,8\%Fe com 0,7\% de $\mathrm{Mn}$ revelando a fase $\alpha-\mathrm{Al}_{15}(\mathrm{Fe}, \mathrm{Mn})_{3} \mathrm{Si}_{2}$ com morfologia em escrita chinesa.

A fractografia de um corpo de prova tracionado, mostrado na figura 80 , revela a extensão das partículas de $\alpha-\mathrm{Al}_{15}(\mathrm{Fe}, \mathrm{Mn})_{3} \mathrm{Si}_{2}$, bem como sua complexidade. Estas partículas, de caráter frágil e morfologia intrincada, são envolvidas pela fase de alumínio $\alpha$, que apresenta elevada ductilidade. Esta associação permite uma melhoria das propriedades mecânicas, conforme constatado nos testes de tração. A figura 81 mostra, em detalhe, a ocorrência de poliedros do intermetálico incrustado na fase de alumínio a e vice e versa. 


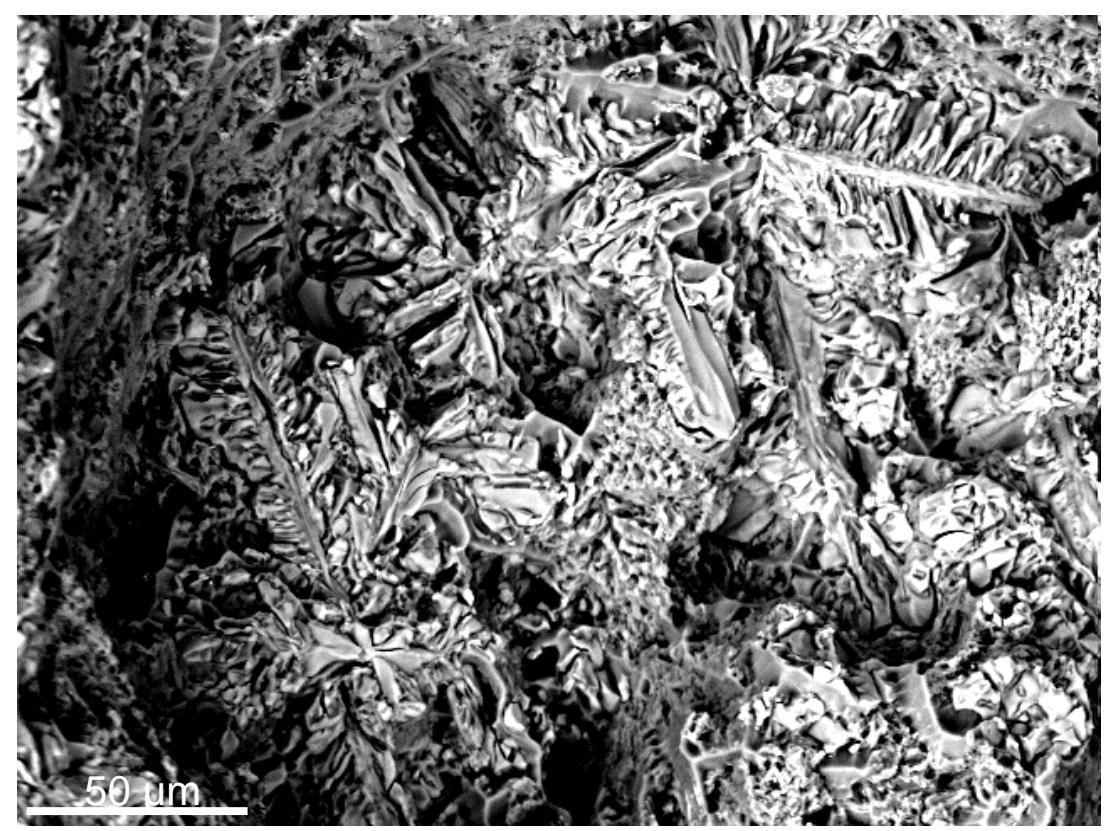

Figura 80 - Concentração de intermetálicos $\alpha-\mathrm{Al}_{15}(\mathrm{Fe}, \mathrm{Mn})_{3} \mathrm{Si}_{2}$

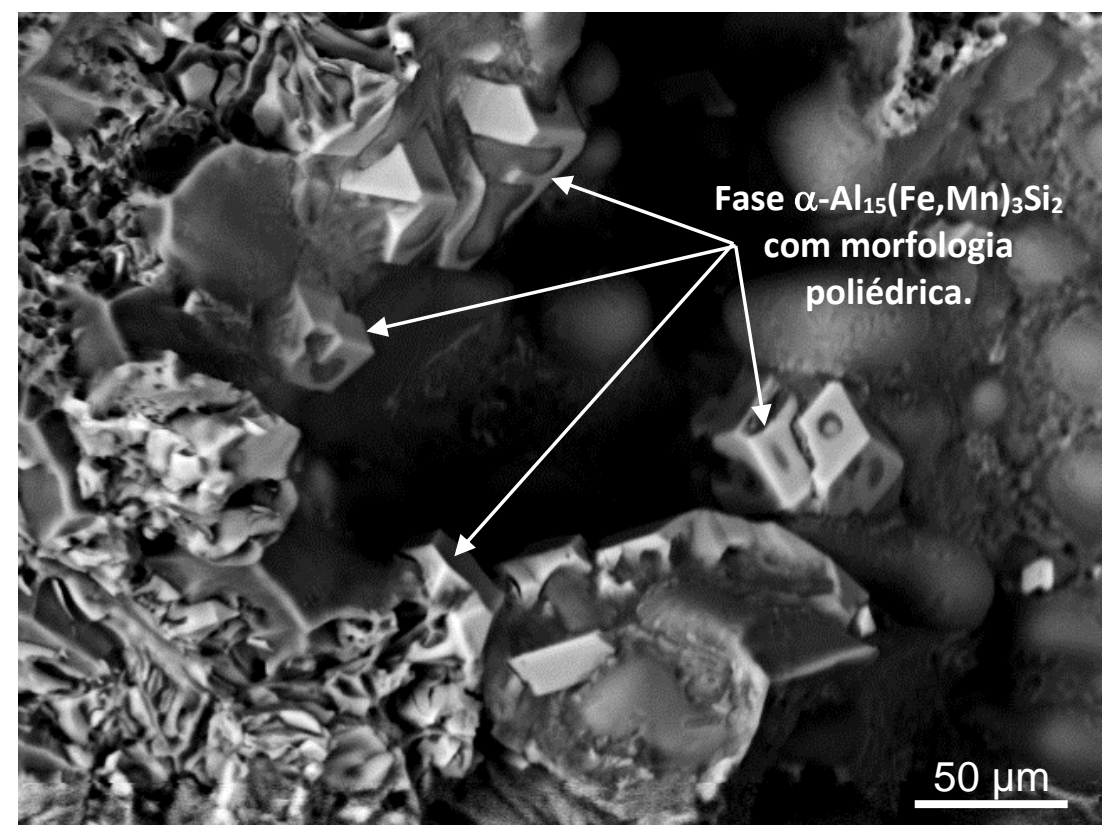

Figura 81- Detalhe do intermetálico com morfologia poligonal. 


\section{CONCLUSÕES}

O estudo da caracterização microestrutural dos compostos intermetálicos e seu efeito no comportamento mecânico das ligas Al-9\%Si com adições de ferro e de manganês permitiram concluir que:

- Para baixos teores de Fe, elevadas temperaturas de vazamento e elevada velocidade de resfriamento, o intermetálico formado foi a fase $\alpha-\mathrm{Al}_{8} \mathrm{Fe}_{2} \mathrm{Si}$ que se apresenta com morfologia tipo escrita chinesa, implicando num discreto aumento nas propriedades mecânicas até $0,4 \%$ de $\mathrm{Fe}$;

- Quanto maior o teor de ferro na liga Al-9\%Si, acima do ferro crítico no diagrama Al-Fe-Si simplificado, a fase $\beta$-AlsFeSi passa a se formar junto com o eutético principal. A partir de $0,8 \% \mathrm{Fe}$ as propriedades mecânicas diminuem significativamente, seja pelo aumento na dimensão e quantidade de partículas da fase $\beta-\mathrm{Al}_{5} \mathrm{FeSi}$, como pelo aumento das microporosidades.

- O aumento do teor de ferro na liga Al-9\%Si provoca redução dos limites de resistência e de escoamento e alongamento devido à formação de partículas de $\beta-\mathrm{Al}_{5} \mathrm{FeSi}$ que apresentam caráter frágil.

- Foi constatada a presença da fase $\beta-\mathrm{Al}_{5} \mathrm{FeSi}$ nos contornos das microporosidades, que pode contribuir, eventualmente, para reduzir o fluxo do líquido eutético interdendrítico, impedindo seu preenchimento e contribuindo para a redução das propriedades mecânicas da liga.

- Nos corpos de provas fraturados da liga Al-9\%Si com teores crescentes de Fe, foi verificado que as fraturas apresentam caráter tão mais frágil quanto maior o teor de Fe na liga.

- O manganês promoveu a alteração da morfologia da fase $\beta$-Als $\mathrm{FeSi}$ de plaquetas para $\alpha-\mathrm{Al}_{15}(\mathrm{Fe}, \mathrm{Mn})_{3} \mathrm{Si}_{2}$ para morfologia tipo escrita chinesa nos teores de até $0,4 \%$.

- Adições a partir de $0,4 \%$ de $M n$ promoveram a formação da fase $\alpha$ $\mathrm{Al}_{15}(\mathrm{Fe}, \mathrm{Mn})_{3} \mathrm{Si}_{2}$ com morfologia poligonal típica de elevado super-resfriamento, quando observado no plano. 
- A análise da fratura de corpos tracionados com 0,4\% e 0,7\% de Mn mostraram que a morfologia tridimensional da fase $\alpha-\mathrm{Al}_{15}(\mathrm{Fe}, \mathrm{Mn})_{3} \mathrm{Si}_{2}$ é poliédrica nos limites das ramificações dendríticas, se estendendo ao longo destas.

- Com adição progressiva de $\mathrm{Mn}$ na liga $\mathrm{Al}-9 \% \mathrm{Si}-0,8 \% \mathrm{Fe}$ ocorre aumento resistência mecânica e com redução do limite de escoamento. $O$ aumento da resistência mecânica com a elevação do teor de $\mathrm{Mn}$ se deve à formação do eutético acoplado, em que uma fase dúctil (alumínio $\alpha$ ) cresce junto a uma fase frágil $\left(\alpha-\mathrm{Al}_{15}(\mathrm{Fe}, \mathrm{Mn})_{3} \mathrm{Si}_{2}\right)$ de longa extensão.

- Até $0,4 \% \mathrm{Mn}$ houve aumento do alongamento para posteriormente apresentar uma tendência de queda o que demonstra o efeito do crescimento das fases frágeis em função da elevação do teor Mn. 


\section{SUGESTÕES PARA TRABALHOS FUTUROS}

a- Tentar comprovar que nas ligas de $\mathrm{Al}-\mathrm{Si}$, na presença de óxidos provocadas por agitação, por exemplo, favorece a nucleação da fase $\boldsymbol{\beta}$ $\mathrm{Al}_{5} \mathrm{FeSi}$;

b- Estudar o efeito do superaquecimento em ligas de Al-Si com teores fixos de $\mathrm{Si}$ e Fe objetivando a mapear as formações das fase $\beta$-Als FeSi e $\alpha$ $\mathrm{Al}_{8} \mathrm{Fe}_{2} \mathrm{Si}$;

c- Determinar o ganho em termos de propriedades mecânicas com a formação da fase $\propto-\mathrm{Al}_{8} \mathrm{Fe} 2 \mathrm{Si}$;

d- Avaliar o efeito da modificação com o uso do estrôncio sobre a formação das fases $\beta-\mathrm{Al}_{5} \mathrm{FeSi}$ e $\propto-\mathrm{Al}_{8} \mathrm{Fe}_{2} \mathrm{Si}$ em diferentes temperaturas de superaquecimento;

e- Estudar o efeito da adição de ferro sobre a formação das células eutéticas nas ligas Al-Si assim como a ocorrência das microporosidades;

f- Comprovar o efeito de adições de outros elementos (Be, $\mathrm{Co}, \mathrm{Mo})$ no que se refere à alteração da morfologia das plaquetas de $\beta$-Als $\mathrm{FeSi}$;

g- Efetuar testes com teores crescentes de Mn para determinar o máximo limite de resistência para um máximo teor de Mn; 


\section{BIBLIOGRAFIA}

[1] NIELS SKAT TIEDJE, JOHN A. TAYLOR, and MARK A. EASTON, "Feeding and distribution of porosity in cast Al-Si alloys as function of alloy composition and modification," Metallurgical and Materials Transactions A, no. Published online: 14 July 2012, July 2012.

[2] W. KALIFA, A. M. SAMUEL, F. H. SAMUEL, H. W. DOTY and S. VALTIERRA, "Metallographic observations of b-Al5FeSi phase and its role in porosity formation in Al-7\%Si alloys," International Journal of Cast Metals Reseach, vol. 19, pp. 156166, 2006.

[3] A. M. A. S. F. S. H. D. a. S. V. L. LIU, "Precipitation of $\beta-A l_{5} F e S i$ Phase Platelets in Al-Si Based Casting Alloys," Metallurgical and Materials Transactions A, vol. 40A, pp. 2457-2469, October 2009.

[4] R. S. RANA, RAJESH PUROHIT, and S. DAS, "Reviews on the influences of alloying elements on the microestructure and mechanical properties of aluminum alloys and alloy composities," International Journal of Scientific and Research Publications, pp. 1-7, June 2012.

[5] J. A. TAYLOR, "Iron containing intermetallic phases in Al-Si based casting alloys," Procedia Materials Science, pp. 19-33, 2012.

[6] Q. HAN and S. VISWANATHAN, "Analisys of mechanism of die soldering in aluminum die casting," Metallurgical and Materials Transactions A, 2003.

[7] E. TAGHADDOS, M. M. HEJAZI, R. TAGHIABADI, S. G. SHABESTARI, "Effect of iron intermetallics on the fluidity of 413 aluminum alloy," Journal of Alloys and Compounds, 2009.

[8] J. Y. HWANG, H. D. DOTY, M. J. KAUFMAN, "The effect of Mn on the microestructure and mechanical properties of Al-Si-Cu casting alloys," Materials Science and Engineering A, pp. 496-504, 2008. 
[9] DUCKER WORLDWIDE, "http://www.drivealuminum.org," 12 Novembro 2013. [Online]. Available: http://www.drivealuminum.org/researchresources/PDF/Speeches\%20and\%20Presentations/2012/The-Past-Presentand-Future-of-Aluminum.pdf.

[10] RICARDO FUOCO, EDISON ROBERTO CORRÊA, "Evolução da microestrutura das ligas Al-Si durante a solidificação," in CONAF 2009, São Paulo, 2009.

[11] American Society for Metals, Alloy Phases and Diagrams, vol. 3, 1992, p. 10.

[12] A. KNUUTINEN, K. NOGITA, S.D. MCDONALD, A.K. DAHLE, "Modification of Al-Si alloys with $\mathrm{Ba}, \mathrm{Ca}, \mathrm{Y}$ and Yb," Journal of Light Metals, vol. 1, pp. 229-240, 2001.

[13] J. MALAVAZI, "Formação dos compostos intermetálicos na liga AI-Si 7 fundida à gravidade," Fundição e Materias Primas, pp. 78-91, Novembro 2012.

[14] L. BACKERUD, G. CHAI and J. TAMMINEM, Solidification characteristics of aluminum alloys, vol. Volume 2: Foundry Alloys, AFS/Skan Aluminum, 1990.

[15] LORELLA CESCHINI, IURI BOROMEI, ALESSANDRO MORRI, SALEM SEIFEDDINE and INGVAR L. SVENSSON, "Microstructure, tensile and fatigue properties of the $\mathrm{Al}-10 \% \mathrm{Si}-2 \% \mathrm{Cu}$ alloy with different $\mathrm{Fe}$ and $\mathrm{Mn}$ content cast under controlled conditions," Journal of Materials Processing technology, pp. 5669-5679, 2009.

[16] L. ANANTHA NARAYANAN, F. H. SAMUEL and J. E. GRUZLESKI, "Crystallization Behavior of Iron-Containing Intermetallic Compounds in 319 Aluminum," Metallurgical and Materials Transactions A, pp. 1761-1773, August 1994.

[17] S. TERZI, J. A. TAYLOR, Y. H. CHO, L. SALVO, M. SUÉRY, E. BOLLER, A. K. DAHLE, "In situ study of nucleation and growth of the irregular $\alpha-A \mathrm{l} / / \beta-A l_{5} \mathrm{FeSi}$ eutetic by 3-D synchrotron X-ray microtomography," Acta Materialia, vol. 58, pp. 5370-5380, 2010. 
[18] L. LU and A. K. DAHLE, "Iron-rich intermetallic phases and their role in casting defect formation in hipoeutectic al-si alloys," Metallurgical and materials Transactions A, vol. 36A, pp. 819-835, March 2005.

[19] Y. H. CHO, H. C. LEE, K. H. OH and A. K. DAHLE, "Effect of strontium and phosphorus on eutectic $\mathrm{Al}-\mathrm{Si}$ nucleation and formation of $\beta-\mathrm{Al} 5 \mathrm{FeSi}$ in hipoeutectic Al-Si foundry alloys," Metallurgical and Materials Transactions A, pp. 2435-2448, October 2008.

[20] Y. AWANO and Y. SHIMIZU, "Non equilibrium crystallization of AIFeSi compound in melt-superheated Al-Si alloy casting," AFS Transactions, vol. 176, pp. 889-895, 1990.

[21] X. CAO and J. CAMPBELL, "The nucleation of Fe-rich phases on oxide films in a Al-11,5Si-0,4Mg cast alloys," Metallurgical and Materials Transactions A, vol. 34A, pp. 1409-1420, July 2003.

[22] W. KALIFA, F. H. SAMUEL, J. E. GRUZLESKI, H. W. DOTY and S. VALTIERRA, "Nucleation of $\mathrm{Fe}$ intermetallic phases in the Al-Si-Fe alloys," Metallurgical and Materials Transactions A, vol. 36A, pp. 1017-1031, April 2005.

[23] XINJING CAO and JOHN CAMPBELL, "Morphology of $\beta$-AlsFeSi phase in AI-Si cast alloys," Materials Transactions, vol. 47, pp. 1303-1312, 2006.

[24] D. N. MILLER, L. LU, and A. K. DAHLE, "The role of oxides in the formation of primary iron intermetallics in a Al-11,6Si-0,37Mg alloy," Metallurgical and Materials Transactions B, vol. 37B, pp. 873-878, December 2006.

[25] X. CAO and J. CAMPBELL, "Oxide inclusion defects in Al-Si-Mg cast alloys," Canadian Metallurgical Quarternaly, vol. 44, pp. 435-448, 2005.

[26] R. GOPALAN and NARAYAN K. PRABHU, "Oxide bifilms in aluminum alloy casting - a rewiew," Materials Science and Technology, vol. 27, pp. 1757-1769, 2011. 
[27] SOFIANE TERZI, JOHN A. TAYLOR, YOUNG-HEE CHO, LUC SALVO, MICHEL SUÉRY, ELODIE BOLLER, ARNE K. DAHLE, "Nucleation and growth dynamics of a-Al / $\beta$-Al5FeSi eutectic in a complex Al-Si-Cu-Fe," in Proceedings of the 12th International Conference on Aluminum Alloys, Yokohama, 2010.

[28] D. Dispinar, J. Campbell, "Porosity, hydrogen and bifilm content in Al alloy castings," Materials Science and Engineering A, pp. 3860-3865, 2011.

[29] L. LIU, A. M. A. MOHAMED, A. M. SAMUEL, F. H. SAMUEL, H. W. DOTY and S. VALTIERRA, "Precipitation of $\beta$-AlsFeSi phase platelets in a Al-Si based casting alloys," Metallurgical Materials Transactions A, pp. 2457-2469, October 2009.

[30] M. A. MOUSTAFA, "Effect of iron content on the formation of $\beta-A l_{5} F e S i$ and porosity in Al-Si eutectic alloys," Journal of Materials Processing Technology, vol. 209, pp. 605-610, 2009.

[31] C. M. DINNIS, J. A. TAYLOR and A. K. DAHLE, "Interactions between iron, manganese, and the Al-Si eutectic in hypoeutectic Al-Si alloys," Metallurgical and Materials Transactions A, vol. 37A, pp. 3283-3291, November 2006.

[32] CAMERON M. DINNIS, JOHN A. TAYLOR, ARNE K. DAHLE, "Iron-related porosity in Al-Si- $(\mathrm{Cu})$ foundry alloys," Materials Science and Engineering A, pp. 286-296, 2006.

[33] Z. MA A.M. SAMUEL, F.H. SAMUEL, H.W. DOTY, S. VALTIERRA, "A study of tensile properties in Al-Si-Cu and Al-Si-Mg alloys: Effect of $\beta$-iron intermetallics and porosity," Materials Science and Engineering A, pp. 36-51, 2008.

[34] N. ROY, A. M. SAMUEL, F. H. SAMUEL, "Porosity formation in Al-9 wt pct Si-3 wt pct $\mathrm{Cu}$ alloy systems: Metallography observations," Metallurgical and Materials Transactions A, vol. 27A, pp. 415-429, February 1996. 
[35] S. A. IMPEY, D. J. STEPHENSONS and J. R. NICHOLLS, "Mechanism of scale growth on liquid aluminum," Materials Science and Technology, vol. 4, December 1988.

[36] X. CAO and J. CAMPBELL, "The solidification characteristics of Fe-rich intermetallics in Al-11,5Si-0,4Mg cast alloys," Metallurgical and Materials Transactions A, vol. 35A, pp. 1425-1435, May 2004.

[37] T. O. MBUYA, B. O. ODERA and S. P. NG'ANG'A, "Influence of iron on castability and properties of aluminium silicon alloys: literature review," International Journal Cast Metals Research, pp. 451-465, 2003.

[38] S. G. SHABESTARI, "The effect of iron and manganese on the formation of intermetallic compounds in aluminum-silicon alloys," Materials Science and Engineering A, vol. 383, pp. 289-298, 2004.

[39] SALEM SEIFEDDINE, STEN JOHANSSON, INGVAR L. SVENSSON, "The influence of cooling rate and manganese content on the $\mathrm{B}-\mathrm{Al} 5 \mathrm{FeSi}$ phase formation and mechanical properties of Al-Si based alloys," Materials Science and Engineering A, pp. 385-390, 2008.

[40] J. L. JORSTAD, "Understand sludge," in SDCE 14th International Diecasting Congress and Exposition, Toronto, 1987.

[41] MAKHLOUF M. MAKHLOUF and DIRAN APELIAN, "Casting characteristics of aluminum die casting alloys," 2002.

[42] J.GOBRECHT, "Gravity-segregation of Iron, Manganese and Chromium in an Aluminum-Silicon Casting, Part I," Giesserei, vol. 61, pp. 263-265, 1975.

[43] SATHYAPAL HEDGE, K. NARAYAN PRADLU, "Modification of eutectic silicon in Al-Si alloys," J Mater Sci, vol. 43, pp. 3009-3027, 2008.

[44] ASTM, Standart Specification for Aluminum-Alloy Permanent Mold B108 - 03a, September 2003. 
[45] L. Sweet, S.M. Zhu, S.X. Gao, J.A. Taylor, and M.A. Easton, "The Effect of Iron Content on the Iron-Containing Intermetallic Phases in a Cast 6060 Aluminum Alloy," Metallurgical and Materials Transactions, pp. 1737-1749, July 2011.

[46] X. P. NIU, B. H. HU and S. W. HAO, "Effect of iron on the microstructure and mechanical properties of Al diecasting alloys," Journal of Materials Science Letters, pp. 1727-1729, 1998.

[47] CAMERON M. DINNIS, JOHN A. TAYLOR, ARNE K. DAHLE, "As-cast morphology of iron-intermetallics in Al-Si foundry alloys," Scripta Materialia, pp. 955-958, 14 July 2005. 